Portland State University

PDXScholar

$4-2-2020$

\title{
Unpacking the Process and Outcomes of Ethical Markets: a Focus on Certified B Corporations
}

Renée Bogin Curtis

Portland State University

Follow this and additional works at: https://pdxscholar.library.pdx.edu/open_access_etds

Part of the Geography Commons, Sustainability Commons, and the Urban Studies Commons Let us know how access to this document benefits you.

\section{Recommended Citation}

Curtis, Renée Bogin, "Unpacking the Process and Outcomes of Ethical Markets: a Focus on Certified B Corporations" (2020). Dissertations and Theses. Paper 5450.

https://doi.org/10.15760/etd.7323

This Dissertation is brought to you for free and open access. It has been accepted for inclusion in Dissertations and Theses by an authorized administrator of PDXScholar. Please contact us if we can make this document more accessible: pdxscholar@pdx.edu. 
Unpacking the Process and Outcomes of Ethical Markets:

A Focus on Certified B Corporations

by

Renée Bogin Curtis

A dissertation submitted in partial fulfillment of the requirements for the degree of

Doctor of Philosophy

in

Urban Studies

\author{
Dissertation Committee: \\ Greg Schrock, Chair \\ Charles Heying \\ Jennifer H. Allen \\ Madeleine Pullman
}

Portland State University

2020 
(C) 2020 Renée Bogin Curtis 


\begin{abstract}
The growth in conscious consumption presents an opportunity to 1) better understand the potential outcomes of ethical market practices as a community-advocacy tool and 2) to consider potential policy considerations. The marketplace has increasingly become an arena for social action. This leads to the question of how can markets facilitate ethical business practices and community benefits? The recent rise of social benefit corporations warrants an evaluation of the outcomes of ethically-driven markets. Using a comparative research design and qualitative interview methods, this study examines certified Benefit Corporations (B Corps) in two selected cities: Philadelphia and Portland. Through interviews with B Corps and Key Informants in the targeted cities, the research investigates how place-based factors support or impede both the certification process and the adoption of ethical market practices, and evaluates participant perceptions about the impacts of becoming a B Corp. Ultimately the research identifies contextual factors which contribute to why and how firms become B Corps and demonstrates how place can limit or enable local ethical markets. The findings suggest ways contextual location-based factors of culture, institutions and relationships in a climate of supporting motivations, can lead to a potentially impactful cluster of ethical market practices. Theoretical considerations include political consumerism/ ethical markets, social entrepreneurship, clustering and agglomeration economies, and community-led social change. The findings may guide policymakers, community advocates or activists, and scholars to better understand the role of place in the adoption of emergent ethical market practices, and to promote enabling legislation and other supportive factors.
\end{abstract}




\section{Dedication}

I dedicate this work to my two deeply insightful and thoughtful daughters, Brianna and Melia, who endured hours and years of mom on the computer, trying to figure out some small contribution to impact-driven knowledge. Someday I expect their community impacts to be far greater, thus appreciate my daughters' eventual contributions towards a hopeful future. I also dedicate this, as the newest member, to the Dr. Bogin club. 


\section{Acknowledgments}

I would like to acknowledge the support and guidance of my academic mentors, especially:

Thank you to my chair Greg Schrock, whose commitment and tireless mentorship went above and beyond to ensure strong skills and exceed expectations for rigor and deliverables.

Thank you to my long-time advisor/ past chair Charles Heying, whose infectious enthusiasm for big hopes in small, surprising places inspired many of my academic pursuits.

Thank you to committee member and long-term professional mentor Jennifer Allen whose thoughtful and meticulous oversight illuminates potential in people and our global systems.

Thank you to committee member Madeleine Pullman who pushed me towards refinement from method through conclusion, and inspired me with her impactful research.

Thank you to my brilliant cohort: Stephan Brown, Tia Henderson and Alan Delatorre, whose brilliance integrated into my internal academic dialogue.

Thank you also to all study participants, who sacrificed time and energy, simply for the sake of doing good. 


\section{Table of Contents}

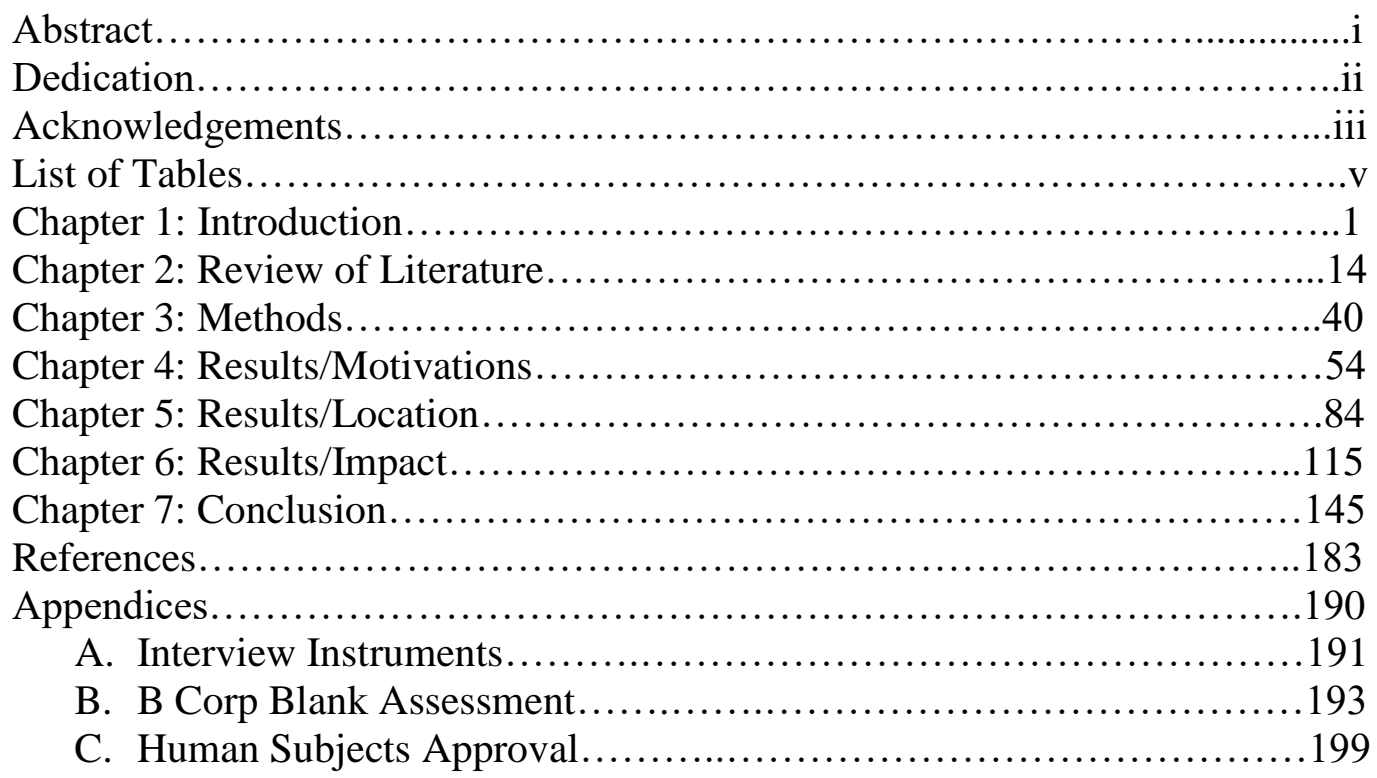




\section{List of Tables}

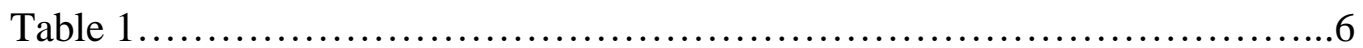

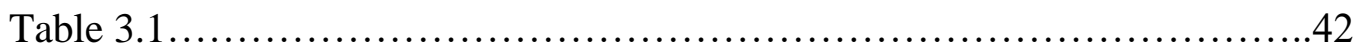

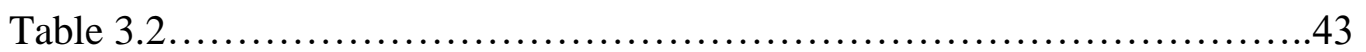

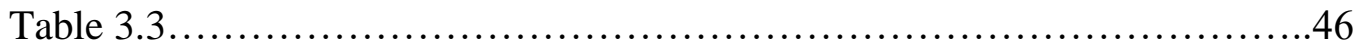

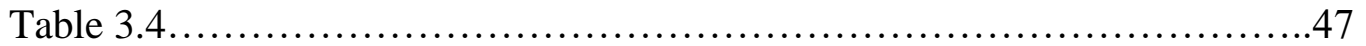

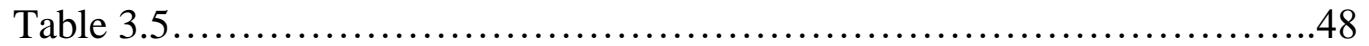

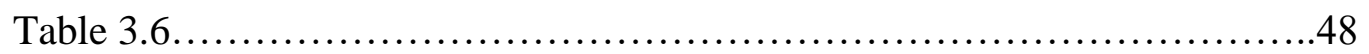

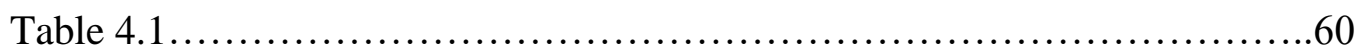

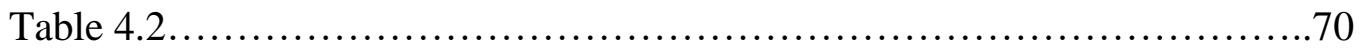

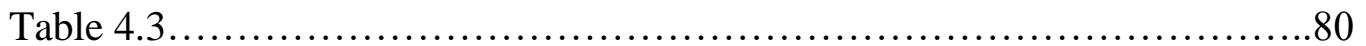

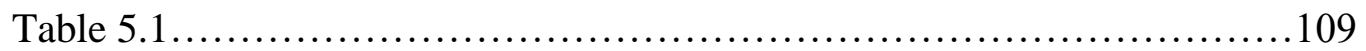

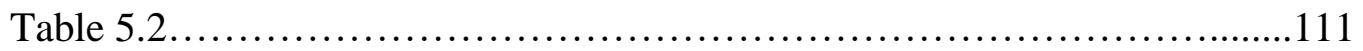

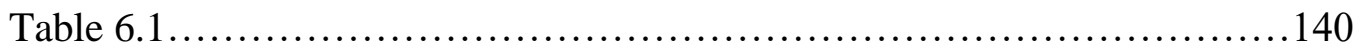

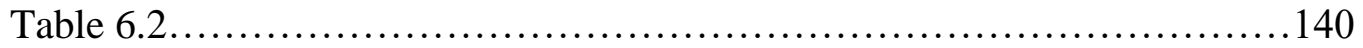


Chapter 1: Introduction 


\section{$\underline{\text { Overview }}$}

How can we infuse morality and justice into the global economy through actions at a local level? High profile conversations are gaining public attention to address this question. For example, global or domestic leaders like the United Nations and United States Business Roundtable discuss the need publicly to re-think market trends and business practices with greater ethical consideration of impact not just profit. What does an ethically-based market mean in practice at the local level? How do urban contexts facilitate or impede ethical market practices? Benefit corporations are a new and rising trend of firms in pursuit of positive social outcomes and warrant further study to understand how businesses and markets imbed ethical practices. This study investigates opportunities and limitations for cities to support ethical markets. The study also expands understanding of potential outcomes of ethical market participation, and through a focus on certified benefit corporations called B Corps. Knowledge contributions of the research topic are potentially relevant to policy and advocacy practices, but also provide an opportunity to enrich evaluative research of ethical markets in terms of methods and goals, and expand relevant conversations about the outcomes of ethical market participation. Analysts of political economy or urban or global social movements may use the findings to assess whether or how to advocate for government regulations or policy to support ethical market practices and to foster enabling conditions for B Corps. 


\section{$\underline{\text { Urban Ethical Markets as Globalization from Below? }}$}

Over the past few decades, the division between political, social and economic spheres has blurred along with the loosening boundaries between the state, civil society and markets (Mayer 2003). Market and activist-oriented actors are similarly not confined to one sphere. As a result, market production practices and consumption choices can take on new significance given their potential social or political impacts. While it is challenging to distinguish traditionally separate but increasingly overlapping spheres in corresponding fields of study, the growth of market practices with social agendas warrants further research.

Urban restructuring during much of this same time period, is partly what motivates these shifts, particularly as forces of globalization have increased impact both transnationally and locally. Locally-based community organizing responds in the context of resulting neighborhood, economic and workforce restructuring, gentrifying and globalizing tendencies. Local communities impacted by forces of globalization, seek forms of resistance or alternatives to globalization. Global or transnational civil society evolved and presents ways civil society reinforces and reflects the dominant political and economic aspects of global forces and what potential exists for grassroots organizations to challenge global forces. Individuals, organizations or communities attempt to circumvent global forces in part through economic exchanges, local movements, political consumerism (Michelletti 2003) and ethical markets (Malpass 2007). While traditionally 
considered disparate efforts, more trends suggest that ethically-oriented market practices hold potential for globalizing from below.

My motivation for this research comes from-in addition to academic interestpersonal experience throughout all states and most major cities in the United States as well as many world cities in thirty countries on four continents, which fostered a commitment to global citizenship and a direct observation of how globalization and market-based practices influence communities. Through technology advances our world and cities are vastly more connected. Yet global forces that enable these connections can also create disparities and imbalanced connections. Meanwhile boundaries between places, institutions, social movements and markets become increasingly blurred. Yet the Unites States continues, for better or worse, to remain a prominent leader on the global economic stage. When in other (often poorer) countries, individuals welcomed me into their communities, and regardless of whether they expressed reverence or resentment they all shared a heightened awareness of our nation's role. That prominence, combined with the frequent unconditional generosity I encountered abroad, solidified for me a responsibility to make global citizenship meaningful. The personal question arises about how can activist-oriented research help understand the potential or limits of markets as a tool for social change? How can markets provide an alternative to economic globalization or corporate corruption? Moreover, how do alternative market practices serve as a tool for social change or foster significant and positive social outcomes? 


\section{$\underline{\text { Social Benefit Corporations \& B Corps }}$}

The recent establishment of social benefit corporations (SBCs) provides an excellent opportunity to understand the potential for local firms and communities to foster ethical markets. SBCs are companies with business practices that pursue ethical processes and outcomes above or in addition to profit gains. They may still pursue and achieve profit but they prioritize a commitment to ethics in their legal structures.

Certified Benefit Corporations are called B Corps and defined as "a new type of company that uses the power of business to solve social and environmental problems." 1 When U.S. states approve SBC legislation, they give legal permission for companies to prioritize mission over profit (Blount, et al 2013). The legislation protects firms and individuals against the risk of shareholder lawsuits for failure to prioritize maximum profit potential or act in the best interest of the corporation. As of February 2014 at this study's inception, twenty states had passed this legislation.

The implementation of SBCs necessitates an assessment process through a specific set of assessment criteria. SBCs must provide reports publically, and can selfreport, but they attain much more legitimacy through third-party certification. The nonprofit organization B Lab fulfills that role as the primary third party certifier to provide third-party validation, public transparency, and legal accountability. B Lab vets and designates eligible participants as B Corps by assessing impacts on four primary impact areas: community, environment, governance, workers. ${ }^{2}$ Not all benefit corporations are certified as B Corps, but no other certification was readily available at

\footnotetext{
1 "B Corporation Home Page." http://www.bcorporation.net (accessed September 15, 2019).

2 "B Impact Assessment Assess Your Impact." https://bimpactassessment.net/how-it-works/assess-yourimpact (accessed September 15, 2019).
} 
research inception. B Corps do not necessarily have to be SBCs or in states passed the legislation, but logically the certification's value is most relevant to an SBC. Thus they are linked. In simplest terms, SBCs are the social benefit corporations, and B Corps are the primary certified type of a benefit corporation. The B Corp website states:

B Corp Certification doesn't just evaluate a product or service; it assesses the overall positive impact of the company that stands behind it.

Certified B Corporations achieve a minimum verified score on the B Impact Assessment - a rigorous assessment of a company's impact on its workers, customers, community, and environment - and make their B Impact Report transparent on bcorporation.net. Certified B Corporations also amend their legal governing documents to require their board of directors to balance profit and purpose. $^{3}$

See Table 1 for a review of the B Corps Impact Areas that determine the overall score and certification eligibility. See Appendix B for an example of the assessment.

Table 1. B Corps Primary Impact Areas ${ }^{4}$

\begin{tabular}{|l|l|}
\hline \multicolumn{2}{|c|}{ B Impact Areas for Impact Reports } \\
\hline Impact Areas & Practices to Evaluate \& Score \\
\hline Governance & accountability \& transparency \\
\hline Workers & relationship with workers \\
\hline Community & impact on community \\
\hline Environment & environmental performance \\
\hline Overall B Score & Total of each Impact Area Score \\
\hline
\end{tabular}

The implementation of SBC legislation poses new opportunities to understand the significance of ethical markets as a business-driven tool that fosters alternative globalization practices and enables the practice of ethically-driven consumption.

\footnotetext{
3 “B Corporation About B Corps.” https://bcorporation.net/about-b-corps (accessed September 15, 2019).

4 “B Impact Assessment Assess Your Impact.” https://bimpactassessment.net/how-it-works/assess-yourimpact (accessed September 15, 2019). Note some recent assessments also include 'Customers' as an Impact Area.
} 
However, given the vastness of that context, one appropriate and narrower focus is an investigation to characterize identifiable conditions which enable or contribute to effective or successful ethical market practices. SBCs offer a way to formalize and legalize ethics over profit in a new, non-traditional business model and a review of B Corps creates an opportunity to evaluate firms' motivations for participation and perceived impact. The development of SBCs raises possibilities of a new model, one potentially compatible with, but a deviation from, other activist frameworks. For example, the Global North/ South divide distinctions are no longer the primary market tension that drives ethical consumerism, as production and consumption trends have expanded in many countries. Specifically the past reported Global South production/ Global North consumption dichotomy is more blurred as the consumer class has grown in poorer countries and richer countries have renewed interest in production. Meanwhile, localism values have risen as a consumer value, but mapping supply chain logistics is not simple enough to provide clear direction for consumer choice or action. Nor is there a guarantee that local is always better. Yet increasingly more businesses have actively begun to evaluate their own practices, to self-assess the ethics of their business practices. These ethical market practices might not be driven by consumer pressures, or by market competition, yet are also not necessarily either a political or apolitical action. This new development calls for further evaluation in pursuit of greater understanding of B Corps as a tool that may enable positive social outcomes.

While a recent phenomenon, there is some research to date. Scholars have begun to examine the evolution and rationale behind SBCs but warn the ambiguity of their legal 
structure and outcomes of implementation leads to vulnerability in accountability, uncertainty about enforcement and potentially perpetuates what they see as the myth that traditional corporations can’t behave ethically (Blount, et al 2013). More understanding is needed to unpack the process behind becoming a B Corps and ultimately the outcomes. Moreover, consideration of the role of location in B Corps development, success and outcomes-specifically through policies, legislative status, cultural contexts, and support networks-will enhance the understanding of B Corps and whether place matters.

This research investigates the phenomena of B Corps to better understand supports in the participation process and assess potential outcomes. This proposed research will explore the outcomes of ethical market practices within selected cities that have a significant B Corporation presence. The outcome categories are those four categories defined through B Lab's assessment of certified B Corps.

\section{$\underline{\text { Purpose }}$}

The purpose of this study was to investigate the implementation process and effectiveness of ethical markets within a place-based context, with a focus on B Corps as a tool to foster positive social outcomes. The study aimed to identify impediments, opportunities and emergent practices through an examination of the process and outcomes of B Corps certification, to better understand the potential and limits of certified benefit corporations as a tool to promote ethical market practices. While B 
Corps are too new and few to measure any significant community impacts, investigation into potential and perceived impacts help move the research forward.

This research investigated B Corps to assess how they identify and to evaluate their potential social benefits or outcomes. The research explored outcomes of these specific ethical market practices primarily at the firm level and at most an individual city level. The study used interviews with B Corps and key informants (KIs) and reviewed secondary online data from B Corp assessments to examine place-based processes and outcomes in order to ask questions like the following: What are the supports or motivations for companies to pursue B Corps certification? What place-specific factors enable or hinder B Corps? For example, what are the local cultural or institutional supports? What policies present opportunities or barriers to establish a local ethical market? How does B Corps certification enable businesses to achieve positive social outcomes? Looking at B Corps, what are the identifiable conditions which enable or contribute to effective ethical market practices? The primary research question is: What are the factors influencing the adoption of certified benefit corporations as an ethical market practice, and what contextual factors facilitate or impede B Corp adoption and outcomes?

\section{$\underline{\text { Secondary Questions }}$}

The research also evolved to address the following secondary research questions:

- What are the motivations for companies to become B Corps and how do B Corps evaluate the value of participation?

- What place-specific factors enable or hinder B Corps including the local cultural, relational or institutional supports and challenges? 
- What are the potential and perceived impacts of becoming a B Corp? What may encourage or limit these impacts and what is the potential scalability?

\section{Expected Findings}

In relation to the three secondary research questions, when the study began, the following findings were expected:

Finding 1: The pursuit of positive social outcomes will be a primary, but not exclusive motivation for B Corps participation. Chapter 4 looks for underlying motivations.

Finding 2: Place will play a role in the success and limits of B Corps. There are identifiable place-based conditions which may inform or impede the successful establishment of local ethical markets. Chapter 5 examines location factors.

Finding 3: The process of becoming a B Corps will enable businesses to produce positive social impacts by providing a tool for their participation within a local ethical market. Chapter 6 identifies types of impacts.

\section{$\underline{\text { Significance and Theoretical Contributions }}$}

The main frameworks involve an effort to place B Corps within the context of blurred boundaries between political, economic and civil society practices. The significance is not only in the meaning or understanding of the B Corp phenomena, but in the relevance to both motivations and outcomes of participation in B Corps as a driver of ethical markets. Like research on social entrepreneurship, the study's emphasis is on businesses as the actors and the goal of the study is to assess how motivations and outcomes contribute to social change and how location helps establish a local market of ethical business practices. Importantly, do outcomes potentially reflect motivations?

Primarily, there's a framework for understanding the range of motivations for B Corp participation. That includes consideration of an ethical market emphasis, but also a 
scalar spectrum as well. For B Corp participants, are intended impacts at a local level and/ or beyond?

Overlapping spheres of markets and movements and global and local actions create theoretical challenges. Yet given the intersections of the "glocal", there's a benefit for urban and social movement activists and scholars to study "the simultaneous articulation of protest on different spatial scales and the embeddedness of urban activism in the broader frame of global social movements" (Köehler and Wissen 2003, 950). Additionally, theoretical discussions have attempted to identify effective or successful political consumerism (Micheletti 2003) or the use of markets to support social movement goals (Balsiger 2010) but the literature lacks evidence of substantial empirical support for these theories. Meanwhile, theorists have proposed the value in consideration of local/ extra-local spatialities through conceptualization of connectedness to the extralocal as a way for ethical markets to provide alternative globalization exchanges (Malpass 2007). Concepts of transnational collaboration have been investigated (O’Neill 2004 , Tarrow 2005) or alternative globalization movements (Dyer-Witheford 1999) yet practices of global citizenship remain impeded within the Global North/South divide (Balarin 2012).

These conversations have expanded to include market exchanges as a means towards social or environmental justice and more ambitiously (yet marginally) to consider the potential for market practices to provide market-based alternatives to economic globalization. In the wake of anti- or counter- globalization and vote-withyour-dollar campaigns and resulting values-based practices-specifically for example 
localism, fair trade and carbon reduction strategies-local markets have evolved seemingly to pursue that alternative. Localism practices are championed by some (Köhler and Wissen 2003) and critiqued by others (Johnston et.al 2009). Meanwhile, any substantial impact on the Global North/ South divide is also questioned (Fridell 2009). Specific to the context of this research design, there is an opportunity to unpack such theories through identification and analysis of relevant data, to evaluate the effectiveness and success of ethical markets outcomes in relation to motivations. This research attempts to expand this complex yet valuable conversation. Additionally, the research may contribute to social movement theory and expand a discussion regarding potential use of market relations as tools for social movement activism and pursuit of embeddedness of market exchanges in social relations (Starr 2010), while research on sustainably responsible supply chain analysis (Pullman \& Sauter 2012) will expand to B Corps. Essentially, given both overlaps and distinctions of global and local actions, markets and movements, community-advocacy research should aspire to articulate meaning of the intersections and generate policy advocacy strategies. Specifically the research can provide a preliminary blueprint for activists to assess whether and why to promote or critique B Corps and ethical market movements, particularly to highlight the potential and limitations.

The study design aims to examine theoretical implications of B Corp participation and address a number of contextual questions: What do the motivations reveal and how do the motivations reflect outcomes? Does participation in ethical markets or the adoption of social benefit legislation or status, suggest support for social change? 
Moreover, does it expand studies of alternative globalization or global civil society to include market-driven positive social change? Are concerns about globalization or resulting inequities a strong motivation? Or are concerns more frequently locallyfocused? Such conversations are primarily semantic in nature though relevant to theoretical discourse. Yet more significantly, a greater understanding of outcomes of ethical market practices, through the example of B Corps, can expand insights on potential opportunity and limits of the market as a vehicle for production of positive social outcomes. Identification of compatible market and social movement goals and overlaps, may contribute to both scholarly and activist goals. Can B Corp-led blurring of institutional boundaries between political, economic and civil society spheres reveal how an ethical market may provide an arena for political action or social change? How important is place to the establishment of a local ethical market? These questions inspire the primary and secondary research questions in order for findings to help us gain understanding and consider implications. 
Chapter 2: A Review of Literature 


\section{Background: Urban Restructuring \& Community Impacts}

Over the past few decades, the division between political, social and economic spheres has blurred along with the loosening boundaries between the state, civil society and markets (Mayer 2003). Market and activist-oriented actors are similarly not confined to one sphere. As a result, market production practices and consumption choices can take on new significance given their potential social or political impacts. While it is challenging to distinguish traditionally separate but increasingly overlapping spheres in corresponding fields of study, the growth of market practices with social agendas warrants further research.

A brief review of intersections between politics, economics and civil society provides a greater context for understanding the significance of socially-motivated market practices. The economic restructuring that began in the 1970s-as evidenced by trends of deindustrialization, manufacturing decline in the Global North, and globalization-facilitated a devolving role of the centralized, beneficent state. This shift led to increased responsibility of cities to respond to civic agendas no longer supported by the state such as community and social needs. Politically driven practices of deregulation, privatization and decentralization likewise contributed to the devaluation of labor, the loss of viable employment opportunities and diminished state welfare budgets. (These discussions are debated, but for the purpose of this study, this well-defended premise is accepted.) Such changes led to civil society's growth to compensate. (Friedmann 1998). Meanwhile involvement from the economic sphere--via private 
charities and foundations-helps support civil society goals, for causes on both the political right and political left. Lobbying efforts by powerful market forces influence public sector activity either through direct funding, or through funding of civil society efforts, thus empowering a private or market sector elite to have a primary influence over policy and political action. Lobbyists and foundations influence policy which directly impacts community conditions. (Friedmann 1998, Roeloffs 2003) At its core, civil society includes those organizations that exist outside of direct state control and supervision. The right tends to view civil society as the institutions that mediate between the individual and the state, while the left views civil society as the resistance mobilizations against hegemony. (Friedmann 1998). This study follows lead from previous research and aligns with this latter definition. Civic groups, private sector interests, and lobbyists stepped up to meet community needs, resulting in overlaps between political, economic and civil society spheres.

Meanwhile, public scrutiny increased over the so-called social sector (of nonprofit and public organizations), while public trust grew in the efficiency and professionalism of businesses. As a result the social sector began to include more public/private partnerships with businesses. This norm shift was not without criticism, as some warned that for-profit firms could undermine missions of nonprofit. Gregory J. Dee and Jaan Elias (p.168) review a book by Norman Bowie that studies the example of university/business partnerships, to question whether businesses would undermine the university knowledge goal because they see knowledge as something to "be owned, controlled, and put to productive... use" (p. 168). However, the book cites other research 
which suggests this fear to be unfounded, as the same concerns around integrity are largely relevant with or without financial incentive, even if such problems are worsened. The review also found that universities began to favor the departments which achieved the greatest financial success. Yet they recognize how "potential value conflicts can be managed effectively through contractual arrangement and university policy" (p.172) and suggest "some commercial practices are directly woven into the core operations of a social enterprise, creating a commercial-charitable hybrid" (p.176.). Other scholars also now refer to businesses with a charitable mission as a business hybrid. (Battilina \& Lee, 2014).

In recent years, both government agencies and nonprofit organizations are "reinventing" themselves to be more businesslike...At the same time, government subsidies have decreased and private donations and grants have not made up the difference... This weakness in government and private funding, coupled with the proliferation of social sector organizations, has fueled intense competition. (Dees \& Elias, 1998, p. 166)

Relevantly, urban restructuring (and the negative impacts on communities) generated incentive to develop new strategies for community advocacy. Urban and global restructuring over the past few decades includes trends towards neoliberalism, public disinvestment and expanded urban governance at the national and local level, and the expansion of economic globalization and both economic and global forces at the international level (Fainstein 1990, Harvey 2006). Communities faced challenges of neighborhood, workforce and economic restructuring, as well as equity disparities of 
racial and class segregation amid gentrifying and globalizing tendencies. Expanded urban governance refers to the way civil society actors take on or influence tasks normally overseen by state systems; including care for community and social needs. Structural conditions impact urban communities and the ways communities respond to these conditions. Economic restructuring dramatically impacted the urban workforce and economic status among marginalized or poor urban sectors (Friedmann 1998). The resulting economic, workforce and neighborhood impacts, necessitate community responses (Burris 2003).

\section{Community-Driven Social Change \& Alternative Movements}

Communities respond to the negative consequences of urban restructuring through community and social organizing efforts, and community economic development efforts. Specific responses include various forms of community organizing from institutionalized forms of civil society such as community development corporations (CDCs), the more politically active methods of grassroots organizing and social movement practices, as well as some actions focused on private sector solutions.

In response to the perceived negative consequences of neoliberalism, restructuring, and economic globalization, community-based resistance movements are on the rise. Peter Evans (2007) identifies globalization forces as neoliberal, corporate, transnational domination, and lower costs in communication technologies and transport. He challenges the natural process of globalization and looks at the capacity of networks and global counter movements to counter hegemony of globalization forces he identifies 
as neoliberal, corporate, transnational domination, and lower costs in communication technologies and transport. He illustrates how the combination of organization and movements are the key to norm change.

It's important to emphasize ways the very forces and tools that perpetuate economic globalization can also be used to challenge the perceived negative results. A relationship exists between global forces of neoliberalism and those movements which arise at both local and transnational levels, leading to a tendency of "glocalizing protest," in which both impacts and actions have local and global ("glocal") roots and points of interactions (Köhler and Wissen 2003). Community movements advanced into the economic arena (Halpern 1995, Jargowsky 2005) and more recently, local and glocal movements directly into markets (Weidenhoft 2008).

Importantly, Bettina Köhler and Markus Wissen (2003) explain that elements of globalization forces may support globalization resistance movements, but also exist within them and may replicate some inequities. Srilatha Batliwala (2002) looks at the potential in some case for transnational civil society movements to be co-opted by organizations that do not serve grassroots organizations or movements, but rather behave like a quasi-state, influencing local governance. To resist without perpetuating structural inequities, Nick Dyer-Witheford presents an alternative model of the "other globalization" (1999):

In the current context a more promising line of initiative is what Jeremy Brecher and Tim Costello call "globalization from below." This refers to the activities of "peoples transnational coalitions," formed across national boundaries by social movements aiming to fulfill mutually supportive objectives for workers in different parts of the world." (p.163) 


\section{Dyer-Witheford also states:}

The fundamental reorganization of capital... has produced not one but two globalization processes - simultaneous, superimposed, interdependent, and antagonistic. The first is capitalist globalization...The alternative, opposing tendency is that of the worldwide counter-movements confronting transnational capital... which appear at first as...localized neighborhoods of survival and communities of resistance, [but whose] struggles generate a series of connections, contacts, coalitions, and networks of cooperation...This is "the other globalization." (p. 163-4)

Meanwhile, James DeFilippis (2004) looks at the impacts of globalization and subsequent changes in local urban economy, policy and politics, and considers how local actors can maintain some autonomy and control over their lives through collectivist, communityoriented or collaborative efforts.

While some responses to community problems are resistance or organizing efforts, others propose to address urban social problems through economic development strategies. Michael Porter (1995) challenges the socially-focused community development models (or presumably social organizing efforts) and proposes an economic model instead, one that helps cities obtain a competitive edge in global economies. Porter claims community developers will be more effective if their strategies benefit and encourage private investment, development and enterprise, by marketing a location's attractions and potentials through local inner city advantages including: strategic location, local markets, and regional business clusters. Porter's critics take issue with his suggestion to resolve urban social problems by promoting economic development over treating issues; or by failing to acknowledge the roles community development or community-based organizations (CBOs) play in the economic development (Harrision, Bennett, and Glasmeler 1997). However, his critics might appreciate a compromise that 
doesn't forgo community development, but includes economic development with a social or ethical prioritization.

Viewpoints aside, over the past two decades, either through institutionalized response, social organizing, or economic development, the marketplace has become an arena for increased community or citizen-led pursuits of social change. Trends of restructuring produce negative community consequences. Responses include resistance and alternative movements, community organizing, or economic development strategies, all different efforts but which create new opportunities for overlapping social actions. As a result, the marketplace has emerged as a popular arena to pursue social change and produce positive community or social impacts. Thus, scholars and activists may want to better understand the opportunities and limits of markets as a vehicle for social action and community or social impacts.

\section{$\underline{\text { Impact-Driven Business }}$}

\section{$\underline{\text { Social Entrepreneurship }}$}

One of the primary examples of how markets have evolved to pursue social action is the increased awareness and prominence of impact-driven businesses. Relevant activist and scholarly discussions about social entrepreneurship and the supply-side of markets focus on social enterprise, corporate social responsibility, and sustainably responsible supply chain analysis. "The archetypal social entrepreneur is one who builds a dualmission business -one with both profit and a nonpecuniary purpose-that embodies 
sustainability" (Katz \& Page 2013). Corporate social responsibility (CSR) standards incorporate ethical guidelines into a traditional business model, while other businesses monitor their standards to ensure sustainably responsible supply chains (Pullman and Sauter 2012). The field of social enterprise has largely identified and defined a new type of business that functions like a hybrid between traditional business and nonprofit organizations-mission-driven businesses (Battilana \& Lee 2014). Additionally, some work to date has examined impact-driven business in an effort to map out a more recent, newer type of business model. For example, research on supply chain management (Pullman, Longoni \& Luzzini 2018) identified businesses striving to not only "reduce social harm" but to "generate social benefit" through social impact supply chain management.

Scholars attempt to understand societal implications of social entrepreneurship and CSR through theory and analysis. For example, Malin Galwell (2013) strives to make the concept of social entrepreneurship empirically meaningful within different epistemological approaches, acknowledging relevancy to both enterprise and civil society. As previously mentioned, Dees and Elias (1998) review a book that addresses business ethics which they claim "demonstrates the value of incorporating ethical considerations into the nuts and bolts of organizational strategy and structure" (p. 166).

"Throughout history, social sector organizations have provided goods and services that, presumably, would not be adequately or appropriately provided if left up to the actions of private markets and profit-seeking firms. Though their specific goals vary, all "social enterprises" endeavor to enhance societal wellbeing in some way, driven more by their mission than the market or profit." (Dees \& Elias, 1998, p. 166) 
They also warn of the risk to mission, when organizations like public universities become too profit-driven or when individual scholars become too self-interested.

Otherwise, scholars (Mair, Battilana \& Cardenas, 2012) "reflect on how social entrepreneurs develop the social entrepreneuring models [SEOs], i.e., how they come up with solutions to the social problems that they aim to address and how they enact them." (p.354) "SEOs address social needs... Research on strategy and organizations has shown that new business models and market opportunities are created by overcoming or ignoring industry boundaries and categorizations.” (p.355)

In summary, the line between for-profit and nonprofit blurs with both the examples of social entrepreneurship and social enterprise. CSR enables businesses to support social causes, but not necessarily at a level equal or beyond the profit motive. This current study examines businesses which claim through certification to put social impact equally or beyond profit, potentially with larger change-making goals.

\section{$\underline{\text { Political Consumerism and Ethical Markets }}$}

\section{$\underline{\text { Political Consumerism }}$}

Discussions around social-change goals and desire for change-making impacts have implications for political action. Questions arise about whether or how market-based practices can be political actions. Political consumerism is a relatively new field of study with growing importance, particularly in the context of social movement studies that use markets to create social change (Balsiger 2010, Wiedenhoft 2008). While political 
consumerism is not necessarily a new or a globally-focused practice, global social movements and global civil society provide a context for understanding the potential relevancy of political consumerism. Political consumerism has been examined within the context of social movement theory (Balsiger 2010) and some scholars observe a potential for an embeddedness of market exchanges in social relations (Starr 2010). Most consumer-led actions of political consumerism include boycotts (rejection of products or services for political reasons) or the increasingly more common practice of buycotts (patronage of products or services as a form of advocacy).

In its most widely recognized application, Michele Micheletti (2003) describes political consumerism as a tool adopted by individuals, groups, organizations or regions to provide alternatives to market processes that are under the control of global forces. Dietlind Stolle, Marc Hhoghe and Micheletti (2005) look at motivation, behavior and frequency of behavior to determine how political consumerism actions can be political. They explore how to measure political consumerism actions, who to study, and what value orientations and social embeddedness are represented in such actions. Their findings suggest that political consumers are not necessarily disconnected from other political processes. One of their biggest challenges is in distinguishing (and measuring) behavior motivated by personal or private concerns versus intended political participation. To resolve this, they argue three qualifying conditions must exist among participating consumers: 1) consumption behavior 2) awareness of ethical or political motives and 3) frequency and indication of habit or behavioral pattern rather than an 
isolated act. This model could also apply to markets in general and include businesses as well, to determine political motivation and intended impact by business practices.

Meanwhile there are strategic reasons for local, underserved communities to act in recognition of globalization's wide impacts and pursue community control over markets (DeFelippis 2004). Yet thus far the literature has focused more heavily on the consumerdriven action. A motivation for this current study includes the desire to investigate the effectiveness of political consumerism as a tool to strengthen local communities, yet with an emphasis on how businesses, enabled by policy, foster those opportunities.

\section{$\underline{\text { Ethical Markets }}$}

Political consumerism overlaps with the concept of ethical consumerism, also called conscious consumption, or within the general phenomenon of ethical markets. The latter incorporate business actors as market-based activists. Ethical market participation (by consumers or businesses) is value-driven, but not necessarily intentionally political in nature. Rather, participants prefer to witness inclusion of ethical practices in some aspect of production, distribution or in the supply-chain transactions-essentially at some (varying) point(s) in the business practice. Yet when ethical markets get woven into policy, especially as a result of advocacy, there is arguably an element of political action. For example, when cities achieve 'Fair Trade Town' certification, they weave ethical market practices into their local policies. While there are debates about how to define market-based practices and motivations as political or ethical, for the purposes of this study, the more common interpretations from the literature are adopted. These markets 
warrant further investigation to better understand if the social impacts or community outcomes of participation reflect the intended values.

A better understanding of the potential outcomes of ethical market practices can help inform policy recommendations and evaluations. Ethically-driven business owners, activists and scholars want to understand how ethical markets provide alternatives to the negative externalities from economic globalization practices and neoliberal policies led by transnational corporations and/or political actors. Moreover, critics of any type of conscious consumption warn consumption emphasis reduces responsibility from businesses or from government regulatory agencies (Muldoon 2006). Thus there is incentive to understand how businesses and policies create ethical marketplaces and evaluate how ethical markets demonstrate, or fail to demonstrate, alternative outcomes.

\section{Ethical Markets in the Local Context}

Some locally-based individuals, groups, organizations or cities adopt consumer or market policies as a tool to reject products or provide alternatives for political reasons (Micheletti 2003, Malpass 2007). Reactions to global forces, political situations or corporate behavior are often primary motivators for local participation in ethical markets. Local ethical markets traditionally address and attempt to correct for the inequities of the traditional Southern producer/ Northern consumer divide but more recently emphasize opportunities for Northern producers, as well. While the terms about ethical or political markets are open to various interpretations, the academic discussions mainly examine the potential and limits of markets as a tool for social action, often in the context of economic 
globalization. An examination of ethical markets in a local context makes these conversations more meaningful.

Importantly, while the big picture motivations for ethical markets may be global, increasingly markets and market-focused policies surface in a local context. In some cases, local policies evolve to support ethical market practices. For example, the cities which undergo a certification process to become Fair Trade Towns, implement guidelines over spending of local public funding on both local and non-local production (Malpass 2007), while others implement purchasing agreements through public policies. Some communities advocate for local markets and economic development (DeFelippis 2004). For example, community-focused market practices evolve to promote local markets (Balsiger 2010) and artisan economies (Heying 2010). Local markets for production and consumption introduce new possibilities to have locally-based impacts. Consequentially, local communities may either drive or experience impacts. Meanwhile, proximity to firms with compatible ethics, or localism values, may result in spillover effects and foster opportunities for innovation.

One consideration to address cautiously is the presumption that local is better. There is sufficient literature to demonstrate local is not always more sustainable, just or even democratic. For example, Mark Purcell (2006) observes an a priori assumption among neoliberal globalization critics, that the local scale is automatically better, and are thus at risk of succumbing to the 'local trap.' E. Melanie Dupuis and David Goodman (2005) similarly warn scholars should "question an "unreflexive localism" ... yet still strive to "forge localist alliances that pay attention to equality and social justice." This 
current research recognizes the potential for biased assumptions about localism, while also accepting the other previously mentioned community economic development literature which demonstrates how local businesses can strive to support community, social, and/or sustainability goals.

\section{Critiques: Impact-Driven Businesses \& Ethical Markets}

Despite many champions, practices of social enterprise/ entrepreneurship/ (corporate) responsibility, and ethical markets have their critics. Theorists attempts to distinguish social entrepreneurship as expression of self-interest, from phenomena responding to needs in society (Galwell 2013). While some research suggests participants act based on perceptions about social necessities, their actions are facilitated by opportunities for entrepreneurship (Galwell 2013). Moreover, critics of corporate social responsibility identify indications of greenwashing or limited accountability to corporate promises (Blount, et al 2013, Muldoon 2006). Some scholars warn ethical markets replicate inequities across borders (Jungar and Salo 2008), or among underserved populations in urban spheres (Malpass 2007, Johnston et al 2009) by perpetuating the power of consumers over producers, or by obscuring labor exploitation through commodity fetishism (Fridell 2007). Yet the U.S. has experienced a significant recent growth in preference for local and/or domestic production (Dupuis and Goodman, 2005), while community economic development has steady support. As a result, the North consumer/ South producer model appears to be increasingly supplanted by including a coinciding North producer and South consumer model (Curtis 2013). As a growing practice with substantial community and public participation, ethical markets warrant 
further investigation to better understand how impacts of participation in ethical markets reflect intended values and to inform policy recommendations and evaluations.

While these debates largely examine the intentions and direct impacts of individual businesses, other work to-date attempts to map their existence and impact across a broader geographic spectrum. Work on urban economies attempts to map economic development across cities. A newer, burgeoning field attempts to understand the relevance and growth of local ethically-driven economic development.

\section{$\underline{\text { Economic Development \& Urban Agglomerations or Clusters }}$}

A discussion on markets should also address some traditional economic issues including contexts pertinent to this study such as local economic development. Most relevant to this research are discussions about urban agglomerations and the localization of innovation, particularly recent research on clusters that appears to capture both ethical consideration and economic opportunities. A question arises about how place matters in the emergence of these new social economic practices relating to ethical markets: Are there reasons such markets emerge more in some places more than others? Essentially, scholars have not sufficiently explored this question of location in the emergence of ethical markets.

Much of the literature that is available focuses on clustering (Porter 2000) by and between associated industries focused on production, but also more recently on knowledge work; yet there is a growing though still small amount of literature on clusters 
driven by an ethic, mission, or impact agenda. Some of the work-to-date includes focus on green economy clustering (Allen \& Potiowsky 2008), sustainable industries (Barry \& Portney 2014), and linking green economic development to social and justice issues through collaborations between economic development, investors, and urban planners (Fitzgerald 2010). Research on the Maker Movement as an aspect of urban economic development addresses the shift from production to services, considers how maker enterprises contribute economically at the local level, and identifies how place is important for the emergence of social practices (Wolf-Powers, et al. 2017).

While green economies are arguably mission-driven industries, as with other types of social entrepreneurship, they do not necessarily reject traditional business models. The sustainable business model is still primarily competitive. They may even attempt to change industry behaviors or practices, yet the question arises about whether they necessarily change markets-at-large.

The literature on urban economies is robust and extends over a century. Jane Jacobs (1969) describes how economies of cities develop through place-based innovation in response to industry needs or exposure to new work ideas. Allen J. Scott and Michael Storper (2007) describe how even in a globalizing world (that distributes manufacturing and production internationally through inter-regional trade), local innovation takes place at an urban or regional level. Anders Malmerg and Peter Maskell (2002) describe how industry agglomeration and spatial clustering may evolve in urban regions through learning and innovation due to either a place's 'local milieu' or informal interactions. While Malmerg and Maskell make the case for local innovation as relevant to firm 
competitiveness, Porter (2000) illustrates how clusters evolve in cities through both competition and cooperation, through development of geographically-based specialized firms and industries, often inter-connected through a knowledge-based economy. These theories contribute to a literature on urban agglomerations and clustering yet often note a need for greater empirical understanding of spacial clustering.

Overall, while some literature-to-date examines politically or ethically oriented markets, social entrepreneurship, and economic clusters including among sustainable industries, there remains a gap in the literature on the development of what we can call an ethical market cluster (EMC). EMCs are clusters of firms driven by ethics or potentially political motivations, to create positive social impacts or what may also be called social benefits. As a compliment and expansion of the concept of a mission-driven business cluster, an EMC encompasses a market rather than a specific industry type. While this research focuses on the business-side, the market includes local communities, clients and customers. Uniquely, the benefit corporation concept arose to address that latter larger and perhaps loftier goal-to change markets and business practices by providing a model of ethically-driven business that strives to minimize negative social impacts and foster positive social impacts. An additional question also arises about how or whether a cluster forms at the local level for firms that are not necessarily associated by industry, but primarily by an ethically-driven motivation to change business practices at large. 


\section{Ethically-Driven Businesses: B Corps}

\section{$\underline{\text { Social Benefit Corporations \& B Corps }}$}

As mentioned in the Introduction chapter, the recent establishment of social benefit corporations (SBCs) provides an opportunity to investigate the potential local impact of ethical markets from a business perspective. SBCs reportedly pursue ethical processes and outcomes above or in addition to profit gains-to support a 'social benefit.' The firms are not necessarily always focused on ethical or sustainable production, yet they include ethical considerations in how they run their business-in other words, they have ethical business practices. While they function as a driver of ethical market participation, SBCs are not necessarily a direct response to inequities from economic globalization such as in Global North/ South relationships. Yet there is an expected underlying response to concerns of corporate corruption or irresponsibility (Chu 2012), presumably in part as a result of economic globalization's negative consequences.

SBCs may still pursue and achieve profit but they prioritize a commitment to ethics in their legal structures. They challenge the "shareholder primacy theory of corporate law" (Hacker 2016, 1752), and like nonprofits, can consider 'stakeholder interests' (often the general public). For background on the (perceived) necessity of legislation, in 1919 "the Michigan Supreme Court (in Dodge vs. Ford Motor Company (1919) established that firms' social responsibility ends at increasing profits for shareholders. Four decades ago, Milton Friedman underscored this argument, and added that it was governments' responsibility to solve societal problems." (Haigh \& Hoffman 
2012, p.130). When U.S. states approve SBC legislation, they give legal permission for companies to prioritize mission over profit (Blount, et al 2013). Twenty states had passed this legislation in February 2014 when the study began, thirty-six had by the end of 2019 . As briefly mentioned, the implementation of SBCs necessitated a certification process with a specific set of assessment criteria, and the nonprofit organization B Lab fulfills that role as the primary third party certifier. B Lab vets and designates eligible participants as B Corps by assessing impacts on the four primary impact areas. See Table 1 (in the Introduction chapter) for a review of the B Corps Impact Areas that determine the overall score and certification eligibility.

Given that B Corps are still a relatively new phenomenon (that began in year 2007), there is minimal literature to date. Of the existing research, some studies focus specifically on B Corps and B Lab, while others examine social benefit corporations overall. Most studies examine implications for business law (Hacker 2016), an area less pertinent to this study thus not discussed at length. The most relevant research to date considers impact of B Corps either as a business model (Stubbs 2017), by location (Hickman et al, 2014), in terms of accountability (Hacker 2016), or importance for policy (Plerhoples 2017), (Toepler 2018), yet all research is too new to be conclusive.

Several studies were conducted around the same time as this research, and thus did not influence this study's design but are nonetheless relevant or complimentary. Wendy Stubbs (2017) conducted an exploratory study of B Corps in Australia to identify their function within a business model, and identify an appropriate analytical framework. Stubbs describes B Corps as a "sustainability-driven hybrid" business model (SDH) with 
aspects of a sustainable business model (SBM), but with greater consideration for external impacts as well as a drive to change industry and markets-at-large. The qualitative findings-through interviews with all of Australia's 14 B Corps-supported B Corp placement within the SDH analytical framework, however with less direct influence on policy and markets despite attitudes indicative of participation within a 'movement.' The research also attempts to unpack trending structural (e.g. process) and cultural (e.g. norms) characteristics of B Corps, and finds a degree of engagement at both levels. Given small sample size (14 B Corps) and geographic limitation (exclusively Australia), Stubbs acknowledges limitations to the study and lack of generalizability. However, the study makes a case for further research needed, especially to understand the potential capacity and limits to scalability, systemic change, and market transformation. Meanwhile, the research of Leila Hickman, John Byrd and Kent Hickman (2014) adds to clustering literature with a focus on mission-driven companies and posits that companies will emerge where there are a higher proportion of people interested in environmental, health and social issues. Their quantitative analysis of early adopters finds that "regions with higher educational attainment, which are politically progressive, have healthier populations, rank high in greenness, and are diverse, tend to have higher B-Corp adoptions." Yet they also find that "higher per capital income is, on average, associated with lower rates of commitment." $(2014$, p.13)

A critical discourse had already begun, echoing many similar positions found in the social enterprise and political consumerism literature. Particular concerns include 
caution that B Corps are not held sufficiently accountable and could provide competition to (supposedly better) regulated nonprofits, or are susceptible to greenwashing:

"Holding corporations accountable, in the normal model, generally occurs in two ways: (1) if the entity is a for-profit corporation, directors are brought to task through a derivative suit commenced by the shareholders; and (2) if the entity is a nonprofit organization, directors or trustees are held accountable through legal actions brought by a state attorney general. Under the current benefit corporation model, however, intended beneficiaries are explicitly denied standing to enforce the creation of a public benefit, both in the courts and in benefit corporations' internal processes. In addition... even shareholders themselves have limited remedies to enforce the creation of a public benefit. Because benefit corporations are for-profit entities and do not receive any unique tax advantages, it is unlikely that, under the current model, state attorneys general would have any power to intervene in a benefit corporation's internal affairs." (Hacker 2016, 1749-50).

The article referenced in the quote above, challenges the potential of the SBC model. Michael A. Hacker (2016) questions accountability for the model and cautions the mechanisms are neither as sufficient as the corporate shareholder model or the nonprofit legal model. The challenge of the model is while directors remain legally accountable to shareholders and through legislative accountability for a public benefit, there is little likelihood shareholders-or the non-shareholders who lack standing-could successfully hold directors legally accountable for their public impact. Third party certifiers do not have enforcement powers (1767), nor do they have the authority to enforce adherence to (or revoke) status like Attorney Generals do over nonprofit organizations. However, while logical points, the author may exaggerate the importance of that oversight, and fails to account for stakeholder power as consumers. Interestingly, the author argues for Attorney General oversight of benefit corporations, which may actually give disproportionate power to the state than either consumers or the corporations want. This 
seems like a good area for further evaluation to better understand perceptions and potential impact.

Meanwhile Alicia E. Plerhoples (2017) posits that public benefit corporations are susceptible to greenwashing or fraud and even warns they provide a means for marketbased charity to cause harm. She proposes 'public benefit corporation status...offers not just an alternative to for-profit corporations but also an alternative to charitable organizations" (p.537). The author highlights the main differences between for-profit and non-profit spheres (other than nonprofit tax-exemption) is the for-profit ability to distribute profit and accountability to shareholders, and argues that benefit corporations need stakeholder accountability to prevent siphoning resources from charity organizations. Stefan Toepler (2018) addresses Plerhoples' concern that the existence of benefit corporations could divert policy and charitable support from nonprofit organizations to benefit corporations. Through an early uptake study, the research asks whether benefit corporations are socially responsible businesses or are they businesses with nonprofit missions, and posits the latter offers competition and threatens to displace nonprofit organizations. The findings indicate there are not enough early adopters to provide competition, however some benefit corporations could be charities but instead choose a business form. While Toepler resolves the actual impact thus far of benefit corporations is small, Plerhoples does highlight one key concern among nonprofit organizations: when given the option of impact investing instead of charitable giving, "philanthropy funders are focusing on business plans instead of the traditional "number of lives saved" metrics when it comes to making funding decisions" (p.554). Two 
solutions she considers and rejects include 1) to change the nonprofit organization (NPO) tax structure to be more favorable to social enterprise (although at risk of increased fraud, unless there is additional oversight from the IRS), or 2) to provide state-level oversight similar to NPOs, although either solution would clearly add burden and cost to the state. Instead she opts for the creation of "stakeholder-stocker governance." The critiques thus far are largely speculative, not significantly empirical.

Otherwise, one potential concern that does not show up in the benefit corporation literature, is the potential for yet another sector to divert state responsibility, and transfer heightened social and environmental accountability with the for-profit sector. There are already plenty of critics that either 1) caution that reliance on civil society to take care of social needs is a deflection of state responsibility or 2) lament how public/private partnerships divert capital or tax-payer funding to less-regulated and less-accountable forprofit organizations, thereby empowering non-mission-driven organizations in the public sphere. (Hacker 2016) However, given the dependency cycle of nonprofit organizations and the excessive influence corporate foundations have on nonprofit organizations' activities and missions (Roelefs 2003), the challenges and threats facing benefit corporations do not necessarily substantially differ from other blurred lines between the three traditional spheres.

Otherwise, to date the research on B Corps has yet to substantially address the scalability potential for benefit corporations. Specifically the question persists about whether the phenomenon indicates a niche market, or one with potential to grow enough to change markets. There are two signs of its potential for growth, as big actors sign on to 
the mission. First, B Lab partnered with the United Nations on an effort to develop tools specifically for multinational corporations to achieve B Corp certification (Feloni 2019). Secondly, a couple hundred CEOs from the Business Roundtable issued a recent statement challenging the shareholder primacy notion and offering other purposes including accountability to stakeholders. The statement indicates a commitment to “investing in employees, delivering value to customers, dealing ethically with suppliers and supporting outside communities are now at the forefront of American business goals" (Fitzgerald 2019).

While acknowledgement of stakeholder purpose by two globally prominent groups suggests potential for growth, a question arises about whether (ethically) purposedriven corporations can compete in global markets if other multinationals prioritize economies of scale and maximized profit. Costs have to shift somewhere, and reliance on the good nature of conscious consumers risks perpetuation of global inequities, as for example, shoppers from wealthier countries (or neighborhoods) pay more for products made by poorer countries (or individuals). While localism values may divert some capital, production still exists primarily through global markets, and localism remains a niche choice. As is often the case with social divisions and ethical markets, the absence of equally distributed choice challenges the notion of equitability and may threaten sustainability. Moreover, for a truly significant impact, adopters must include larger-scale corporations, particularly in mass production and manufacturing. Thus, the state and civil society remain pertinent, as countries will need to adopt legislation, and thirs party nonprofit certifiers and/or state-based auditors will need to monitor for fraud prevention. 
For ethical markets to disrupt the traditionally exploitive patterns, a leveling out of choices is needed. This goal seems well beyond the immediate capacity or goals of benefit corporations. Yet there is sufficient reason to consider how and whether, the spread of ethical markets through benefit corporations like B Corps, has capacity to contribute to a more sustainable and just world.

As previously mentioned, the potential for growth is now on the horizon, given recent direct or related support on a larger global stage. Both the United Nations partnership and the Business Roundtable examples suggest potential for the idea of B Corps to spread and gain a wider support. Thus there is potential for an eventually more globally-distributed impact.

However, before even venturing an extensive understanding about the conceivable impact on the world stage, we can start to understand the potential for and impact of B Corps, by looking at the local level. By understanding where, why, whether or even should they work in an individual city, we can begin to gain insight into their potential and the value of scalability. Thus questions arise about whether or not an economic cluster can develop between firms whose primary association is a social benefit, what local factors contribute to the cluster development, and what motivates local participants. 
Chapter 3: Methods 


\section{Overall Approach and Rationale}

Given the newness of benefit company legislation and B Corps certification, there was not much research to date at the study inception. A qualitative method aimed to produce more information from which to plan future studies, including the possibility of quantitative methods. Through qualitative research this study expands insights about the topic. The methodology employs a comparative multi-site design approach and primarily uses semi-structured interviewing and case studies of research subjects to richly identify meaning and perspective surrounding participation in locally-based ethical markets, in order to understand the contextual factors. The researcher invited participants to address criteria relevant to the process and outcomes of becoming a B Corps, included an assessment of place and other comparative criteria, and specifically addressed secondary research questions. Interviews reviewed the experiences with certification processes and legislation development.

\section{Data Gathering Methods}

\section{$\underline{\text { Site \& Population Selection }}$}

The design targeted B Corps from two selected cities. The purpose of examining two cities was to conduct both a within-case and across-case study, for comparative purposes. The two sites were Portland and Philadelphia, cities with some comparable criteria (for example as major urban centers that are large but not global cities, with 
approximately the same number of B Corps-see Table 3.1) yet variation in culture and some socio-economic, demographic information. (See Table 3.2.) The research design assumed the similarities will enable exposure of more pronounced and significant differences in findings. Portland was chosen as a city known for its sustainability and localism values. Philadelphia's geographic location, socio-cultural history and diversity, make it a more unique city to emerge as a frontier of B Corps and sustainability. The two selected cities have mostly similar criteria yet controlled for varying criteria. Criteria included:

- The number of B Corps/ per capita

- Population level (while cities are different in size-Philadelphia is about two and a half times the size of Portland-they are considerably closer to each other in size than very large metropolitan areas such as NYC and LA)

- SBC legislation status

- Socio-economic \& demographic information on income, education and workforce from 2012 census data

- Socio-economic \& demographic changes between 2000 \& 2010 census

- Sustainability score from Kent Portney's 2012 City Rankings ${ }^{5}$

Table 3.1 B Corp Population and Legislation Status at Research Planning Phase in January 2014

\begin{tabular}{|l|c|c|c|c|c|c|}
\hline \multicolumn{1}{|c|}{ Location } & $\begin{array}{c}\text { Number of } \\
\text { B Corps by } \\
\text { City or US }\end{array}$ & Population $^{7}$ & $\begin{array}{c}\text { Number of B } \\
\text { Corps by } \\
\text { Population }\end{array}$ & State & $\begin{array}{c}\text { Date } \\
\text { Legislation } \\
\text { Passed }\end{array}$ & $\begin{array}{c}\text { Date } \\
\text { Legislation } \\
\text { Activated }\end{array}$ \\
\hline Philadelphia & 26 & $1,548,000$ & 0.001 & PA & 12-Oct & 13-Jan \\
\hline Portland & 31 & 603,106 & 0.004 & OR & 13-Jun & 14-Jan \\
\hline National US & 700 & $313,873,685$ & 0.0002 & N/A & & \\
\hline
\end{tabular}

5“"Our Green Cities Sustainability Index.” Ourgreencities.com (accessed February 2014).

6 "B Corporation Directory." https://bcorporation.net/directory (accessed January 16, 2014).

${ }^{7} 2012$ "US Census" https://www.census.gov/prod/2012pubs/acsbr10-19.pdf (accessed January 16, 2014) 
Table 3.2 Socio-demographic Data \& Growth Rates Based on 2012 Census Data $^{8}$

\begin{tabular}{|c|c|c|c|c|c|c|}
\hline Location & $\begin{array}{l}\% \text { of } \\
\text { Population } \\
\text { with } \\
\text { College } \\
\text { Degrees }\end{array}$ & $\begin{array}{l}\text { Population in } \\
\text { Managerial, } \\
\text { Professional } \\
\text { and Creative } \\
\text { Occupations }\end{array}$ & $\begin{array}{l}\% \text { of Population } \\
\text { in Managerial, } \\
\text { Professional } \\
\text { and Creative } \\
\text { Occupations }\end{array}$ & $\begin{array}{l}\% \text { of } \\
\text { Population } \\
\text { below } \\
\text { Poverty }\end{array}$ & $\begin{array}{c}\% \text { of } \\
\text { Degree } \\
\text { Growth } \\
2000 \text { to } \\
2010\end{array}$ & $\begin{array}{c}\% \\
\text { Population } \\
\text { Growth } \\
2000 \text { to } \\
2010\end{array}$ \\
\hline Philadelphia & $23.2 \%$ & 216,817 & $14.0 \%$ & $26.2 \%$ & $6.2 \%$ & $3.3 \%$ \\
\hline Portland & $43.1 \%$ & 136,535 & $22.6 \%$ & $17.2 \%$ & $10.5 \%$ & $4.1 \%$ \\
\hline National US & $28.5 \%$ & & & $14.9 \%$ & & \\
\hline
\end{tabular}

Less controlled conditions to consider included:

- Cultural context

- Historical or social conditions

Regarding the controlled conditions, the cities had some distinctions

demographically, according to census data available at the start of the study. Based on

2010 Census, Portland was the whitest big city in the US (77\% white) while Philadelphia had one of the largest African-American (42\%) populations that is slightly greater than the than white population $(41 \%)^{9}$. Additionally, while both cities are large, Philadelphia is about two and a half times the size of Portland. Census data from 2012 revealed greater poverty levels and slower growth rates in Philadelphia; with higher education attainment levels and a slightly larger percentage of the workforce in managerial, professional or creative occupations in Portland.

\footnotetext{
${ }^{8} 2012$ "US Census" https://www.census.gov/prod/2012pubs/acsbr10-19.pdf (accessed January 16, 2014) 2012 “US Census Quick Facts” http://www.census.gov/easystats/\# 2012 (accessed January 16, 2014) http://quickfacts.census.gov/qfd/states/41/4159000.html (accessed January 16, 2014) http://factfinder2.census.gov/faces/tableservices/jsf/pages/productview.xhtml?pid=ACS_12_1YR_CP03\&p rodType=table (accessed January 16, 2014) Includes combined numbers for management, business \& science, and the arts.

${ }^{9} 2010$ "US Census" https://www.census.gov/quickfacts/fact/table/philadelphiacitypennsylvania,portlandcityoregon/POP010210 \#POP010210 (accessed February 19, 2020).
} 
As demonstrated by the Sustainability Index Score ${ }^{10}$, both cities had established substantial sustainability agendas. Portland's score was 35 and Philadelphia's score was 31. For context, both cities had green economic development strategies, although Portland is more branded for its green image. Portland made in-roads as a primary domestic producer for efficient transportation including manufacturing and retail of street car and bicycle parts or products (Fitzgerald 2019), and also as a national leader in climate action planning. Philadelphia attempted to re-brand itself through the Next Great City campaign and the Greenworks project as a city invested equally in green infrastructure and equity (Schrock et al 2015).

Economically, both cities have similar advantages and limitations. Both are port cities, with coastal water-way access, yet through inlets. With river access, they are less established centers of trade than larger cities with more direct coastal access (like NYC or LA) (via rivers), however have been and remain important trade routes. Both cities have established technology industries, though not at the level of their biggest regional rivals (NYC and San Francisco. Otherwise Portland is known for athletic wear and craft brew production, while Philadelphia has substantial financial industries.

Regarding less controlled characteristics, the cities have some overlaps and differences culturally and historically. Both tend towards Democratic and progressive politics. Both have a reputation for identifying and responding to social conditions. Philadelphia has been a champion of social rights since the civil war era, and an important location for emancipation. Historically Portland, a younger city, has

\footnotetext{
${ }^{10}$ Our Green Cities Sustainability Index.” Ourgreencities.com (accessed February 2014).
} 
championed individual rights, and regularly challenged the status quo, with a do-ityourself attitude. More recently (in the late twentieth century) both cities experienced common trends around the nation of disinvestment, urban decay then renewal, and most recently (into the twenty-first century), both experienced rapid gentrification, most notably Portland. Planning efforts in Philadelphia have attempted to mitigate gentrification while in Portland planning efforts have emphasized environmental policy and practice. Culturally, Philadelphia has a rich historical heritage, with substantial influence of African-American and other diverse culture, while Portland has become a haven for artisanship, independent music and localism values. Both cities are reputed as LGBTQ-friendly. Both are also supportive of the arts, with public art woven into Philadelphia policy and public access to art enabled by Portland's permissive policies over use of space for production and events.

While these controlled and uncontrolled characteristics are not tested and analyzed in the research, they are important aspects of both cities, and part of what makes each one interesting. The research did not control for the influence of cultural or historic conditions, but they are relevant considerations, specific to the potential importance of location.

$\underline{\text { Participant Recruitment }}$

Primary research participants were businesses representatives from all B Corps identified in each city on the B Corps website. Representatives includes owners or managers when available, staff involved in the assessment process, or a company 
spokesperson. Given the small number of B Corps (at study inception in January 2014, Philadelphia: 26, Portland: 31) per candidate city for a maximum total of 57, all were targeted and recruited for participation. Recruitment targeted one city at a time in recruitment waves based on firm size and type to ensure adequate diverse representation of participants, and then gradually recruited all possible candidates once sufficient representation was established. A few candidates never responded, but the others who declined reported being too busy at this time. The participation met targeted participant numbers (24), thus a refined selection strategy was unnecessary, and the total participation response rate was $42 \%$. (See Table 3.3)

Table 3.3 Firm Response and Participation rates

\begin{tabular}{|c|c|c|c|c|c|c|c|}
\hline City & $\begin{array}{l}\text { Total } \\
\text { Number } \\
\text { of B } \\
\text { Corps at } \\
\text { Study } \\
\text { Inception } \\
(1 / 16 / 14)\end{array}$ & $\begin{array}{l}\text { Number } \\
\text { of Firms } \\
\text { that } \\
\text { Agreed to } \\
\text { Participate }\end{array}$ & $\begin{array}{l}\text { Participation } \\
\text { Rate }\end{array}$ & $\begin{array}{l}\text { Number } \\
\text { of Firms } \\
\text { with No } \\
\text { Response }\end{array}$ & $\begin{array}{l}\text { Number } \\
\text { of Firms } \\
\text { Declined }\end{array}$ & $\begin{array}{l}\text { Number } \\
\text { of Firms } \\
\text { with } \\
\text { Delayed } \\
\text { Response }\end{array}$ & $\begin{array}{l}\text { Number } \\
\text { of Firms } \\
\text { with } \\
\text { Initial } \\
\text { response } \\
\text { but No } \\
\text { Follow } \\
\text { up }\end{array}$ \\
\hline Philadelphia & 26 & 12 & $46.2 \%$ & 4 & 0 & 2 & 3 \\
\hline Portland & 31 & 12 & $38.7 \%$ & 5 & 4 & 1 & 3 \\
\hline Total & 57 & 24 & $42.1 \%$ & 9 & 4 & 3 & 6 \\
\hline
\end{tabular}

Participants also included several key informant interviews with (advocacy and certifier) support actors (KIs), to focus on issues of their perceived motivations, barriers, successes and outcomes of B Corps assessment and certification. A couple primary interviews took place early on during the research, although after some of the B Corps interviews had already transpired. Responses to preliminary interviews with four total KIs (two per city) provided information to help refine understanding of process related to B Corps, particularly in the context of motivations, local supports, and outcomes. A 
preliminary online search and a snowball sampling strategy was used to identify those actors important to the social benefit company implementation process both at B Lab and in terms of partner organizations within and beyond the selected cities.

\section{$\underline{\text { Study Participants }}$}

See tables below for data on city and study participants. All firms are small or mid-sized, consistent with most B Corps, except for one larger firm in each city. Additionally, a couple firms are small local chapters with larger, non-local affiliates. None are large corporations at the level of well-known B Corps Seventh Generation, Ben \& Jerry's or Patagonia, but no firms of that size are located in either city. See Tables 3.4, 3.5 and 3.6 for breakdowns of the study participants by city, industry/type and sector.

Table 3.4Total Number of Firms per Sector by City at Study Inception

\begin{tabular}{|l|l|}
\hline Portland & $\underline{\text { Philadelphia }}$ \\
\hline 4 production & 2 production \\
\hline 4 service & 4 service \\
\hline 1 tech service & 3 tech service \\
\hline 2 product distribution & 2 product distribution \\
\hline 1 product/service distribution & 1 product/ service \\
\hline
\end{tabular}


Table 3.5 Philadelphia Firms by Industry \& Sector

\begin{tabular}{|ll|}
\hline Philadelphia Industry/ Firm Type & Philadelphia Sector \\
food producer & production \\
Wholesaler & production \\
producer/wholesaler & product/ distribution \\
media services & product/ service \\
health services & service \\
cleaning services & service \\
eco service & service \\
Marketing & service \\
web services & tech service \\
graphic design services & tech service \\
software services & tech service \\
Manufacturing & production/ distribution \\
\hline
\end{tabular}

Table 3.6 Portland Firms by Industry \& Sector

\begin{tabular}{|ll}
\hline Portland Industry/ Firm Type & Portland Sector \\
Manufacturing & production \\
ecological products & production \\
Wholesale & production \\
medical supply & production \\
wholesale food produce & product distribution \\
ecological service & product distribution \\
Media & product/service distribution \\
technology service & Service \\
strategy \& marketing & Service \\
Investing & Service \\
Consulting & Service \\
software services & tech service
\end{tabular}

\section{Data Gathering Steps}

Primary data gathering steps proceeded as follows:

1) Interviews with four B Corps advocates (including B lab certifiers)

2) Semi-structured interviews with twenty-four B Corps in two selected cities, including a second interviewee at three different firms, for a total of twentyseven interview subjects.

3) Review and organization of available assessment data (on four categories) for interviewed B Corps from publicly available assessment data. 
Data gathering involved 45-60 minute in-depth interviews with B Corps staff (from the small number of employees) to obtain individual insights to the research questions. Interviewees were asked and mostly appeared in-person for interviews, or through Skype as a secondary option, or the interview guide was emailed, filled out by the recipient and emailed back, as a last resort. The interview guides was designed to provoke responses to the research questions. Semi-structured interviews were conducted with Key Informant (KI) advocates. (See Appendix A for Interview Protocol.)

The initial purpose of reviewing publically available assessment data was to be informed about each firm's assessment results. However the scoring data was not particularly insightful, interesting, or relevant to the interview data. Thus this data was initially reviewed merely in preparation for interviews, as part of a company review. The second phase of data review was an organization of the assessment data to collect and categorize information about the firm types.

\section{Data Analysis Procedures}

Procedures consisted of secondary data review of B Lab data, and digitallyrecorded interviews accompanied by note-taking, and review of available secondary online sources. Analytic procedures included examination of the transcripts and coding into categories, themes, and patterns. The following themes related to B Corps were explored along with others that develop as research progresses:

- Motivations for development of B Corps

- Outcomes of B Corp participation

- B Corp advocacy and support networks, actors who implement policies

- Assessment criteria (types, changes, strengths, importance) 
- The role of policy in development of B Corps

- Location-based opportunities, barriers or limits

The data was analyzed for the themes, key words and issues, and perspectives of study subjects, across and within cities.

\section{Reliability \& Validity}

As the primary method for analysis involved interview data, multiple levels of data review were implemented to ensure consistency of interpretation. Coding occurred several times, at different phases and time periods, and with repeat analysis efforts. Interviews were recorded then listened to in entirety at least one extra occasion, with new note-taking efforts to re-transcribe content, in order to review and compare to the preliminary note-taking that occurred during the interviews. Any discrepancies were reviewed, analyzed and reconciled. Coding was analyzed several times including within the context of reviewing responses to other questions. In total, the analysis steps were repeated at least four times for all data. Additionally, the interview instrument was confidentially tested on a KI, before implementation, then re-assessed and improved for eventual use with all of the study subjects. Information gathered from that interview subject and instrument was excluded from analysis.

\section{$\underline{\text { Trustworthiness }}$}

The methodology of this research applied directly towards the research goals, thus established initial trustworthiness. In other words, the population and data selection methods were appropriate choices for a descriptive research study of this design. 
Otherwise, the study did not require a large population sample, so the expectation was that the number of participants and the data they provided would suffice. (See "Ethics and Political Considerations" for more on negotiating entry). Finally, the participants were informed of study findings to support their current and future work.

The researcher's approach was one of polite diplomacy, yet communicated an intellectual commitment to the work, as to not waste participants' time. Moreover, the researcher's incentive was to strengthen community outcomes of ethical markets by identifying strategies and information resources.

Additionally, the researcher recognized concerns representatives from the business sector may have about their (industry's or organization's) portrayal. Thus, the researcher studied and applied the established interview techniques in order to minimize this impact. Moreover, the researcher's advocacy goals may bias the data interpretations. Yet the semi-structured interviews were recorded and accompanied by extensive notetaking to minimize the risk of confirmation bias, and reduced the extent of the researcher inserting her interpretations during the data collection. Data was coded so participants receive unique identifiers to preserve confidentiality.

Finally, this study will be of particular value for studies of ethical markets, political consumerism and social benefit corporations, as well as alternative globalization movements, and of potential interest to activist-oriented or community advocacy scholars. The data was organized to preserve confidentiality and without clear identifying information. The findings are available via this dissertation for examination by future researchers who are interested in related studies, particularly those who explore 
alternatives to the negative externalities of globalization through market-based solutions. The research aspires to identify the limits and potential of market-based solutions through both a critical and exploratory lens.

\section{$\underline{\text { Ethical and Political Considerations }}$}

It was necessary for the researcher to conduct the study in accordance with the Human Participants Review (HSRRC) and to submit a proposal to PSU's HSRRC. Approval was provided throughout the study's duration. To conduct the research, the researcher first negotiated entry to identified B Corps with email requests for individual dialogue and/or interview recruitment. Given variations in association styles, contact attempts varied including phone calls, or visits to firm locations as a last resort. The researcher also applied a snowball sampling strategy to gain access into the advocacy or support organizations, given the linkages that already exist.

In relation to the participants, the study followed within the parameters of human participants' ethical guidelines. In consideration of the participants' schedules the researcher was transparent regarding the expected time commitment. Participation was confidential, with recognition that the businesses are vulnerable from exposure. Thus, in the presentation of findings, the researcher made sufficient efforts to conceal identity of individuals and businesses by obscuring identifying information about them and assigning only general characteristics based on their firm type. Otherwise, the interviewer/surveyor maintained a respectful attitude with sensitivity to personal or demographic issues. Finally, the researcher avoided deception as there was no interest in 
masking the intent of this research, was honest about the goals, and with regards to reciprocity acknowledged the potential contributions of the study. Upon request, participants provided signatures of consent. They were promised confidentiality, but informed that exceptions will arise only if interviewees disclose reports of self-abuse.

\section{Limitations \& Expanded Research}

As will be reviewed in the Conclusion chapter, the research design had some limitations of the research design for future research to address. For example, B Corps are mostly small and occasionally mid-sized firms ${ }^{11}$ as are this study's subjects. Thus the implications do not necessarily apply to larger corporations. Additionally, the research examines one particular type of ethical business model-B Corps-which while seemingly representative of other ethical business models potentially do not represent all ethical business models. The conclusion also includes recommendations for additional research questions and the pursuit of quantitative methods. Survey research is advisable to assess the general trends across businesses and varying conditions. Survey research could also target patrons of SBCs or B Corps to assess and unpack their motives for participation. Otherwise, further theoretical considerations through expanded research could attempt to reconcile the ethical market and economic development literature, to identify overlaps and distinctions, enrich both conversations and provide more opportunities for policy implications.

\footnotetext{
11 "Frequently Asked Questions." https://bcorporation.net/faqs\#faq-target-40101 (accessed February 17, 2020).
} 
Chapter 4: Results/Motivations 


\section{Motivations Chapter Introduction}

\section{THE B CORP DECLARATION OF INTERDEPENDENCE:}

"We envision a global economy that uses business as a force for good. This economy is comprised of a new type of corporation-the B Corporationwhich is purpose-driven and creates benefit for all stakeholders, not just shareholders." 12

Given how profit is widely recognized as the primary motivation for most businesses, the existence of B Corps presents a challenge to that narrative. One primary goal of this study was to investigate the motivations that drive B Corp firms to participate in a business that does not necessarily prioritize profit first. Specifically, the interview questions asked why businesses become B Corps, what drives and how they value participation. Participating firms were also asked about their primary motivating values and desired impacts. Key Informants (KIs) were asked to share observations about firms that become B Corps or sought their support as B Corps. The research questions aimed to identify motivations for participation and to assess whether the pursuit of positive social outcomes was a primary, but not exclusive motivation for B Corps participation. The methods and analysis aimed to address the secondary research question: What are the motivations for becoming a B Corp and how do B Corps evaluate the value of participation? This secondary research question about motivation ultimately informs an aspect of the study's main research question: What are the [motivating] factors influencing the adoption of certified benefit corporations as an ethical market practice?

\footnotetext{
12 "B Corporation About B Corps.” https://bcorporation.net/about-B Corps (accessed August 25, 2019). This is an excerpt from the Declaration.
} 
Responses considered the study's main theoretical implications for B Corp participation, with emphasis on political consumerism/ethical markets and social entrepreneurship. Specifically the findings address how B Corps display markets as a tool for political change, and whether participation is a form of social entrepreneurship. As part of the study and the goals to better understand these theoretical implications, the interviewees ${ }^{13}$ from B Corp firms were asked the following questions from the Interview Protocol (see Appendix A):

1. Why did you or your company decide to become a B Corps?

2. What primary values (if not addressed) drove your company's motivations?

5. How do you evaluate the value to your business? Of B Corps, of impacts? How do you define success?

8. How important is it to positively impact your community? The world? Provide an alternative to mass corporate-based markets? Why?

Additionally, Key Informants (KIs) from nonprofit or public agencies were asked the following interview questions from the Interview Protocol (see Appendix A).

4. What have you observed about companies that choose to be B Corps?

9. Describe the individuals who contact you or seek support.

The interviews with firms and KIs revealed consistent themes across both cities and a few trends that were more specific to each city, but generally they shared similar priorities. What appears to drive interest in becoming a certified B Corp is support for the B Corporation goal to "balance profit and purpose." The chief motivation for participation among interviewed firms is a sense of purpose beyond profit alone, or by specific ethical values. Firm representatives described principles that motivated their alliance with the B Corp mission to seek impact beyond the bottom line value. Their ethics were often in line with some aspect of the B Corp Declaration of Interdependence

\footnotetext{
${ }^{13}$ Unless the context mentions all study participants or specifies Key Informants (KIs), "interviewees" or "participants" usually refer to firms.
} 
or the triple $\mathrm{P}$ (people, planet, profit); often consistent with the B Corp goal to "meet the highest standards of verified social and environmental performance, public transparency, and legal accountability" as well as to accelerate "a global culture shift to redefine success in business and build a more inclusive and sustainable economy."14 While the two cities shared similarities, variation was observable as well. Generally, B Corps in both Philadelphia and Portland shared a desire for impact on the community-at-large, but conveyed different goals internally within their own firms.

\section{$\underline{\text { Being a B Corp }}$}

"The [CEO] came from a nonprofit background and felt good about starting a business with purpose, following the triple bottom line approach before the term was widespread. The goal was to impact community and enable staff to have benefits."

-Philadelphia web service provider

\section{$\underline{\text { Adding Mission to Business }}$}

"[We] come from wanting to do good...[for the] people, planet, profit...[in] all three areas, not just the bottom line... I worked in nonprofits all my life and don't want to rely on grants."

- Philadelphia food producer

Given that our society has a mission-driven organizational structure in the nonprofit sector, interviewees were asked about why they did not choose a traditionally mission-driven organization instead of a business. Specifically, firms and KIs were asked:

"Why not a nonprofit organization or a charity arm?"

\footnotetext{
14 “B Corporation About B Corps.” https://bcorporation.net/about-B Corps (accessed August 25, 2019).
} 
Generally interviewees recognized overlap, while most had distinct reasons for why they chose a business model over a nonprofit organization (NPO). Many were familiar with nonprofit organizations, and appreciate opportunities for partnerships. A few B Corp interviewees had come from a nonprofit background that informed either their appreciation or rejection of that model. Additionally, some interviewees had considered operating a mission-driven NPO instead of a firm. About half of the firms either already have charity aspects or would like to include them within their for-profit model. Several had strong relationships with NPOs, or even operated comparably by having an NPO-like board, while a couple had considered becoming an NPO.

Most of the interviewees operated with mission-driven attributes of, or associations with, nonprofits, For example, one Portland medical supply firm explained how the company was co-founded by a partnership between one person who did not like the unsocially-minded actions of a past business workplace, and another person with a nonprofit background who was critical of business practices. However, they acknowledged the distinctions between nonprofit and for profit organizations and appreciated impactful opportunities in the for profit sector. One Philadelphia web services firm explained, "It's nice to have freedom...nice to make profit and have work/life balance. Maybe in the future if we're bigger, we'd have a charity arm but that wouldn't change our desire to be a B Corp. [Being a B Corp] allows business to be one way without [having an arm that has] opposing values...[and] hypocrisy... I could list many companies [which act in order to] alleviate guilt. [But] I want to donate to 
nonprofits, and to support different worthwhile emergent causes, for example food banks."

\section{Philadelphia \& Portland Firms}

Overall, about half of the Philadelphia firms and a quarter of Portland firms described themselves as comparable in structure, or preferring the mission drive of an NPO, or associated with NPOs. However the rest clearly wanted a business and explained they thought they could have a greater impact as a firm, including those with a prior NPO background.

In particular, Portland firms conveyed greater conviction about being a firm, not an NPO, with many emphasizing the challenges to NPO structures and beliefs that firms have greater impact. Small variation between the cities could be attributed to Portland's robust nonprofit sector. However, the most noteworthy findings are about firms' belief in the greater potential positive impact from the business sector rather than civil society. See Table 4.1 for summarized results.

\section{KIs on Adding Mission to Business}

KIs were asked the same question and also emphasized the significant role NPOs and government play, but found both insufficient without business involvement, too. Philadelphia KIs echoed the firms' sentiment with one stating "we need to change how businesses are run." Consistent with the firms, Portland KIs pointed out NPO challenges, given as one KI explained, how "tough it is [for NPOs] to accumulate wealth," then 
reiterated how "there will always be a role for them." Another Portland KI explained the essential role for businesses in all spheres including the public, with the observation that "the line between for-profit and non-profit is increasingly blurred. Businesses take on civil works, as municipalities focus more on basic services." Ultimately both firms and KIs endorse the goal for businesses to have impacts, in a mission-driven capacity yet as a firm, consistent with the B Corp mission to "drive a global movement of people using business as a force for good." 15

Table 4.1. Motivations: Adding Mission to Business

\begin{tabular}{|l|l|}
\hline Value to Business & Why not Nonprofit Organization? \\
\hline B Corps trends & $\begin{array}{l}\text { Most wanted a firm, but many saw } \\
\text { comparisons associations with NPOs. }\end{array}$ \\
\hline Philadelphia distinctions & Half had considered NPO. \\
\hline Portland distinctions & $\begin{array}{l}\text { More committed to being a firm, in part } \\
\text { for those who had NPO background. }\end{array}$ \\
\hline
\end{tabular}

\section{Why B Corp?}

"I started the company [engaged in] activism. I wanted a company we'd want to work with excellent benefits, ethics and passions. I started to turn toward the triple bottom line. [It's] very crucial that order: people, planet, profit. Profit first, changes purpose. [As I grew] I could connect with other businesses. I came from a nonprofit background... [but struggled after] the economy crashed. When I overcame challenges, I decided it was good time to join B Corps and fit its mission ... business for greater good."

-Philadelphia tech service firm

"We were involved in legislation. As a social change agency, B Corps fits into our model. It gives us credence in our community, helps to identify us in our community."

-Portland marketing firm

\footnotetext{
15 “B Corporation About B Corps.” https://bcorporation.net/about-B Corps (accessed August 25, 2019).
} 
To understand the primary motivations behind becoming a B Corp, firms were asked directly about why they became B Corps and what drove their company's motivation to participate. Specifically they were asked the following two questions:

"Why did you or your company decide to become a B Corp?"

"What primary values drove your company's motivations?"

Generally, firms answered both questions quickly and with ease. Whether interviewees were CEOs or staff involved with impact assessment, they appeared to know well what drove their firm's participation, which was usually presented as consistent with their own individual drive as well. For a couple interviewees, who were not major decision-makers at their firm, they conveyed their understanding of how the decision-makers came to those decisions. In response to the questions, some interviewees described the process of deciding to become a B Corp, whereas most described the appeal of becoming a B Corp. See Table 4.2 for summarized results.

\section{Becoming a B Corp}

Descriptions of the process to join the B Corps network provided some insights about underlying motivation, at least in terms of what led to the eventual adoption. Some firms in both cities addressed how or when they became a B Corp. Specifically they indicated three different phases of involvement: 1) at inception of their firm, 2) when recruited to join or 3) gradually through an evolution within their firm. Of these interviewees, a couple Portland firms described a process of becoming a B Corp when they started their business, while a couple Philadelphia firms were either recruited or eventually chose to pursue B Corp certification. Considering Portland's reputation for 
sustainable businesses and civic action, this is perhaps not surprising or remarkable. However, given B Lab's proximity to Philadelphia, one would perhaps also expect some newer firms to be aware of B Corps at the firm's inception.

\section{Philadelphia Firms}

Among the interviewees, Philadelphia B Corps did not actively seek out becoming a B Corp, and only the web services provider identified as an early adopter. Rather, most Philadelphia firms were part of another network-Sustainable Business Network (SBN)-and exposed to B Lab through that membership. Soon after B Lab's inception in 2007, taking the assessment became part of SBN membership, although membership did not require certification. In some cases, exposure to SBN or B Lab led to implementation of the process, particularly since B Corps started in the Philadelphia region. One interviewee served as SBN's co-chair. Another interviewee from a manufacturing firm explained, "when the SBN board decided companies had to go through assessments, we wanted to make it have meaning and not just be greenwashing." A couple firms-which were not SBN members-never pursued B Corps, but were approached by B Lab, because of their firms' missions and reputations. One of those two interviewees, the food producer, explained, "B Corps fit our model, not the other way around. They approached us. We were not in the business for profit. ... but our business [pursues] nurturing production for staff, which is good for [staff] and for the business." Meanwhile the interviewee from the tech service firm had started the business many years before learning about B Corps, and did not immediately join, but gradually came to 
realize how B Corps fit their mission. Overall, a trend among many Philadelphia firms was the process of becoming a B Corp through affiliation with a network. Only the software firm interviewee identified as an early adopter and explained compatibility as "the [CEO] came from a nonprofit background and felt good about starting a business with purpose."

\section{Portland Firms}

Interestingly, despite geographic distance from B Lab’s Pennsylvania headquarters, only a few Portland firms were proactively driven to become B Corps. Four Portland companies started out with B Corps in mind. One advertising firm's CEO explained, "we had [staff] involved with B Corps from the start. We embedded sustainability, social and environmental, as part of all we did." As indicated in the quote earlier in the chapter, the marketing firm was involved from the start of B Corps and was involved in legislation, claiming "B Corps fits into our model." A few Portland firms demonstrated a trend to become early adopters.

\section{$\underline{\text { Mission-Driven }}$}

While most interviewees added a mission to their business, for many their mission was the driving force behind becoming a B Corp. Overall, findings were largely consistent across the two cities. About half of all interviewed B Corps described a mission as their firm's general business purpose, one compatible with the B Corp rating criteria (identified in the Introduction chapter). For example, some firms produced socially-minded products or provided environmental consultancy. Generally, the goal of 
these firms was to achieve their desired impact, but through a traditional business model rather than as an NPO. As mentioned, a few firm founders in both cities came from a nonprofit background and wanted to incorporate missions into their businesses, rather than by running a nonprofit agency. These mission-driven firms were initially driven to pursue as a B Corp, the types of impacts they pursued already through their business goals. Typically, they did not necessarily report a financial advantage as their goal in becoming a B Corp. Generally the mission-driven distinctions across cities were not substantial, but there were a few small trends within cities. Overall, firms' ethical values appeared to drive participation more significantly than their pursuit of economic gain. When unpacked, mainly general but also some specific motivational themes emerged. Many firms described a desire to have some type of positive impact. Several emphasized community or civic impact. For example the Philadelphia software firm had considered becoming an NPO but became a businesses to pursue both "civic and social impact" and built their identity around that, claiming "I never wondered why am I doing this. I [was pursuing] meaning and impact." The Portland eco-service firm described how their mission "aligned [with B Corps] and contributed to community... [to help] make cities become more livable." The Philadelphia media firm explained "[we were] more interested in impact than money. We don't make much money and didn't get into this due to a desire for business, but we got into it because of [support for] the work."

A few firms were more general in their aspirations for primarily a big picture type of impact. Some became B Corps because "it's the right thing to do." They liked the B Corps mission or found it compatible with either people/planet/profit (3P) or triple 
bottom line (TBL) values. A few Philadelphia and Portland firms identified being part of a greater movement to produce either social change or change markets, by demonstrating how the "market can be used for the greater good" or a model of "businesses for the greater good.” A Portland eco-producer-claimed to have a social and environmental mission, and stated "our company improves lives... we believe market forces are the way to make change." Some firms were hopeful that business will lead change as a primary driver of ethical market participation.

Some Philadelphia and many Portland firms said B Corps as a whole validated their values. A few firms from both cities articulated having both general and more specific driving values, as well as impact goals. For example, the Philadelphia software firm claimed to "follow the triple bottom line approach before the term was widespread. The goal was to impact community and enable staff to have benefits." That interviewee went on to describe "wanting a company we'd want to work with- with excellent benefits, ethics, passions."

When describing their more specific driving values, several other firms mentioned workers, as a main focus. One Philadelphia interviewee from a health service firm described their mission, and explained "we provide quality jobs to people who are low income, who can't support themselves, and we provide quality care while building our business." Some Philadelphia firms also appreciated participation in a larger ethicallyoriented network as part of their work. One interviewee from a Philadelphia marketing firm described a "quality of work in [our] workgroup. Our work culture is supportive of staff and provides resources they need and fulfillment." That same interviewee explained, 
“we support social and environmental values." Similarly, the Philadelphia software firm described how they "wanted a company driven by employees. ...driven by... doing good work. As the company grew ... [we] became staff-driven... and built our identity around civil and social impact."

\section{Philadelphia \& Portland Firms}

While there were not clear distinctions between participants from the two cities, some trends and variations were detectable both across and within study participants from the two cities. For example, Philadelphia firms were more likely to become a B Corp to participate in a mission-driven network, or to support their workers. While Portland firms pursued more general goals to provide support, including often wanting to change markets.

\section{$\underline{\text { Social Entrepreneurship }}$}

Roughly half of the firms described themselves as both entrepreneurial and impact-driven. Profit or a competitive edge was not the primary motivation for participation among interviewed firms, but not necessarily disregarded. Some firms had a social entrepreneurial business model and while not the main goal, hoped to achieve a traditional (financial) benefit to their business. Several companies perceived B Corps certification as a representation of what they already practiced. Other firms more greatly appreciated how being a B Corp conveyed those practices or their values to a wider 
audience. While these firms aimed for impact with their business model, and usually the business purpose of their product or service, they admitted a strong profit drive as well. Some firms even hoped to obtain a small benefit from being a B Corp, either marketing or profit. A number of firms in both cities had different goals in the validation of their values. Some wanted to demonstrate or communicate them. A couple firms appreciated or desired a brand benefit. One firm benefited from access to the greater B Corps community. However most firms did not heavily emphasize participation in the network as an incentive except for one firm that claimed to be "always interested in broadening our network." Participation or membership in the community-at-large was rarely a primary motivator, but for some a small benefit. Others hoped for a greater benefit, including a couple interviewees who wanted a competitive edge to help them survive financially. Yet even those firms which desired a financial or marketing advantage emphasized other impactful motivations as well.

\section{Philadelphia Firms}

While otherwise not notably distinct, many Philadelphia firms were drawn to become a B Corp, specifically because they believed certification was resistant to the greenwashing they had observed with other certifications. They also wanted to demonstrate their authenticity, to demonstrate they were not greenwashing. A trend among many Philadelphia firms was to seek authentication of their practices and values. One Philadelphia software firm claimed they wanted to “become a B Corp as an opportunity to rearticulate who we were. We were mission-driven but didn't promote 
[that]." Another [retail] firm critiqued all the "greenwashing in organic and local [labels]. Sustainability is about more [and I want] to educate and show [that] transparently."

\section{Portland Firms}

While otherwise not notably distinct, many Portland firms emphasized a desire to communicate their values or possibly to achieve a marketing or CSR strategy through participation. More often than in Philadelphia, some Portland firms were driven to obtain marketing advantages and to externally communicate ethical practices through achieving certification. A Portland tech firm explained they "wanted to differentiate in [their industry]...wanted to show their values... and their culture." As previously stated, the marketing firm likes how being a B Corp gives "credence in our community, helps to identify us in our community." While even those firms typically emphasized other motivations over a marketing advantage, a greater trend among many Portland firms was desire to communicate their practices and values.

\section{Tool/ Metrics for Evaluation}

Generally, firms which wanted to validate and communicate their values, also greatly appreciated having the tool for evaluation. Specifically, a couple of firms appreciated how the tool provides metrics, to measure and monitor improvements, and thereby contribute to their potential for impact. These firms in both cities wanted to evaluate or verify their practices and pursued certification as a self-monitoring 
assessment tool. A few appreciated having metrics for assessments or liked how the assessments provided “insights to improve." One Philadelphia graphic design firm didn't change as a result but appreciated both being able "to communicate metrics and to have metrics...essentially we were doing what B Corps do without credit, or without knowing if we were doing it right." Another business's mission matched B Lab's, while two businesses specifically matched the environmental or sustainability aspects of the mission, with one explaining, "we support social and environmental values." Overall, several firms were motivated to engage because participation provided a tool to measure and communicate their impact.

\section{Philadelphia \& Portland Firms}

While there were not clear distinctions between participants from the two cities, some trends and variations were detectable both across and within study participants from the two cities. For example, Philadelphia firms were more likely to become a B Corp in order to affirm their values and practices. Portland firms were more likely to become a B Corp to evaluate their practices and look for opportunities for improvement.

Key Informants on 'Why B Corps?'

"Companies care about money...success... also non-traditional business focus: fare wages...civic/good works, and the environment."

When KIs shared observations about B Corp motivations, their depictions were comparable to the firms. KIs were asked "What have you observed about companies that 
choose to be B Corps?" Their responses were compatible with the firms' responses about why they became B Corps. The Philadelphia KIs described B Corps as driven by TBL or 3P models, consistent with several of the firms' self-descriptions. Also consistent with how some firms seemingly perceived themselves, KIs described B Corp firms as collaborative, wanting the business model to grow and aspiring to be part of a pack that follows that model. For example, one Philadelphia KI explained all B Corps want to feel like "[it's] not just me: [but] the context of something bigger"]. Portland KIs described B Corps as being on the frontier of desired transition, also consistent with Portland firms' reported support for changing markets. While KIs did not actively discuss market-based value, none mentioned a perception of profit as a major goal. However, they did echo the sentiment that B Corps aspire for impact. Overall, KIs did not observe traditional business benefits some B Corps claimed to appreciate, but their observations were otherwise mostly consistent with the firms and between cities.

\section{Why B Corps Summary}

Generally, as demonstrated by interviews with both firms and KIs, the primary motivation of participation among firms in both cities was value-driven. Some firms were early adopters, including firms with missions as their business purpose, while other firms gradually became B Corps especially after participation through community connections or within a network. Some firms wanted to have a direct impact, while others wanted to validate their values. The impacts firms pursued were either specific-related to sustainability, workplaces, or social outcomes-or more general as change-makers-to 
have an impact on industry, community, or markets-at-large. Those who wanted to validate their values were motivated either by a desire to authenticate or evaluate how effectively they pursue their values internally, while others wanted to communicate their values externally (for example to a customer base). (See Table 4.2.)

Table 4.2. Motivations: Why B Corps?

\begin{tabular}{|l|l|l|l|l|}
\hline $\begin{array}{l}\text { Place-base } \\
\text { for trends }\end{array}$ & $\begin{array}{l}\text { Becoming a B } \\
\text { Corp }\end{array}$ & Mission-driven & $\begin{array}{l}\text { Social } \\
\text { Entrepreneurship }\end{array}$ & $\begin{array}{l}\text { Tools/Metric for } \\
\text { Evaluation }\end{array}$ \\
\hline Across cities & $\begin{array}{l}\text { Many firms } \\
\text { gradually } \\
\text { evolved to } \\
\text { become B Corps. }\end{array}$ & $\begin{array}{l}\text { Firms had impact } \\
\text { missions. } \\
\text { Some wanted to } \\
\text { validate their (often } \\
\text { TBL) values. }\end{array}$ & $\begin{array}{l}\text { Wanted to convey } \\
\text { ethical practices to a } \\
\text { wider audience. }\end{array}$ & $\begin{array}{l}\text { Appreciated metrics, } \\
\text { to measure and } \\
\text { monitor } \\
\text { improvements. }\end{array}$ \\
\hline $\begin{array}{l}\text { Philadelphia } \\
\text { distinctions }\end{array}$ & $\begin{array}{l}\text { Networkers: Some } \\
\text { were recruited } \\
\text { through a } \\
\text { network. }\end{array}$ & $\begin{array}{l}\text { Communitarians: } \\
\text { Some wanted to } \\
\text { participate in the } \\
\text { network. } \\
\text { Many wanted to } \\
\text { support workers. }\end{array}$ & $\begin{array}{l}\text { Authenticators: } \\
\text { Wanted to convey } \\
\text { authenticity; lack of } \\
\text { greenwashing. }\end{array}$ & $\begin{array}{l}\text { Validators: Wanted } \\
\text { to validate their } \\
\text { values \& practices } \\
\text { through the tool. }\end{array}$ \\
\hline $\begin{array}{l}\text { Portland } \\
\text { distinctions } \\
\text { Monge-makers: } \\
\text { More general in } \\
\text { support. } \\
\text { Wanted to change } \\
\text { markets. }\end{array}$ & $\begin{array}{l}\text { Early Adopters: } \\
\text { Some started } \\
\text { firms with B } \\
\text { Corps in mind. }\end{array}$ & $\begin{array}{l}\text { Many wanted to } \\
\text { communicate their } \\
\text { values to client/ } \\
\text { customer base. }\end{array}$ & $\begin{array}{l}\text { Evaluators: Wanted } \\
\text { to evaluate their } \\
\text { practices through } \\
\text { the tool. }\end{array}$ \\
\hline
\end{tabular}

\section{Evaluation of Participation}

$\underline{\text { Value to Business \& Success }}$

Firm interviewees were also asked the following question thread:

"How do you evaluate the value to your business? (Of B Corps, of impacts?) How do you define success?"

The question of evaluation and value were often understood by firms in both cities as either a quantitative assessment to use metrics and identify the business and financial value of participation, or as a quantitative or qualitative assessment of the impact of participation. Impact in this context refers specifically to the internal firm or 
external community impact of becoming a B Corp. Among the interviewees, there were some distinct trends notable in both cities in terms of how they understood and responded to the question. As when asked why they became a B Corps, several interviewees had already emphasized the evaluation or tool component, some firms were more likely to have considered the value to their business, while others acknowledged they hadn't necessarily evaluated the consequence of participation. In the context of how the individual firms themselves prioritize value, most were motivated to create impact. Yet when they defined success, most of the firms still aspired to achieve impact, but usually also addressed the traditional business concept of economic success.

\section{Philadelphia Firms}

The question of evaluation was often treated by Philadelphia firms as about financial or economic value through quantitative metrics. Specifically, they often understood the question as asking whether or not they collect data to assess the financial value to the firm of being a B Corp. To a lesser degree, they understood the question as about community or workplace (social) impact. It was often answered in terms of traditional business values: profit, employee retention, and for one growth. However despite an understanding of the question in terms of economic value, the firms also often reported they don't evaluate the economic value of becoming a B Corp, and prioritize impact on community and/or staff as well as place.

Generally, Philadelphia interviewees did not themselves evaluate participation in metrics, but more often assessed the value based on impact or purpose of participation. 
The web services interviewee explained, 'It's hard to answer. We don't monetize necessarily. [Participation] gives us...greater sense of purpose. We care about staff, the neighborhood, city, environment, community; we give back... [There's] value to clients as well as staff [and] trust [gained].” Another who started a small consumer product retail firm, reported, "Mostly we care to do something for the community. We don't evaluate worth. This is who I am, what the business is." For the manufacturing interviewee, the value of evaluation was to quantitatively assess impact, asking, "the biggest piece is, [will this] make any systemic change? There's a little value in assessments. It tightens our internal processes. We're trying to coach to push us to more change, and it is helpful to see [if it is] having an impact."

On the other hand, many Philadelphia interviewees define success differently than how they value participation in B Corps. A common response was to still think about impact, but often through a more traditional business assessment-through profit, growth, employee retention, referrals-and often a combination of the impacts identified as values and traditional measures of success. For example, the CEO of the health services firm reports "Success is the triple bottom line [and includes] worker retention, low turnover, and happy clients... we have to have an efficient business." The interviewee from the manufacturing firm defined success as, "creating a better world. We need the bottom line but by itself that's ethically empty." 


\section{Portland Firms}

In Portland, many interviewees also appeared to interpret the question of evaluation and success as one about metrics, but as a measure of either financial value or impact. Some valued the community impact of using the B assessment to evaluate their business practices. More often than the Philadelphia firms, Portland firms evaluated success in terms of impact-specifically on their community, place or even the industry. However, like Philadelphia firms, many also identified success as a traditional value demonstrated in terms of customers, profit or growth. For two interviewees, participation provides a model for how to have impact-one mentioned impact through the B Corps network and the other aspired to contribute towards a more generalized social change.

While community or workplace impact was priority, Portland interviewees were more likely than Philadelphia interviewees to actually evaluate the financial value to their business of having those metrics. Among some Portland firms, the metrics were also used as a public relations tool-a more traditional business value-and for internal inspiration. "We wanted a good score...to engage... connect more with staff. We wanted to share it with consumers," said the wholesale food producer. The interviewee from the ecoproduct firm explained how their "focus is people, planet, AND profit. We value profittraditional business metrics, ratios, debt, equity, etcetera." Another, from the tech service firm, said they were "tracking the benefit of participation in client numbers and the benefit on the HR side... Research shows more millennials want [community] values in business." Another, from the advertising firm, was very clear-the value was in "business growth... the value to attract and maintain clients." One interviewee reversed the trend 
and defined value strictly in marketing terms. Another, from the marketing firm, explained about value, that "clientele expect it. ...It's a big marketing advantage, especially in the space we work. It's an expectation." Yet despite their interest in economic value benefits, these same firms also pursued success in terms of larger impacts. For example, the interviewee from the marketing firm explained, "We strive towards social change; we try to measure ... [those] impacts."

Other Portland firms also valued the general and larger impact of 'doing good.' One interviewee, the CEO of a small wholesaler, explained "the biggest value is having a guiding document versus a vague idea of wanting to do good things. It's having someone research best practices versus doing that labor ourselves." The interviewee from the media firm evaluated both value and success in terms of wider social impact, to assess the value they create in their community "as a business with a value-driven impact, that's our goal. We do impact report annually... Success is through those measurements [in the] millions of dollars [generated] in the local economy." Another interviewee from an investment firm appreciated the value of how B Corps "align our governance obligations with mission and purpose. It makes the whole business more sustainable." Meanwhile the wholesaler CEO appreciated the "guidance of having someone else reporting best practices versus doing that labor ourselves"... as the "best value of participation."

\section{Key Informants on Value \& Success}

As previously mentioned, KIs did not actively discuss market-based value. Thus none mentioned a perceived business value of profit as a major goal among B Corps. 
They did however echo the sentiment that B Corps were impact driven, thus while KIs did not actively define success, one might extrapolate they would have viewed success similarly to the B Corps, in terms of both impacts and profit.

\section{$\underline{\text { Desired Impact Scale }}$}

B Corps interviewees were also asked the following question thread:

"How important is it to positively impact your community? The world? Provide an alternative to mass corporate-based markets? Why?"

As already well established through responses to the preceding interview questions, impact was a primary motive for participation. When asked specifically about importance and scale, all of the interviewed firms reported the importance of having a positive impact, at various scales. They all aspired to impact their community, the world, or to provide an alternative to mass corporate-based markets. The most common response emphasized the importance of each of these types of impact, most frequently among Philadelphia firms. The explanations also varied between the cities. While many firms from both cities wanted to provide an alternative to mass corporate-based markets, this meant something different among the interviewees. Philadelphia firms pursued a more general impact whereas more Portland firms wanted to strengthen local markets.

\section{Philadelphia Firms}

Positive impact was important to all Philadelphia interviewees. Most commonly, firms desired a positive impact on their community, world and to provide an alternative. Several also emphasized just community. One only mentioned the world and another 
only mentioned an alternative. A few interviewees explained their support for an alternative specifically in terms of an alternative business model, including two whose pursuit of community benefits resembled the mission-driven work of non-profits. Overall, Philadelphia firms largely pursued impacts at various scale levels, but with impact goals often of a fairly general nature.

Generally, Philadelphia firms expressed enthusiasm for each type of impact. The food producer explained they are all "very important; it's a perfect marriage, an all-in-one endeavor. We want to impact wellness, community, and neighborhood. We're largely in the business for community and neighbors, not worried about competition. [We're not interested in] false marketing, not greedy, and we think on a big scale." The web service provider wanted to "make change, help people, the global community and more here. Philly has hunger and poverty; it's not isolated... stop putting profit first-we can change the world and still have enough." One interviewee emphasized it's "what the business is founded on," while another said their business is "a place for good... to show another business model, not just the bottom line." Still another emphasized the alternative as "vital-one of most important things about what we are" while also clarifying that "local, community and global are exactly what we're about."

Community was generally most important for those who didn't prioritize all three types of impacts. One interviewee explained, "community is why we're in business-the people who work here,' while another said, “community impact is a huge driver."

Of those firms interested in a larger impact, some also clearly wanted to maintain some traditional aspects of business. The software provider described an alternative 
business model, but wanted to remain profit-driven, explaining, "we don't want to be alternative to profit-driven; we need to shift back to kindness and responsibility [in business]." The interviewee from the marketing firm only emphasized impact on the world, yet also addressed a type of responsibility, stating, "we don't focus much on corporate alternatives... we use infrastructure and create markets and direct unavoidable patterns of consumption to ones less damaging."

\section{Portland Firms}

Positive impact was also important to all Portland interviewees. A few desired a positive impact on their community, world and to provide an alternative. A couple emphasized just community and world, while one emphasized world and alternative. A couple also mentioned only a community or only an alternative impact. However, many of the Portland firms wanted their impact of any type to be local. Several firms want to change business practices at large, a few others were focused on change at the industry level, and one specifically desired a non-local impact.

As mentioned, fewer Portlanders emphasized all impact types and less clearly than Philadelphia participants. The wholesaler CEO wants "to do both [local vs. world]" and explained it's "easier to understand impacts of community (locally) versus the world. When I was younger, I didn't like business-the people behind profits-but it's nice to see community leaving the world better than we found it." The eco-producer said all three are “extremely important. B Corps-are one of most inspiring things in the last couple of generations. If all companies were better, [there would be major] impact." While the other two interviewees more clearly communicated support for community and the world, 
the software firm CEO claimed support primarily only for those two impact types but sounded in favor of all three with a desire to "learn through local community, to educate others, on how... to have a ripple effect on vendors and suppliers and change markets." An interviewee who only identified community and alternative, gave comparable responses and said it's "great to be part of movement but we're very localized."

Meanwhile, those Portlanders who only identified one impact type were most clear about articulating the scale of their impact goals. The sustainability consultant who was only a community supporter explained, "to whatever degree [possible] we support...locally-[it's] emotionally rewarding and [we get] to be part of the community." The tech service interviewee stated firmly that their "main focus is [to provide an] alternative to mass corporate-based markets."

\section{Key Informants on Desired Impact}

KIs did not actively discuss desired impact scale, except for a couple of comments from Philadelphia KIs. One Philadelphia KI observed B Corps as committed to community, worker care" while the other stated as "the business models grow, so does the scale [of impact]."

\section{Evaluation to Business Summary}

Overall, despite some appreciation for the potential economic value to their businesses, the interviewees prioritized the potential to have an impact, as a motivating driver for participation. The firms appeared to see success primarily in terms of 
community impact, workplace impact or even as a general impact-at-large. However, they often still defined success more traditionally and most appreciated the traditional financial value to their business; particularly among Portland firms which actively hoped for some business benefit from participation. Overall, the firms in both cities clearly conveyed the importance of having a positive impact through their business. They often pursued an impact at more than one scale-at either community, the world and/or through creating an alternative model. (See Table 4.3.)

Table 4.3. Motivations: How do you evaluate value, define success for your business? How important is impact?

\begin{tabular}{|l|l|l|l|}
\hline $\begin{array}{l}\text { Value to } \\
\text { Business }\end{array}$ & How define value & How determine success & Desired Impact/ Scale \\
\hline B Corps trends & $\begin{array}{l}\text { Traditional business/ } \\
\text { financial value, often in } \\
\text { terms of metrics. }\end{array}$ & $\begin{array}{l}\text { While many firms want } \\
\text { traditional success, they } \\
\text { see success more in terms } \\
\text { of impact. }\end{array}$ & $\begin{array}{l}\text { Impact their community, } \\
\text { the world, or to provide } \\
\text { an alternative to mass } \\
\text { corporate-based markets. }\end{array}$ \\
\hline $\begin{array}{l}\text { Philadelphia } \\
\text { distinctions }\end{array}$ & $\begin{array}{l}\text { Define as measure of } \\
\text { financial value through } \\
\text { metrics; but don't use } \\
\text { metrics themselves. }\end{array}$ & $\begin{array}{l}\text { Identifies community } \\
\text { impact first but also } \\
\text { defines as financial value. }\end{array}$ & Wanted general impact. \\
\hline $\begin{array}{l}\text { Portland } \\
\text { distinctions }\end{array}$ & $\begin{array}{l}\text { Measure of either } \\
\text { financial value or } \\
\text { impact. }\end{array}$ & $\begin{array}{l}\text { More likely to define as } \\
\text { community impact but } \\
\text { also considers traditional } \\
\text { business value. }\end{array}$ & Hoped for local impact. \\
\hline
\end{tabular}

\section{Motivations Summary}

\section{Motivations: Why B Corps}

Findings reveal a mission drive for participants, but through a business model.

Given the mission-drive of B Corps, there's potential overlap with nonprofit organizations (NPOs). When asked why the firms were not instead NPOs, most wanted a 
firm, but many saw comparisons or associations with NPOs. However half of Philadelphia firms had considered becoming an NPO. Portland firms were more committed to being a firm, in part especially for those who had an NPO background.

Specific to becoming a B Corp, findings reveal value-based motivations. Firms became involved through several means. Many gradually became involved after eventual exposure. Yet many in Philadelphia were recruited through a promotional nonprofit network, while a few in Portland started their firms with the intention to become a B Corp.

Many firms were primarily mission-driven, with some including a mission in their business purpose, and others emphasizing a mission in how they do business. Many firms had specific impact missions as part of their business purpose, and many wanted to validate their (often triple bottom line) values. Some in Philadelphia wanted to participate in the network or to support workers. Some in Portland wanted support from participation in the B Corps community, or wanted to change markets.

Regarding social entrepreneurship, most B Corps wanted to convey ethical practices to a wider audience. Philadelphia firms also wanted to convey authenticity, their lack of greenwashing. Portland firms were more likely to want to communicate their values to client/customer base. Overall, however, social entrepreneurship did not seem to be a primary goal.

A more significant motivator was to use the tools/metrics for evaluation. Firms appreciated metrics, to measure and monitor improvements. Philadelphia firms wanted to 
use the tool to validate their values and practices. Portland firms wanted to evaluate their practices.

\section{Motivations: Defining Value \& Success}

While not the primary motivation for becoming a B Corps, most have traditional business values. Philadelphia firms often define value as the financial gain measured through metrics, but don't necessarily use those metrics themselves, or at all in terms of evaluating the benefits of being a B Corp. Portland firms define value as both financial or impact.

On the other hand, while many firms want traditional success, they determine success in their business more in terms of impact. Philadelphia firms identify community impact first but also still define success as financial value. Portland firms are more likely to define success as community impact.

Regarding the desired scale of impact, most subjects want to impact their community, the world, or to provide an alternative to mass corporate-based markets. Philadelphia firms more often wanted general impact, while Portland firms often hoped for local impact.

\section{$\underline{\text { Conclusion }}$}

The pursuit of positive social impacts appeared to be a primary, but not exclusive motivation for B Corps participation. Impact scales include community-based, worldbased, firm-based, location-based, industry-based as well as business-model-based and 
include creating an alternative model. Most firms want a traditional business, and do not seek certification primarily for a marketing advantage or for financial success, yet some hope to obtain some traditional benefit. Most are driven by their values to have an impact directly through the impactful work they perform, by operating with ethical standards, or even operating like an NPO or at least associating with an NPO to pursue a mission. While firm interviewees varied regarding their specific desired impacts (for example some emphasized environmental benefits), versus contributing to a more general good, the Key Informants observed them primarily committed to the big picture goals of doing good and participation as part of a movement. They emphasized how participants want to know "[it's] not just me: [but] the context of something bigger," and to be part of a new business model for growth that heralds a market transition. Overall the findings affirm drive for positive social impact and market change markets, with some indication of a social entrepreneurial agenda, as well. 
Chapter 5: Results/ Location 


\section{Location Chapter Introduction}

Investigating the location factors of economic development is a well-established trend in the field of urban studies. For decades, research has attempted to understand location factors that lead to industry clusters, including more recently, urban-based sustainability or green clusters. However, the rise of ethically-driven markets with businesses in pursuit of a social benefit, provides opportunity to explore the development of an ethically-oriented market cluster (EMC). One goal of the overall study was to investigate the location factors that influence firms to become or sustain as B Corps. This study aims to understand aspects of the role of place in B Corp development. During the interviews, B Corps were asked questions about local supports or challenges, and about their relationships with other B Corps. Key informants (KIs) were asked to explain their role in providing support to B Corps, as well as how they became involved with B Corps. Interview questions aimed to identify the influence of civic institutions or organizations which support B Corps, local culture, and relationships between different (particularly local) B Corps. The methods and analysis aimed to address the secondary research question: What place-specific factors enable or hinder B Corps including the local cultural, relational or institutional supports and challenges? This secondary research question about location ultimately informs an aspect of the study's main research question: What location factors influence, facilitate or impede the adoption of certified benefit corporations as an ethical market practice? 
Responses considered the study's main theoretical implications for B Corp development, with emphasis on economic development, and localization and agglomeration, in the context of ethical markets. Specifically the findings begin to identify location factors which influence B Corp development, as an example of a localized innovative cluster for ethical markets. As part of the study and the goals to better understand these theoretical implications, the interviewees ${ }^{16}$ from B Corp firms were asked the following questions from the Interview Protocol (See Appendix A):

3. Please tell me about the process. How did you become a B Corp? What outside supports assisted you?

6. Describe your relationship with other B Corps? Competitive or collaborative?

7. How important is the location? What are the supports? Challenges? Role of local culture?

Additionally, as part of the study Key Informants from nonprofit or public agencies were asked the following interview questions from the Interview Protocol:

1. Tell me about your organizational background and how you became involved?

2. How do you support companies that become B Corps?

A discussion of location attempts to assess aspects regarding the role of place. In this context, it is helpful to define role of place for the purposes of the study. Location was introduced and understood (during interviews) primarily in the context of geographic scale, usually at the city level. Specific place-based factors examined in this study include: relationships, civic institutions or organizations of civil society including governments, and local culture. The latter also warrants definition, however. While a deeper exploration of how to define the latter factor warrants additional research, for the

\footnotetext{
${ }^{16}$ Unless the context mentions all study participants or specifies Key Informants (KIs), "interviewees” or "participants" usually refer to firms.
} 
purposes of this study, local culture is accepted as an informal concept used by study participants, mostly referring to local community trends or the local social climate.

Given the intersections of both the interview questions and these factors, the responses often highlight the intersections between some key place-based factors related to relationships, institutions and culture. For example, discussions about relationships highlight networks that support relationship formation, or networks enabled by institutional supports, all of which exist to a large extent to reflect local culture. The discussion also leads to consideration of why these location factors matter, what is important, and how these factors interact with each other to enable the development of an EMC. Overall, this chapter addresses the part of the research question that asks "what are the location factors?" in the context of asking about the enabling supports and identifies both those supports and their intersections. (See Table 5.1 for summarized results.)

\section{$\underline{\text { Relationships }}$}

A key component of the location factors, as a strong aspect of building and strengthening local infrastructure, involves relationships with other B Corps. Thus, participants were asked about those relationships-specifically whether they were collaborative or competitive-to better understand how or whether they provide support. The exact question was:

"Describe your relationship with other B Corps? Competitive or collaborative?" 
The Key Informants (KIs) interviewed discussed their relationships with local B Corps, when asked:

"Tell me about your organizational background and how you became involved?" While these relationships were not necessarily exclusively locally-focused, the question for firms about relationships was mostly understood and responded to within a local context. Both Philadelphia and Portland firms identified KI interviewees as main supports. The KIs responded to the question appropriately by elaborating on their involvement and support of B Corps. The findings demonstrate how both Philadelphia and Portland firms are largely collaborative and how KIs strengthen relationships, yet highlight how Philadelphia networks consisted primarily of two key organizations, while the Portland networks were more dispersed and not necessarily directly connected to other B Corps.

\section{Philadelphia Firms on Relationships}

When asked about relationships with other B Corps, the trend among Philadelphia B Corps was to emphasize collaboration. None of the Philadelphia B Corps indicated a solely competitive relationship with other B Corps. While a couple firms described relationships with other B Corps as both competitive and collaborative, all others described relationships as non-competitive. Many described networking events, happy hours, partnership opportunities, and other relationship-building interactions. In addition to emphasis on collaborative relationships, Philadelphia firms identified primary networks as central to formation of those relationships. 
Philadelphia interviewees identified two primary networks which foster relationships between B Corps. Those two networks are enabled either through association with the nonprofit organization, B Lab, or through memberships with the nonprofit organization, Sustainable Business Network (SBN). (These agencies are further discussed in the upcoming section on Institutions.) Additionally-and as also mentioned in the Motivations chapter-half of the Philadelphia firm interviewees identified an advantage of SBN membership. They benefited either through SBN's partnership and shared promotional efforts with B Lab, or directly through interactions with other B Corps.

Otherwise, Philadelphia B Corps often described at least minimal engagement with either network as a positive aspect of participation, including with some potential benefits. Most firms attended events or had opportunities for partnerships through participation in those networks. For example, the web service firm described a mostly collaborative business environment and explained, "When someone looks for tech services that we don't do, we recommend other [B Corps]. Sometimes it's competitive to get tech staff from one company to another, but it's mainly friendly. Others recommend [each other] to clients." Participation did not always provide direct (or economical) benefits (as also mentioned in the Motivation chapter), but some firms conveyed appreciation for the associations, and or of key champions such as those B Corps which take leadership roles in the network. The software firm interviewee described the relationships as a "peer network of learning" in which to "learn from others with similar values and [develop] new ideas or policies." The marketing firm interviewee saw being 
part of local B Corps as "creating a marketplace of like-minded businesses... that are socially aware... with goals greater than themselves as indicators of success."

Regarding geographic aspects of relationships, many Philadelphia highlighted mainly local city-based networks. While all Philadelphia B Corps interviewed were in SBN, they often had relationships with other businesses in the SBN network, including those that were or weren't B Corps. For several firms interviewed, the relationships they described were within a wider network of impact-driven businesses, not always specifically with other B Corps. For example, the web services firm explained other B Corps "aren't always a good fit" for collaboration in order to "uphold their high standards." Yet that firm always looks for "good businesses, and will always go to other businesses in the CSR communities... an indication of a company that cares." Similarly, the graphic design interviewee explained "there are not many B Corps in Philadelphia. We work with vendors that do good, but we have trouble within the B Corps community to be the right fit." Only one interviewee-from the eco-service company-emphasized localism, by stating the firm "likes to have local partners: locally-owned, small businesses to support the local economy."

A few firms also described their relationships as basically inactive. Their level of engagement was reportedly influenced by the type of work they do, their capacity, or their perceived benefit of active engagement. For example, if their work was primarily virtual or dependent on relationships outside the region, the local network held lesser perceived relevancy. The cleaning services interviewee explained the limits to collaboration with B Corps being part of a franchise they need in order to market 
themselves. That interviewee explained "I'm not aware of [local relationships] because there are lots of issues with the franchise, so partnering with others...can be tough... clients don't know about workers... and all accounts get reviewed through the franchise." The wholesale food producer expressed disappointment at peers within the local network, and wanted the relationships to be more collaborative. That firm also observed a trend that other (non-B Corp) sustainable businesses lose interest in [networks] when they fail to experience a marketing advantage. The interviewee suggested "other businesses market the values but then when they see the consumer base doesn't care, don't try to uphold values, whereas B Corps try to be transparent.” While most firms did not hope to gain a traditional business advantage from membership in the networks, a couple firms hoped participation would at least keep them afloat and were disappointed to not achieve that result.

\section{Portland Firms on Relationships}

When asked about relationships with other B Corps, the trend among Portland B Corps was also collaboration. As with some Philadelphia firms, a couple Portland firms described the relationship as both competitive and collaborative with one using the term 'coopetition.' Some highlighted competition within their industry. Portland firms were more likely than Philadelphia firms to report collaboration with other networks outside of B Corps circles (for example, industry-based), while several Portland firms identified a collective influence on market change. One Portland B Corp experienced no direct benefit from participation, while another emphasized solely the community (but not 
business) benefit. Yet several Portland B Corps did seem to appreciate some (potentially indirect) benefits to participation. Generally, Portland firms emphasized collaborative relationships and identified dispersed networks as relevant to those relationships.

As with Philadelphia interviews, most Portland firms emphasized the collaborative aspects with other B Corps. Nine mentioned collaboration. One larger firm claimed to have "no competitive thoughts" and declared, "all boats rise with the tide. ${ }^{17}$ ", Several identified support from other firms, including at networking events such as bimonthly lunch meet-ups, local B events and the champion retreat. One mentioned the opportunities that evolved due to the leadership of active champions or firms, such as an invitation to a roundtable with the Mayor at the time (Charlie Hales). The media firm interviewee stated that in Portland, B Corps are "collaborative completely.... We have just started to collaborate to leverage and to help promote [each other]." A couple firms lacked time or failed to achieve significant benefits, but still appreciated the collaborative opportunities.

On the other hand, several Portland firms described participation within the B Corps network as providing a competitive advantage outside of the B Corps circles, even if they were not necessarily able to identify direct or measurable benefits. For example, the media firm mentioned how collaboration has led to leveraging and promotion. Several other firms mentioned promotional activities together, for example the interviewee from the manufacturing firm claimed they "worked with other B Corps on

\footnotetext{
${ }^{17}$ Kennedy, John F. Remarks in Heber Springs, Arkansas, at the Dedication of Greers Ferry Dam Excerpt from speech, "A rising tide lifts all the boats and as Arkansas becomes more prosperous so does the United States...” https://www.presidency.ucsb.edu/documents/remarks-heber-springs-arkansas-thededication-greers-ferry-dam accessed February 22, 2020.
} 
promos together...as part of a marketing, co-branding strategy." Another from the marketing firm stated clearly that participation in B Corp and other impact-driven networks "is a marketing strategy... as part of a referral network. We're in a community of organizations that hire us." The eco service firm interviewee described a degree of competition but still emphasized primarily the relationships as "exclusively collaborative but within coopetition."

Differently from Philadelphia firms, most Portland firms mentioned participation in several other non-B Corp-associated networks, in addition to direct association with the B Corps community. Specifically, four firms mentioned collaboration with other networks in addition to B Corps, at both local and nonlocal levels. One firm appreciated opportunities for local introductions, but also networked with B Corps nationally, thus had relationships within the at-large B Corp network. The type of industry or firm seemed to influence the propensity for relationships. Those with industries beyond the local level, including those who operated virtually or remotely or had large-scale production, often pursued collaborations other than with local B Corps.

In terms of geographically-based relationships, while Portland firms largely emphasized local level, some identified relationships at different geographic scales. As previously mentioned, one firm described beneficial relationships through introductions to other B Corps locally, but also networked with B Corps nationally. While another interviewee-from the tech service firm- explained different relationships at different geographic scales, "local is collaborative, [but we're] competitive at the national level." Meanwhile a couple other firms described relationships within a broader impact-driven 
movement. Not necessarily politically motivated, they saw the movement as an effort to change how business is conducted. The investor interviewee explained that "we don't consider ourselves social enterprise. Our area is traditional business, but we're invested, in [being our] finest. We aim to bring [our] whole humanity to work."

One interviewee-from the consulting firm-summed up well the thoughts of many Portland firms. Through participation the interviewee claimed to be "part of a community that shares value, and is making a difference" then added, "through that we find comradery; yet some are competitive, some are collaborative."

\section{KIs on Relationships}

KIs in both cities reinforced the firms' emphasis on collaboration and networks. KIs from both cities described supportive relationships both between firms and within networks. Philadelphia KIs described the same two primary networks that foster and support these relationships. Portland described several types of dispersed networks that foster and support these relationships.

\section{Perceived Importance of Location: Institutions \& Culture}

While institutions make up an element of local relationships by strengthening networks, they also support the infrastructure to enable those relationships, as does the cultural climate. To understand institutional supports and supportive cultural factors, 
when firms were asked to describe the process of how they became a B Corp, they were also asked:

"What outside supports assisted you?"

To better assess the role of location, firms were also asked about the importance of location. Specifically, they were asked the following questions in their interviews:

"How important is the location? What are the supports? Challenges? Role of local culture?"

Firms' responses to the support and location questions-across cities-addressed aspects of civil society, government, infrastructure, economic development, and social or community values. The support question was generally understood in a local context, except for occasional reference to the nonprofit B Lab, which while local in Philadelphia, was not in Portland. The supports appeared to fall into either institutional or cultural categories, with some overlap.

As part of the effort to understand the significance of location, KIs were also asked about the importance of location. Specifically, they were asked the following questions in their interviews: barriers."

"Tell me about the supports here (locally); including events, groups, champions or When asked about the local supports, KIs in both cities described opportunities and barriers not inconsistent with what the firms claimed. However they tended to emphasize opportunities of policy, infrastructure and government roles to a greater extent with less mention of local culture. 


\section{Public Policy \& Legislation Background}

Essential to B Corp proliferation is public policy to enable them. A key step is the passage of state legislation. Both Oregon and Pennsylvania passed legislation to formally allow social benefit corporations in 2013 (Pennsylvania: HB1616 ${ }^{18}$ ) and 2014 (Oregon: HB2296 ${ }^{19}$ ). At the city level policies have the potential to enable or impede their operation. Both Philadelphia and Portland identify city policies that are at least minimally supportive, such as small tax credits, while Philadelphia also reportedly has some tax challenges, discussed in the next sections. However, as discussed in greater detail later, local tax structures can pose some challenges to small businesses (in Philadelphia). City governments also have small initiatives or incentives which do not necessarily provide substantial financial impact, but symbolically convey support and encouragement for B Corps.

\section{$\underline{\text { Perceived Importance of Location: Institutions }}$}

Generally the focus of location and support was at the urban level. Institutionally, primary supports include organizations which initiated or bolstered those networks described in the Relationships section. These institutions play a key role in both cities, but with small distinctions between the two cities. As reviewed, two primary nonprofit

\footnotetext{
${ }^{18}$ https://www.legis.state.pa.us/cfdocs/billinfo/bill_history.cfm?syear=2011\&sind=0\&body=H\&type=B\&bn $=1616$ (accessed December 10, 2019).

${ }^{19}$ https://olis.leg.state.or.us/liz/2013R1/Measures/Overview/HB2296 (accessed December 10, 2019).
} 
organizations provide support in Philadelphia, whereas as also mentioned, institutional support in Portland is more general and dispersed.

\section{Philadelphia Firms on Institutions}

Generally, Philadelphia firms saw location as important, but their reasons varied by firm type and how they defined location. Most firms identified both opportunities and challenges based on location. Influential opportunity factors include affordability and economic opportunities, civil society and government supports. Some firms identified the city's tax structure as a challenge. Overall interviewees emphasized local institutional support.

In terms of defining location, most Philadelphia firms referred to the city at large but some interviewees discussed location in terms of a neighborhood, or their virtual network. The web services interviewee explained investment in their neighborhood and said they "came to the [under-invested] neighborhood. We tried to retain integrity. We wanted to help it improve without co-opting it or by creating change." They wanted to be an impactful force to support neighborhood needs, but not through top-down gentrification.

In Philadelphia, B Lab and SBN are the two major organizations which provide the primary institutional support, and in partnership with each other. B Lab as a nonprofit arose to support and promote the social benefit corporations which specifically became known as B Corps through B Lab's third party certification. According to their website, "B Lab is a nonprofit that serves a global movement of people using business as a force 
for good. B Lab's initiatives include B Corp Certification, administration of the B Impact Management programs and software, and advocacy for governance structures like the benefit corporation." ${ }^{20}$ According to their website, SBN's mission is "We envision a future where businesses are investors in the quality of life for all citizens. We challenge and support the business community to build profitable enterprises that serve community needs, share wealth, and protect the environment." ${ }^{21}$

In addition to the relationships SBN and B Lab help foster through enabling the networks, they also proactively advocate for B Corps in the city and state. SBN is located in city limits while B Lab is located in a nearby suburb, Berwyn. Given SBN and B Lab's proximity to Philadelphia, they are positioned to help launch and sustain the city's B Corps.

Many of the interviewees were first exposed to B Corps by SBN. SBN promoted B Corps to all members and required they take the assessment, not necessarily to become a B Corp but for self-evaluation. As a result, some firms discovered they met the criteria, others discovered areas to improve, and a number of SBN members opted to investigate B Corps. The web services provider explained "SBN helped with information, and helped to connect us to opportunities... including other businesses who we spoke with about processes and to obtain support." Other firms pursued B Lab and found them, according to the marketing firm interviewee "accessible for questions or comments including when we sought guidance [on the certification process]. While B Lab provided a key support role for several interviewees through certification process, the software firm interviewee

\footnotetext{
20 “B Corporation About B Lab." https://bcorporation.net/about-b-lab (accessed December 10, 2019).

${ }^{21}$ Sustainable Business Network Mission, Vision, Values." https://www.sbnphiladelphia.org/who-weare/mission-vision-values/(accessed December 10, 2019).
} 
explained, "If not for SBN, it would have been maybe years before we even knew about B Corps.” Additionally, a couple of firms were approached either by SBN or B Lab because of their reputations as impact-driven, then invited to become certified.

Outside of SBN and B Lab, a couple of key leaders or consultants also played a role in sustaining the B Corp infrastructure. The graphic design interviewee explained, "we went through the certification with help. The first time [we did the] assessment, we didn't do great. An independent consultant helped us do our homework."

In terms of opportunities, firms reported contributions from the institutions and civil society as key contributing factors, as well as demographic factors that enhance the city's business infrastructure. One interviewee observed a "deep, diverse nonprofit sector" whereas some described that rich civil society as supportive of local business. Interviewees also valued opportunities based on the city's size and affordability, especially when compared with other cities like NYC, Boston or DC. They appreciated lower cost of living, while according to one interviewee, Philadelphia taxes are more invested into the community than in NYC. The media firm stated these factors enabled them to be a "medium fish in a small pond," while the interviewee from the eco-service company stated they "love NYC but it's huge and has lots of companies."

Key challenges mentioned by interviewees included limitations on profit in part due to the city's high and complicated businesses taxes. Several interviewees addressed challenges in terms of a business climate with excessive tax burdens. The local tax costs to run a business seemed high by interviewee standards, as nearly half the interviewees mentioned taxes as a challenge. They discussed two primary taxes: business privilege and 
net profit tax and also described complicated processes. One retailer explained "Philly's tough on taxes, I can't do them without an accountant." Yet some also saw the benefit of taxes, even if a burden. The media firm interviewee explained "I could move one mile away and spend less [on taxes] but I want to support Philly." The manufacturer even expressed appreciation for the taxes and stated, "the city is trying to make changesschools are under-funded." Several firms similarly described a desire to invest in Philadelphia's improvements, while also noting the city's persistent need for improvement.

\section{Portland Firms on Institutions}

Portland firms generally saw location as essential, unless they had a business model for which location was not relevant. Portland firms identified institutional support, but through several different resources, rather than through mainly a couple primary resources as in Philadelphia. Most firms identified location-based opportunities and just a few challenges, but not with the local institutions.

Interviewees described several Portland organizations or programs which provided institutional or infrastructure-building support. Key supports include Portland State University (PSU), particularly their Business Outreach or Masters of Business Administration programs, as well as a few for-profit advocates: a law firm to help with the legalities (INMAX), a local consultant, an impact investor, and a financial advising firm. The medical supplier credited PSU and explained how their firm was "in the first round of PSU's impact entrepreneur program, which continues to be supportive, and does 
a lot to build culture in Portland." The wholesaler explained "it helps to access our supports... a free education... training from the Small Business Association (SBA)... [and] free business counseling." Nearly half of the firms also identified other B Corps as strong local supports. A couple firms described Portland as the perfect city for a B Corps business due to these local institutional supports, while a couple also mentioned non-local institutions with a strong Portland presence, such as the local chapter of Net Impact ${ }^{22}$ or BALLE $^{23}$. B Lab was helpful to several firms as well, despite not being local.

Interestingly, only one firm mentioned the influence of city government. Otherwise, Portland interviewees had less to say about institutions than about culture.

\section{KIs on Institutions}

The KIs provide a key element of infrastructure support and described those roles, and also reinforced some of the findings from the firms, though not necessarily with the same emphases. When asked "how do you support companies that become B Corps?" KIs in each city had different emphases, which also overlapped but slightly differed from the firms in their respective cities.

Like the firms, Philadelphia KIs described the network created and how the KIs themselves promote B Corps at gatherings, and as a means of creating what resembles market distinctiveness. They also mentioned the challenging tax structure. They saw the significance in their own roles as key actors providing local support.

\footnotetext{
${ }^{22}$ Net Impact. https://www.netimpact.org/ accessed February 22, 2020.

${ }^{23}$ Business Alliance for Local Living Economies. https://community-wealth.org/content/business-alliancelocal-living-economies accessed February 22, 2020.
} 
Consistent with firms, Portland KIs saw less of a significance of any key actors, but instead emphasized larger local or civic infrastructure. They explained the overall attractions of the city, pointing out the local infrastructure that arose to promote and connect B Corps. Portland KIs also identified the support of civic government, specifically planning agencies (Portland Development Commission and the Bureau of Planning and Sustainability, organizations never mentioned by the firms). One KI described resources that arose to provide infrastructure to support social enterprise. That $\mathrm{KI}$ also suggested businesses have an opportunity to help in the provision of municipal services, given limitations of city government resources.

Otherwise KIs in both cities were more likely than firms to discuss the evolution and process of the institutional supports to become B Corps, including in a historical context to identify the supports that grew and sustained B Corps. Philadelphia KIs mentioned infrastructure, hubs, the significance role of founders, and the necessity of legislation. They also "described how B Corps evolved naturally given the location as their place of origin. One described their own roles in enabling "connections among peers, through retreats, and events." Portland KIs mentioned support from various programs and civic improvement efforts, as well as business associations and universities that helped launch and promote B Corps. One KI explained how local government helps firms connect to technical assistance and assess their impact. Another relayed how PSU's Net Impact program "attracts people to the city [while] the program attracts infrastructure." Thus, from a process perspective, the importance of advocacy may be less obvious to the firms than the importance of some key actors and factors, but essential 
according to KIs who recognize the necessity of supportive policy, infrastructure and government.

\section{Perceived Importance of Location: Culture}

The sub-question about role of local culture was important in its contributions to the study. Upon reflection, the question could have been expanded into a separate question to better unpack, or is worth examining in follow-up research. However, the responses provided interesting insights about one of the most significant aspects location aspects of B Corp support, and revealed the different role and influence of local culture in each city. Interviewees largely responded to this question with descriptions about local community characteristics.

\section{Philadelphia Culture}

Philadelphia firms were less likely to emphasize local culture as an essential support. However there were a few examples. There was reference to a culture that supports social values. Some firms experienced support at the neighborhood level. Key challenges included economic limitations. Overall, the local climate was described as socially-minded and supportive of small businesses, with some potential limitation to economic viability.

According to a number of interviewees, Philadelphia is a socially-minded city. The software company stated the city has a "local culture for which there's a sincerity to 
make society better." Others referenced the social values. The graphic design interviewee identified community and peer support, in response to their (positively) impactful work in a gentrifying neighborhood, and even described that specifically as a selling point to consumers [clients/] who also want to support the neighborhood. Meanwhile the web servicer identified local supports such as "local events, advertisements, efforts to participate and spread their work, and efforts which create a vibrant living city."

Other interviewees described a climate supportive of small businesses. The graphic designer explained "we have a very entrepreneurial mindset. We're both old school and new school. Those who are 45 and under, look for more [in their work]. There will also always be traditional capitalists." Another interviewee explained the strong business climate and stated "Philly is booming for small businesses."

Culture was also mentioned either somewhat neutrally or as a challenge, with emphasis on economic challenges. Even with progress in the city, a couple interviewees described struggling economic conditions that were tough on the local business climate. The software firm interviewee explained "downtown is experiencing economic development but remains deeply challenged." A couple firms described barriers to running a business in the city, exclaiming "it's competitive to run a business." Two other interviewees generally described the location as poor overall, specifically in terms of running their firms. The eco-service company interviewee described a brain drain and explained the city has a "tough time to retain graduates or recruit graduates." Meanwhile, those firms which operated virtually or remotely appreciated their local relationships, but 
found little relevance to their firms. Another interviewee-the producer/ wholesalerexplained while they had some local relationships, their online community was also significant, and the majority of their business wasn't at the local level. Yet overall, the Philadelphia interviewees had more to say about opportunities in the city, despite some challenges.

\section{Portland Culture}

Portland firms generally saw local culture as a key part of location, regardless of market opportunities provided by the location. Challenges were few and more often firmrelated or a commentary on mild local economic limits.

Generally, interviewees find Portland to have a very supportive culture. The medical supplier summed up the Portland perception, "Portland is a great place to do this. It's a supportive local culture. There's not a ton of local money to support local culture. But I would rather have culture than money." Other interviewees echoed similar themes about the city's great culture and their appreciation.

Portland firms strongly emphasized the local city culture as the primary driving support for B Corps. A couple interviewees specifically identified "supportive local culture" or identified the "sustainable values." Another mentioned sustainability-related events, like Portland Green Drinks, which promote community-building collaboration and subsequently encouragement of ethically-driven business. The manufacturer stated firmly, "local culture is what allowed us to stay in business." The wholesaler explained "Portland culture is very amenable. People tend to share values; [it's] really common in 
Portland to be passion-driven." A couple firms described the cultural impact on markets, as explained by the wholesale food producer "Portland has a market deeply rooted in sustainable values... Many in the community value good treatment-of product, of community, of staff. Stakeholders have an interest." The media firm interviewee explained "Portland is the right fit for B Corps because of local conscious consumers. We're a business that does the right thing-a perfect fit for Portland. We have no Portland challenges." All but one defined local culture as the city, excluding only the investor who mentioned the whole state and proclaimed "our firm probably wouldn't have started elsewhere but Oregon. Oregon has a long tradition of pursuing social and environmental impact of business." That firm also explained that starting in Portland led to their expansion as "since [inception], we have found a groundswell all over the nation and world for [our] business."

A couple firms described Portland as the perfect city for a B Corps business. The media interviewee claimed to have no challenges and described Portland as "small...big... quirky... 'it's Portland." In other words, it has advantages of being both small and large enough, while Portland's locally-based flavor provides its competitive advantage. Another, from the eco-service firm, explained "collaboration is very significant here. Most of Portland moved here for a better lifestyle, and gave up jobs for better livability." Both the size and lifestyle appear to enable an infrastructure that supports B Corp firms.

However local culture is not pertinent to every type of firm. If a firm's industry or market is not local, then as the eco producer stated plainly, "being in Portland is not 
relevant." The tech service interviewee observed how support locally "is increasing, but was very little initially... yet we can work from anywhere... since most of our workforce is remote." Similarly, the marketing firm interviewee stated that "while the bulk of business is done here... because we're progressive and environmental... and have a Portland ID that matches our brand... most of our clients are national.” The eco-servicer stated "location is the last mile logistic - the last mile of goods. We must be in a dense urban area. Portland is not dense enough." The medical supplier identified as an "issue" the need for more relationships with an overseas market and lamented that "sometimes Portland feels not internationally connected enough.” However, even the tech service firm which lacks a local market and works remotely, conveyed appreciation for how "B Corp is a hub." Moreover they chose to work in a specific neighborhood to make local connections. Thus, while location is not always relevant to an industry, that was not a huge detractor, in part because these same interviewees also reported appreciation for the attributes of local culture.

Otherwise, there was some mention of limited economic opportunities. For example, as previously mentioned, the medical supplier lamented there is "not a ton of local money to support local culture" even if the interviewee didn't mind that limitation. Additionally, the consulting firm interviewee pointed out that while there are "lower costs to provide administrative supports," Portland's "not a great place to make money because it's too small."

Yet generally, while the location could be irrelevant or pose minor or industrybased limits, overall Portland firms reported more positive aspects of local culture. None 
mentioned what they described as significant cultural challenges. Thus, Portland firms may operate within a culture that largely reinforces and reflects their values, but perhaps without the wealth to support a robust economy.

\section{KIs on Culture}

The interview question for KIs about local supports did not specifically ask about culture, yet the responses were revealing. Philadelphia KIs did not specifically mention culture or community, while Portland KIs emphasized local community. Otherwise, many KI comments echoed the firms from their city.

While KIs from both cities identified an environment that supports small businesses, descriptions were different. Philadelphia firms described a generally favorable climate due to the city's "small town vibe... with lots of pride... and a mentality... to invest." Philadelphia KIs also emphasized a supportive infrastructure (echoing the institutional themes previously discussed), but unlike the firms, did not specifically mention the culture. Meanwhile, Portland KIs reinforced the statements by Portland firms about a supportive local culture, especially in the form of infrastructure. Similarly to the firms, Portland KIs noted the local community supports-including the KIs themselves-in promotion, for example by holding gatherings or events about B Corps.

Both cities also identified a few challenges which hinder the proliferation of $\mathrm{B}$ Corps, fairly consistent with what the firms reported. Particular and common to both cities according to KIs, are local economic limitations. One Philadelphia KI mentioned a 
large amount of debt in Philadelphia as an impediment to growth. That KI explained "so many students leave... student debt [is an issue]...there are not enough jobs...or with [good] pay." Meanwhile Portland KIs also identified the limitations of industry given insufficient distributors and suppliers. One Portland KI also mentioned that despite supportive infrastructure, there is "little community buy-in (perhaps yet), specifically to B Corps.”

Yet overall, like with firms across cities though with a greater emphasis in Portland, KIs described what can be understood as a mostly favorably local culture or climate, and conveyed a desire for additional-mainly economic-opportunity.

Table 5.1. Location: Supports \& Challenges

\begin{tabular}{|c|l|l|l|}
\hline $\begin{array}{l}\text { Population } \\
\text { site }\end{array}$ & Relationships & Institutions \\
\hline $\begin{array}{l}\text { Study } \\
\text { population } \\
\text { trends }\end{array}$ & $\begin{array}{l}\text { Relationships promote } \\
\text { \& strengthen. They are } \\
\text { collaborative with other } \\
\text { B Corps unless virtual. }\end{array}$ & $\begin{array}{l}\text { Policies \& institutions } \\
\text { make B Corps possible. } \\
\text { They are public, nonprofit } \\
\text { \& for-profit supports. }\end{array}$ & $\begin{array}{l}\text { Attitudes, activism trends } \\
\text { \& business climate } \\
\text { support. The economies } \\
\text { pose limits. }\end{array}$ \\
\hline $\begin{array}{c}\text { Philadelphia } \\
\text { distinctions }\end{array}$ & $\begin{array}{l}\text { Formal Network: B } \\
\text { Corps collaborate within } \\
\text { two main networks. } \\
\text { Appreciated a network } \\
\text { advantage. }\end{array}$ & $\begin{array}{l}\text { Centralized: Two primary } \\
\text { institutions help. City } \\
\text { taxes hinder. }\end{array}$ & $\begin{array}{l}\text { Socially-minded: City is } \\
\text { socially aware. City is a } \\
\text { good size, affordable \& } \\
\text { supports small business. } \\
\text { There is a brain drain. }\end{array}$ \\
\hline $\begin{array}{l}\text { Portland } \\
\text { distinctions }\end{array}$ & $\begin{array}{l}\text { Informal networks: B } \\
\text { Corps collaborate with } \\
\text { several networks. } \\
\text { Received marketing } \\
\text { advantage. }\end{array}$ & $\begin{array}{l}\text { Decentralized: Support is } \\
\text { dispersed. No challenges } \\
\text { noted. }\end{array}$ & $\begin{array}{l}\text { Localism: City is locally, } \\
\text { community and } \\
\text { sustainably-minded. Size } \\
\text { is good. Market is too } \\
\text { small. }\end{array}$ \\
\hline
\end{tabular}

\section{Intersections: Portland Example}

Relationships, institutional policy, and culture all combined for a seasonal event in Portland that illustrates the city's intersecting supportive factors. Over the holiday 
seasons of 2018 and 2019, several Oregon-based B Corps combined resourced to operate a temporary pop-up shop (B Store) in the Lloyd Center-the largest shopping mall located near the city center. The collaboration reflects a series of relationships as reportedly a number of Portland-based B Corps chose to work together and share the space as both a fundraiser and promotional event, as well as to educate patrons or consumers. Sometime after the completion of the interviews, several B Corps had formed a group to work together to support and promote each other, called B Local PDX ${ }^{24}$ through various means such as the pop-up shop, B Store ${ }^{25}$. Portland city policies and local initiatives promote temporary use of commercial and public space, both to enable low-risk accessible entry for small entrepreneurs and to provide additional income or rent for under-used and available space including through pop-up shops (Curtis 2015). In 2018 and 2019, the Lloyd Center hosted 25 pop-up shops and featured 100 brands for the holiday season, through their initiative 'Lloyd Local ${ }^{26}$ ' including the B Store. Presumably, an incentive for Lloyd Local was expectation for a receptive audience, given Portland's reputed support for local business.

Interestingly, while the presence of a popup shop is of interest, the products themselves also reflect Portland's culture and present a unique opportunity for B Corps. Products for sale included artisan teas, coffees, specialty foods, and wines-signature examples of Portland's artisan economy (Heying 2010). The pop-up shop's primary

\footnotetext{
24 “B Local PDX About B Local PDX." https://www.blocalpdx.com/about-b-local-pdx (accessed December 21, 2019).

25 "B Local PDX Get Ready to Shop the B Store." https://www.blocalpdx.com/news-feed/2019/b-storeopening-2019 (accessed December 21, 2019).

26 "Lloyd Center Join the Pop-up Retail Movement at Lloyd Center." https://www.lloydcenter.com/lloydlocal/(accessed December 21, 2019).
} 
promotion was a passport tasting to Oregon's B Corp wineries, to highlight the world's largest cluster of B Corp wineries. Thus, not only do B Corps appear to be spreading in Portland, an industry B Corp wine cluster has emerged within the region's already established industry-based cluster.

\section{Growth}

Noteworthy, given the time that passed since research began in January 2014 and analysis concluded in September 2019, secondary data reveals the extent of how B corp numbers expanded in both cities and at large. The number of B corps in Philadelphia grew only by $35 \%$ in 5.75 years, despite proximity near B Lab, the nonprofit organization that launched the B Corp movement, a relative rate of stagnation, when compared with the national rate. The US number of B crops grew by $146.86 \%$ during this same time period. For comparison purposes, the number of B Corps in Portland grew by over two and a half times in size (by 258\%). (See Table 5.2.)

Table 5.2 Total B Corps Growth by City \& US over 5.75 Years

\begin{tabular}{|c|c|c|c|}
\hline City & $\begin{array}{c}\text { B corps by city at } \\
\text { study start 1/16/14 }\end{array}$ & $\begin{array}{c}\text { B corps by city at } \\
\text { study end 9/14/198 }\end{array}$ & \% growth \\
\hline Philadelphia & 26 & 35 & $35 \%$ \\
\hline Portland & 31 & 114 & $268 \%$ \\
\hline US* & 700 & 1728 & $147 \%$ \\
\hline
\end{tabular}

*Total of B Corps worldwide on 9/14/19: 3825

27 "Certified B Corporation B Corp Directory." (accessed January 16, 2019).

28 "Certified B Corporation B Corp Directory." (accessed September 14, 2019). 


\section{Location Summary}

A discussion of location attempts to assess the role of place, in terms of the supportive and challenging factors. The main place-based aspects included relationships, institutions and culture. Relationships within the city's supportive infrastructure are important and lean towards non-competitive. Most firms are collaborative with other B Corps unless their work is remotely or virtually-based. Philadelphia firms tended to collaborate within two main networks, and really appreciated that network advantage. Portland firms tended to collaborate with several networks, and may have received a small marketing advantage from joining forces, even if they did not track a clear financial impact.

Another key location-based factor involved institutions. Supports include public, nonprofit and some for-profit groups, as well as enabling policies and business initiatives. In Philadelphia firms the same two primary institutions that provide the network for relationships, also provide help with the certification process. However Philadelphia firms also indicate the high and complex city taxes create a barrier for them to run their businesses. Portland firms reported wider, dispersed support, and noted no challenges with local institutions.

Meanwhile, local culture also plays a significant role in terms of support and challenges. In both cities, local attitudes, activism trends and the business climate provide support. However economic realities pose limits on viability as a business. Philadelphia is an affordable socially-minded city that supports small business. However in addition to 
local economic challenges, the city reportedly has a brain drain, which impacts the workplace. Portland is community, locally and sustainability-minded. The city's size renders it good for small businesses-not too big or too small-yet the market is too small, particularly for any firm that relies on large-scale production.

\section{$\underline{\text { Conclusion }}$}

In summary, the relationship, institutional and cultural aspect of location, are largely important to the adoption of B Corp practices, but with some variety across city and firm type. Most B Corps appreciate the opportunities provided by collaborative relationships with other firms and networks, including networks of varying scales. However there were some exceptions. Specifically, those that operate remotely, virtually, or within a larger market may find location less relevant or even challenging, whereas a few B Corps hoped for greater collaboration. The degree of collaboration or scale of participation varies based on the type of firm (whether operates locally, virtually, or within a larger market), but participation appears to offer the possibility for many of competitive advantage. A cluster of support may partially arise, but not necessarily at the industry level unless the firm can operate primarily and sufficiently at the local level. However, for an industry cluster that already exists-such as the Oregon wine industrythere appears to be potential for an industry B Corp cluster to arise, as well.

In terms of factors to provide support, local culture, infrastructure and civil society seem most relevant. Many firms found local culture supportive, particularly social values in Philadelphia and green, community or localism values in Portland. Some firms 
in both cities even suggested investment in neighborhoods or the city was marketable. Supportive infrastructure and civil society was identified by a few firms and all KIs as significantly important, especially in Portland. Infrastructure in both cities supports value-oriented businesses through the proximity to many value-driven networks. Additionally, firms in both cities describe the support for small businesses. Civic institutions appear to provide key support for, implementation and promotion, including through initial policy advocacy. There also appear to be a few key actors or champions in both cities, who help strengthen the B Corps network including Judy Wicks ${ }^{29}$ in Philadelphia, a couple of B Corp CEOs in Portland, as well as Stephanie Ryan ${ }^{30}$ from B Lab. Otherwise, government support helps with promotion and somewhat with incentives, but largely does not seem as essential as other supports. To a smaller extent, firms and KIs did identify some challenges, primarily taxes in Philadelphia and according to firms in both cities, limitations on economic opportunity and industry or market capacity. However, firms and KIs largely seemed to find location important and beneficial.

\footnotetext{
29 "Judy Wicks Bio." Judy Wicks is founder of SBN and BALLE. http://judywicks.com/bio accessed February 22, 2020.

${ }^{30}$ Blahnik, Heather. "Aisec Life. Industry Focus: B Corporation with Stephanie Ryan.” https://www.aieseclife.org/page/StephanieRyan accessed February 22, 2020.
} 
Chapter 6: Results/ Impact 


\section{Impact Chapter Introduction}

“[Being a B Corp] can be a game changer for some, but didn't change us... While we love it-it gave us certification, more documentation and recognition-it didn't change who we are. It did give staff a source of pride, and it creates connection... We're part of a niche community, which is all great, even if it didn't change how we do business." Portland media firm

One goal of the overall study was to investigate reported and perceived impact of being a B Corp. Interview questions asked firms about changes to B Corps firms, and about interviewee perceptions regarding potential scale of impact-specifically if they thought B Corps were a niche market or were a potentially scalable model. KI interviews and responses did not directly address all of the same issues except for consideration of the model's scalability. Identification of actual social or market impact was well beyond this study's scope. However interviews provided insights into participant perceptions about impact on the B Corp movement, as well as about potential for a future market expansion. The expected findings were: The process of becoming a B Corps will enable businesses to produce positive social impacts by providing a tool for their participation within a local ethical market. Impact areas were originally thought to focus on types of changes (i.e. the assessment categories), but interviewees described impact areas that were internal (cultural or operational), or external (markets or community). The methods and analysis aimed to address the secondary research questions: What are the potential and perceived impacts of becoming a B Corp? What may encourage or limit these impacts and what is the potential scalability?

Responses considered the study's main theoretical implications for B Corp participation, with emphasis on political consumerism/ethical markets, social 
movement/change and social entrepreneurship. Specifically the findings address how B Corps perceive markets as an arena for political change or tool for social outcomes, whether participation is another form of social entrepreneurship, what factors contribute to or impede success, and potential policy implications. As part of the study and the goals to better understand these theoretical implications, the interviewees ${ }^{31}$ from B Corp firms were asked the following questions from the Interview Protocol (see Appendix A):

3. Please tell me about the process. How did you become a B Corps? [Responses to 'What outside supports assisted you?' were reviewed in location chapter.] 4. How did becoming a B Corps change the company, clients/ customers, community?

12. Is this a niche market? Do you think it's a scalable model?

14. Do you see any way you have contributed to B Corps/ B Lab; and/or to CSR? Additionally, Key Informants (KIs) from nonprofit or public agencies were asked, like the firms, the following interview question from the Interview Protocol (see APPENDIX A).

12. Is this a niche Market? Do you think it's a scalable model?

While the research question attempted to unpack the processes as well as identify facilitation and impediments to outcomes, the interview responses provided more significant insights into different factors, particularly regarding perceptions about potential and actual impact. Interviews revealed participant perceptions of impact more at the firm level than externally, yet interviewees believed in the potential to impact markets-at-large to change and become more socially beneficial. As with motivations, the scale of perceived impact varies. The findings revealed more about different scales of

\footnotetext{
${ }^{31}$ Unless the context mentions all study participants or specifies Key Informants (KIs), "interviewees" or "participants" usually refer to firms.
} 
impacts rather than significantly different impact areas. Interviewees tended to report internal impacts at a greater level than a (mostly local) community level, and only a marginal (at most) impact reported on markets-at-large. Yet interestingly, a majority of interviewees think the model is scalable to the level of causing market change, despite reporting nearly no market-level impacts at this time. This contrast highlights again the greater motivation for participation being ethical values rather than traditional market values. Moreover, the internal impacts reported weren't necessarily substantial changes to business practices, but provided more opportunity to affirm or evaluate practices. Most firms are attempting to do what is right, and hope the trend will catch on to become more scalable.

\section{$\underline{\text { Impact to the Firm }}$}

Firms (only) were asked:

"How did becoming a B Corps change the company...clients/ customers... the community?"

While the question was open-ended and open to interpretation by interviewees, most responded to this question most readily in terms of internal changes at the firm level. (As described in the next section, some firms discussed external impacts on markets, communities or clients.) While a few interviewees in both cities observed no change, more reported changes. Changes included ways to evaluate whether and how to meet goals, or how to support or attract staff. Changes were largely observed at an internal level in both cities, but occasionally at a community level exclusively in Philadelphia. The other difference between cities was the trend exclusively among 
Portland interviewees to emphasize the impact of the assessment tool itself. Otherwise, a small number of firms in both cities emphasized little to no impact, while others described limitations to certain impact areas, especially any impacts achieved through connections to the community. No one specified limitations of the tool itself. (See Table 6.1 for summarized results.)

\section{Firm level}

The most frequently identified changes were at the firm level. These changes were largely either cultural or operational, but overall internal. At the cultural level, there was a shift in staff or company morale, or changes to the firm's ability to attract staff. At the operational level, the firms changed how they conducted business, and used the assessment to appraise, affirm, or improve their impact goals.

However a few firms explicitly claimed little to no internal change because of how committed or value-driven they already were. The Philadelphia marketing firm explained "being a B Corp is not a driver of the company or a priority." Meanwhile three Portland firms explained being a B corp was-in the words of the consulting firm- "the type of company we already are.” The Portland wholesaler explained, "[becoming a B Corp helped us] think of how things affect the assessment, but we thought of that anyway.” The Portland investor proclaimed, becoming a B Corp “didn't change us; we always intended to run that way." 


\section{$\underline{\text { Workplace Shift }}$}

For those firms which did change internally, the most direct impact seemed to be on firm culture. Several interviewees shared observations about internal cultural shifts. For example, the Philadelphia software firm explained "[being a B Corp has become] the first thing of what we say [about our company]... Because of that, we have begun to attract staff who wanted that... it has changed the culture of our organization and became a hallmark of our hiring; $90 \%$ of interviewees are B Corp and mission-driven.” The Philadelphia manufacturing firm said the assessments were effective to start internal conversations and "inspire chats" especially with "one key employee" who was not necessarily on board with the B Corp mission until the firm conducted the assessment. As previously shared, the Portland media firm explained certification gave "staff a source of pride."

\section{Community Connection}

Responses that directly mentioned community, focused primarily on how connections to a larger community impacted the firm. Two Philadelphia firms reported being part of a community as the greatest impact of participation. One (the graphic designer) explained that participation “gave us a community. It's small, but we're part of something bigger... There are lots of other professional organizations to join, but without [providing] the same source of pride." The software firm explained, participation "introduced us to a network of other companies who cared about the same things. [Participation] is more important as part of a community. We met people of like mind." 
Direct or indirect impacts from participation in a community were rarely mentioned, and primarily by Philadelphia firms.

Meanwhile, a couple Portland firms appreciated community impacts but did not experience any direct impacts. As previously mentioned, the Portland media firm explained how participation "creates connection... We're part of a niche community." The wholesaler claimed there was no impact, but said it was "nice to know we're part of a club."

Otherwise, most interviewees did not describe observed community impacts. However, some of those impacts are embedded in their responses. For example, the Philadelphia retailer explained they "feel and respond to impact and provide input in community even if [that input] is not marketed, not explicit." The Philadelphia media firm described an impact on philanthropy, thereby indirectly producing community benefits.

Meanwhile, several interviewees specified only limited impact of being part of a community. One interviewee in each city lamented that they didn't feel any impact from participating in the community. The Philadelphia food producer firm explained, "I don't have a positive view... [participation] brings no support." The Portland wholesaler explained, they were "not a big part of the local community [but have] been to one or two events." 


\section{$\underline{\text { Tool for Affirmation }}$}

A number of interviewees from both cities-articulated most clearly by those from Philadelphia-appreciated how the assessment helped affirm their values and practices. The Philadelphia health firm explained that while "it [didn't change us], it affirmed what we were doing." The Philadelphia web services firm appreciated the affirmation of their identity as part of an effort for change: "Being a B Corp sets us apart as one of a community of companies that stands behind a commitment to the triple-bottom-line of People, Planet, Profit." As previously mentioned, the Portland media firm said "it gave us certification, more documentation."

\section{$\underline{\text { Tool for Evaluation }}$}

The most common theme that emerged among interviewees, when asked about impact, was appreciation for the assessment as an operational tool for creating or monitoring internal change.

A number of interviewees, mostly from Portland, emphasized evaluative impacts, and the value of going through the assessment. They appreciated the tool as metrics or a tracking tool to monitor impact, or to set up improvement goals. The tool provided "baseline and tracking" for one firm and "internal metrics" for another. The Portland marketing firm explained "just doing the assessment makes us re-analyze policies. You get specific to improve what you think you're doing. Re-analyzing and documenting created better processes. We [now] want to say 'use local or B Corp vendors.' Without the process, things slip through, but the assessment brings [everything] to attention. We 
walk the talk." The Portland tech service firm stated, "B Corps helped us grow up. We didn't have many reports or proof of [impact]. It gave us structure, held us accountable...Maybe there was no change, but we became accountable." The software firm specified "the main benefit is that it's no longer subjective. [The impact is] specific, quantifiable, rigorous."

Others described how they changed, operationally. The eco service firm stated it “doesn't change us, but [provides] a roadmap for growth. The assessment focuses on how to run the company, less on what you do... The assessment guides us in growth... [on how we think about] supply chains and who we order from or subcontractors, and on how we develop accounting employee practices." The Portland manufacturer described an even more substantial internal impact and said, "Now we refer back to it [and consider] how to strengthen our own commitment.... to continually improve. We're working with others; [we've] come out of the woodwork and we give advice." Philadelphia echoed this appreciation for an internal impact on operations. The producer/wholesaler explained, "We were very early to become one [a B Corp]-so there was not that much change. It did, however, shape how we grew the company and how we looked at the company moving forward (and how others looked at it).”

\section{Impact of the Assessment Process}

As discussed in the Location chapter interviewees were asked to talk about the assessment process. The interview question "Please tell me about the process. How did you become a B Corps? What outside supports assisted you?" primarily addresses 
location-based supports. Yet some responses also described impacts to the company that were primarily internal, based on participation in the process, the network, or use of the tool. These findings were often consistent with firm identifications of impacts, highlighting similar internal shifts. Descriptions of impacts on the firm from the assessment process came down to [3] categories: 1) the experience created an opportunity for external guidance or participation in a network 2) undertaking the assessment introduced new data and/or data tracking, and 3) the act of the assessment process itself was new and impactful.

Several firms in Philadelphia described how external guidance helped them through the assessment process, or inspired them by being part of a network. The web services provider said, "SBN helped with providing information and helped to connect us to opportunities...Judy Wicks ${ }^{32}$ was an inspiration. Participation gave us access to a great community... [we] eventually met other businesses and spoke to them about the process and support."

In Portland (only), several firms discussed the impact of using or implementing data tracking tools during the assessment, consistent with prior findings indicating appreciation for the evaluation tools. The wholesale food producer stated, "[Before] we lacked baseline tracking. We looked to [supports] to define and figure out [what was needed for] certification [and were] actively engaged through Net Impact (at PSU). The assessment changes every few years, which is partly why it's so daunting... so complex... [We have] so many vendors...many processes [to assess].” The Portland

\footnotetext{
32 "Judy Wicks Bio." Judy Wicks is founder of SBN and BALLE. http://judywicks.com/bio accessed February 22, 2020.
} 
wholesaler said the tool helped document what they do, and explained that when they “started ... we didn't have the answers... [and got help for the assessment from B Lab]. We didn't need to make changes; it was more a matter of documenting what we do... Mainly B Lab provided examples.”

For a number of firms, participation in the assessment process itself created some impact simply by exposing firms to a new process of evaluation. The Philadelphia software firm explained "A lot of the B Lab evaluation... process [created] a new idea of [doing other] things." The Philadelphia health services firm explained to complete the assessment they "went through a long and complex, hard to understand process... and spent a couple hours." The Portland eco-product firm similarly explained impacts of the assessment process, as they went "online to B Lab to do the assessment test--[in] three to four hours, [with] no outside resources. We were contacted by B Lab for clarification [and had to] revise replies [when] asked for support documentation.”

Consistent with responses to the question directly about impact on firm, the assessment process appeared to impact firms somewhat differently between the two cities. More Philadelphia firms appreciated the opportunity to receive guidance and be a part of a network. More Portland firms appreciated the tracking tools. However a number of firms in both cities appreciated how conducting the assessment itself impacted their company, just by introducing them to new practices or ideas. 


\section{Impact Outside the Firm}

In response to the aforementioned interview question, "How did becoming a $B$ Corps change the company...clients/ customers ... the community?" some firms addressed impacts outside the firm, although to a lesser extent and frequency than the previously described internal impacts. (See Table 6.2 for summarized results.)

\section{Community-at-large}

Interestingly, not a single firm identified their impact on the non-B Corps community-at-large, in response to the interview question. Yet similarly to their perceived minimal impacts on markets, a couple firms described themselves as not big enough to have significant impacts on the community-at-large. However, as described later in the discussion about perceived scalability, there are implications of a common perception regarding the potential to have community impact. Also worth noting, firms are not likely to observe or assess their community impacts, given the extensive resources required for an external assessment, compared with a much easier opportunity to examine internally. While perhaps KIs are better positioned to evaluate impacts of B Corps either by firm or geographic region, this is likely beyond their capacity as well. Currently, perhaps the best opportunity for a firm to examine their external impact is through the assessment process, by comparing assessment scoring results and tracking changes over time. 


\section{Clients/ Customers}

Generally in both cities, few firms highlighted substantial impact on clients or customers (or to attract them). The exception was potential attraction of investors including for a couple of firms in Portland who conceivably achieved an investor marketing impact. However, several firms from both cities also specified there was little to no detectable financial impact. It is worth noting, that firm knowledge regarding the marketability effects may be limited, given the reliance on voluntary feedback from clients or customers, and lack of resources for an extensive external evaluation.

Of the few client/customer impacts mentioned, most were secondary impacts. For example, the Philadelphia manufacturer stated they had "started to tell potential new clients [about being a B Corp], to share more of what we're about...to lend credibility of integrity and trust... this was a secondary benefit." The Philadelphia health firm explained "people are curious... it doesn't hurt though it doesn't necessarily bring in clients." However three Portland firms (each focused on a product with some touted health benefit) saw actual or potential leverage with investors. The Portland manufacturer explained "in terms of customers, we haven't had super serious change, but had more value-based investors. That was huge." Similarly, the Portland medical supplier had not achieved noticeable impact, but explained, "investors care; [it gives] legitimacy to our approach... While there's little impact, the assumption is of inherent good. [Our] mission matters, which reassures investors."

A more common theme among interviewees was to specifically declare little to no financial or marketing impact to attract clients or customers. As previously mentioned, 
the Portland media firm said "it gave us... recognition" but as already highlighted they clarified that becoming a B Corp “didn't change who we are.” The Philadelphia manufacturer stated firmly, "there was very little impact with regard to clients and customers." The Philadelphia food producer stated "[becoming a B Corp] didn't have an impact" as another reason they lack a positive view. This sentiment was echoed in Portland by one firm that stated "there was a minimal effect on customers... Most don't care." Interestingly, the same Portland medical supplier that found certification reassures investors, also stated outright there was "no marketing value" but explained that generally impact is not relevant to their industry or field which lacks customers. Their 'customers' are basically other firms which "don't think much [about impact." The limited client impact, except with the occasional investor in Portland, reinforces the Motivation chapter's finding that a direct marketing advantage is not a significant motivator to participation. While the interviews generally did not address this area in great detail, there's likely more to analyze about variation in customer and client appeal than this particular study allows.

\section{$\underline{\text { B Corps Markets }}$}

Another consideration is the impact firms have on B Corps as a market-based movement. Firms were asked the question "Do you see any way you have contributed to B Corps/ B Lab; \&/or to Corporate Social Responsibility?" Responses lacked significant detail. However the general trend was to claim at least a marginal impact, on promoting B Lab and B corps overall, as well as to help advance the movement of businesses doing 
good. As mentioned in the Location chapter, several B Corps (mainly in Portland), including firms interviewed for this study, played key roles in the promotion of B Corps, thus likely contributed to their expansion. A few Portland firms were engaged early on or in legislation. Primary ways to promote participation included modeling the idea of businesses-doing-good, educating others about B Corps, or political advocacy.

Just over half the Philadelphia firms were asked this question and of those some described efforts at promotion of either B Corps or business-doing-good. The Philadelphia marketing firm explained, "Definitely; when I talk about creating markets... I try to enable... those in middle markets... to grow their businesses." The graphic designer explained, "[I impact] other businesses... [through a] business-doing-good model... but not yet B Corps." The food producer explained "We have our own standards and missions that happen to align with B Corps and CSR. If that contributes to their mission it was not intentional. We're just doing what we feel is right." As the Philadelphia web services firm explained, "We constantly are able to educate clients, fellow businesses, and people we meet through networking events-about B Corps and what being a socially responsible business means." A couple other Philadelphia firms (the food producer and the producer/wholesaler) reported, no or uncertain impact.

Most Portland firms were asked the question, and responses conveyed some degree of engagement or promotion. For example, the marketing firm claimed they both "promoted [B Lab] and worked with B Lab to improve the assessment." Additionally they "helped small businesses who were fearful of the assessment...helped [them] to start it." Meanwhile the media firm explained their leader "was involved with local politics... 
helped with local legislation, and was asked to speak on behalf of B Corps or benefit corporations." The investor also helped with legislation and "held educational seminars talking about benefit corporations." The wholesaler's input was more tepid but still affirmative, explaining they "talked to others [we] know (businesses)... we inform consumers, blog, tell friends... [on a] small-scale... [but are] not super active in lobby efforts."

Additionally, as mentioned in the Location chapter, the number of B Corps has grown, suggesting a possible scaling up. (See Table 5.2.) Domestically, since study inception the number of states that passed legislation grew from 20 in 2014 to 36 by the end of 2019. While Philadelphia did not see substantial growth (35\%), the US did (at 147 $\%$ ) and saw growth at a rate higher than the national average (at 268\%), despite the passage of 16 additional state legislations. (See Table 5.2.) There's potential growth at the international level as well. B Corps is about to launch a partnership with the United Nations, an implication of potential growth in their significance, as well as a likely indication of future expansion (Feloni 2019). Presumably, one likely impact of B Corp promotion is the growth in the number of participating firms, which brings up additional questions about potential to scale up as a larger market-based movement.

\section{Niche Market or Scalable Model?}

"[We] need better networks and quantifiers and to get the word out. B Lab is doing their best but we need McDonalds, Coke, or Comcast to champion [B Corps] because it's the right thing to do... before it catches on to traditional business. [Now] we have Patagonia, but it needs to be someone the world wouldn't expect. Currently it's a little 'hippie'...not 
high-powered. .... if someone can jump in and show a quantifiable benefit we can change the market."

-Philadelphia graphic designer

Interviewees were asked to share their thoughts on the scalability potential of B Corps. Specifically firms and KIs were asked about B Corps:

"Is this a niche market? Do you think it's a scalable model?"

The purpose of the question was not to ask interviewees to predict the future, but to gain insight into how they perceived the potential for scalability of the B Corp model (generally referred to by participants in the context of markets or movements), to better understand how or whether potential impact was relevant to them. Interviewees responded with views about factors conducive to the model's potential scalability, rather than as if asked to predict the future scalability. The purpose of the scalability question, and how respondents appeared to understand it, was not to address scalability of their own firms. In their responses, the majority of firms in both cities largely expressed confidence and hope in the scalability potential of the B Corp model, especially in Portland where all but one firm responded affirmatively. However, several of the Philadelphia firms who found the model scalable, also saw it currently still as a niche market. Several interviewees in both cities hoped it would be scalable but were unsure about potential. A few interviewees also saw scalability negatively, thus hoped B Corps would remain niche. Several interviewees shared a few perspectives, such as one Portland firm that stated "I hope it's scalable. It should be, and it probably has gotten more scalable in the last few years. It's no longer just a niche market. That's my impression." Frequently, and especially in Portland, they found the model scalable at the market level, 
due to observations of growing support for impact-driven movements. (See Table 6.2 for summarized results.)

\section{Scalable}

"[It's] very scalable! At the end of the day the consumer believes in and wants to support businesses that do good for the world. These can be from as small as a local shop to as big as a publicly traded company. I see no limitation."

-Philadelphia producer/wholesaler

Firms who responded to the scalability question largely claimed the B Corp model to be scalable, generally referring to a scaling up to a larger-market level. All but one Portland interviewee and two-thirds of Philadelphia firms, who responded to the question, agreed the model is potentially scalable. For them the question is less about 'if' than about 'how' or 'when.' Most provided as an explanation, observations of either a growing movement of ethically-oriented business practices and markets (including consumers), or a few examples of large-scale corporations who chose either B Corp or other ethically-driven certification.

Portland firms shared examples of scaling up to indicate potential. The ecoservice firm said "we have publicly traded companies that decided to become B Corps through their boards." Similarly, the tech service provider said the model is "definitely scalable. [Look at] Patagonia, Ben \& Jerry's, and Seventh Generation. It [can be] a global distribution model," while the consulting firm said, they think it's scalable because there is "no reason any company couldn't be a B Corp." These participants saw these publicly 
traded, larger companies as evidence of the potential for large corporations to pursue ethics in conjunction or ahead of maximized profit.

On the other hand, given how other certifications or CSR efforts (i.e., organic) can be a marketing advantage, many interviewees also see the potential marketability of B Corp certification. While again, the purpose of the question was not to obtain their projections or conjecture, it is interesting to note that participants perceive themselves as part of an effort that could reach global scale.

Moreover, some firms described how they saw potential scalability as an indicator of a larger, growing movement. Two Portland firms see an evolution taking place currently. The eco-product firm stated "this is our mission to prove [it's scalable]. In the next generation this will be business as usual." The medical supplier similarly "sees some changes in decades ahead...more enterprise" and claimed, "we're at a point in societal evolution where ways of business practice in the First World is environmentally and socially unsustainable. People are catching on." The Philadelphia web services firm suggested B Corps are part of a larger, growing movement, and are "proven to be a growth sector from all I read," then went on to explain, "My kid who is eight years old, and millennials... they [all] want to find meaning in what they do.” Meanwhile, the Portland investor stated they were part of a growing movement to change business in general, and explained, “All businesses have social impact. Some people think of B Corps as if profit motive is an apology or give away. We think [we] grow impact the business creates. We hold [ourselves] responsible for our own business and strive to make as much impact as possible. If that's the spirit, then it's not a niche, and is actually 
less risky and more profitable than a business that ignores humanity." Thus, firms in both a cities see the potential future impact due to a growing awareness of the need for change.

$\underline{\text { Niche }}$

A few firm interviewees saw B corps as niche at this time because they observed too little movement-too few B Corps and not a single Multinational Corporation (MNC)and too little appeal to MNCs. While few interviewees overall thought B Corps were a niche market, some Philadelphia firms also thought it was both niche and potentially scalable. The Philadelphia food producer expressed, "I think it is scalable and it is a niche market that is becoming increasingly mainstream." The Philadelphia graphic designer stated, "it is both. It's still niche, still in its infancy. It needs to hit a threshold. Many think it's not that important. [It comes down to] an old/new school mentality."

Others in Philadelphia were more skeptical, yet not necessarily devoid of hope. They saw limitations at either industry or scale levels. Two identified B Corps specifically as "boutique" and one claimed [markets] "can't do this on a big scale" while the manufacturer specified "it's boutique because there are many sustainable networks. Certain kinds [have] benefit and very few are in manufacturing." The software firm described certification as a barrier and noted the number of participants were too few to qualify: "I don't think [it's scalable?]. It gets harder to qualify. They raise the bar and standard. I don't think B Lab's objective is to lead." However that same interviewee still saw potential indirect impact when they followed up that skepticism with the question, "But can B Corps help lead a cultural change? That could scale. Cultural change doesn't 
require everyone to become a B Corp. But 15-20 million [social benefit] corporations?... 1500 B Corps is not significant enough [to] raise standards."

Only one Portland firm thought it was niche, and not scalable. The wholesale food producer explained that it's hard for a publicly traded company. For most public companies, it is "tough to write into the [bylaws], if they are privately held because the board and owners [have to] want to use a firm for good, more than for the bottom line."

\section{$\underline{\text { Scalability Hopes }}$}

If firm interviewees didn't think the model is scalable-in both cities though more in Philadelphia-they mostly wished it could be, and expressed ways they envisioned or hoped the model could scale up. In particular, they saw potential increase if the movement grows, inclusively across political spectrums, or reached a large enough corporation to draw attention.

Many in Philadelphia who didn't think B Corp model is currently scalable hope it will be eventually. For example, the Philadelphia manufacturer who found B Corps currently boutique, initially responded to the question by stating, "That's the big question. I don't know, but hope so. If it grows large enough, there will start to be a changeover... We need radical transformation... change of laws to focus on multiple bottom lines, not just profit; [to create a] fundamental shift. We can create opportunities to help people make change. [Then there could be a] change factor." The health firm stated they "hope it's scalable. Lots of businesses see the value. They are socially responsible and [pursue] more than the bottom line... There are people in the movement, who are 
democrats and republican. B Corps are nonpartisan.” The graphic designer sees B Corps currently as a niche market, now wants to see expansion and in the previously mentioned quote, saw potential for a market-level change if a large corporation becomes a champion.

Similarly, a couple Portland firms believe the model's scalable but hoped to enhance its potential. The consulting firm said, "it will become more widespread if more know." The software firm explained, the "biggest barrier is to make the case to larger entities." The marketing firm said "It will help by getting competitors" and added “[which] will help with my brand, too." Thus they even saw potential to impact their business if the model grows, a view not necessarily shared by other interviewees, as explained in the next section.

\section{$\underline{\text { Scalability Concerns }}$}

A couple firms shared concerns about the B Corp model's scalability, not necessarily viewing that level of growth positively. The Portland wholesaler thinks B Corps are a scalable model but fears "[what happened with] organic...fair trade... large companies... Labels... made them less trustworthy. Growth equals more red tape and it becomes tougher for little companies; small firms can't follow the rules or [pay] license fees." But that firm also thought "B Corps won't appeal to major corporations." Another Portland firm-the tech service provider-sees B Corps as scalable but warned, when a firm "expands to a global distribution model... it becomes more complex." The Philadelphia marketing firm reinforced this concern, warned of lowered standards 
following increased scalability and explained, "the problems of [increased] certification are that demand goes up which means quality goes down. So [you have to] update the standards constantly... If everyone is a B Corp, it has less meaning." The interviewee worried that B Lab would lower the standard so they could increase the scale, reducing the rigor and standard of the certification. But that same firm still had hope in potential benefit and went on to say, "But it can push the economy as a whole to embrace values. We can improve workers, the environment, and society as a result of B Corps; and [contribute to] creating good."

Secondary news sources provide an example of the aforementioned scalability concerns. One large Portland-based B Corp has fallen under scrutiny at times and received a fair amount of press, including around B Corps status. New Season's Market, a regional natural grocer chain, has been accused in the past by employees of unfair labor practices, union-busting and of greenwashing. While in a dispute around union organizing, employees contacted B lab to voice concern around inconsistency at the company and request revocation of the B Corp status. However there did not appear to be follow up, thus presumably resolution was reached (but no other news articles were found). Moreover, B Lab provides a method to contact them and challenge a company's report, and they also may audit the company at any time. ${ }^{33}$

Then more recently, after considerable growth and expansion into new stores and regions, NSM was sold to the larger, non-local company, Good Food Holdings out of South Korea. Within weeks of the announcement, some employees found themselves

${ }^{33}$ Certified B Corporation Complaints." https://bcorporation.net/complaints, accessed December 10, 2019). 
temporarily out of work, when their kitchen was closed down (Herron 2019). However the still-local management announced quickly that wages would be paid and work would continue (Herron 2020). Moreover, the new company does not have a bad reputation, even if not necessarily at the B certified standard, but claims to be "dedicated to investing in local food retail companies where we can each maintain our own unique and deep relationships with customers that we have in our local community" (Davidson 2019). The local establishment announced continued commitment to their ethical practices and to the certification status. Regardless, the social media coverage observed (anecdotally) by this researcher, was highly critical and skeptical, even calling for a boycott. The question arises if a non-local company is automatically distrusted for being non-local, is the Portland localist consumer base too skeptical and will fallout follow, leading to the market's demise? The question addresses what happens when firms scale up, and out beyond location. How do local policymakers deal with the conundrum? Moreover, how will B Lab handle criticism if backlash threatens their certification branding?

Overall, while concerns persist and the example aside, interviewed firms mostly were mostly hopeful about the prospect and benefit of scaling up. Portland firms especially saw more potential and expressed less reservation about that potential. Several Philadelphia firms may have found B Corps to be a niche market, but they also expressed hope and potential about future scalability. 


\section{KIs on Scalability}

While interviewees in both cities perceived potential scalability of the B Corp model and expressed some concerns, KIs were overwhelmingly optimistic. These findings were confirmed by both Philadelphia and Portland KIs.

Specifically, KIs in both cities differed in their views regarding whether or not B Corps are scalable or niche. A Philadelphia KI expressed hope that it was scalable but currently identified B Corps as niche. Whereas a Portland KI assuredly affirmed that B Corps were not niche and are definitely scalable. Furthermore, the Philadelphia KI stated the value in the "lots of ways to create impact... such as through ethical supply chains," and stated they hope the model scales "massively," at least through strengths at the "panindustry/region/ impact area [level]," but they emphasized how tough it was to truly scale that impact. However the Portland KI emphasized their observation of accessibility and the many options, to indicate scalability. Generally distinctions between the two cities were not as pronounced in their observations about the ultimate potential impact of B Corps. Ultimately, the significance of the potential for scalability may be relevant to motivation for participation, and to their desired scale of impact. 
Table 6.1. Internal Impact

\begin{tabular}{|l|l|l|l|l|}
\hline Study Site & Workplace Shift & $\begin{array}{l}\text { Impact from } \\
\text { Community }\end{array}$ & $\begin{array}{l}\text { Tool for } \\
\text { Affirmation or } \\
\text { Evaluation }\end{array}$ & Impact of Process \\
\hline $\begin{array}{l}\text { Study } \\
\text { population } \\
\text { trends }\end{array}$ & $\begin{array}{l}\text { Impacted some } \\
\text { workplace } \\
\text { culture. Changed } \\
\text { some operations. } \\
\text { Created } \\
\text { assessment } \\
\text { process. }\end{array}$ & $\begin{array}{l}\text { Minimal impact } \\
\text { from Community: } \\
\text { No notable trends } \\
\text { across cities. }\end{array}$ & $\begin{array}{l}\text { Appreciated how } \\
\text { tool operationally } \\
\text { helped affirm } \\
\text { values \& evaluate/ } \\
\text { improve practices. }\end{array}$ & $\begin{array}{l}\text { Created an } \\
\text { opportunity for } \\
\text { external guidance. } \\
\text { Introduced new } \\
\text { tracking. Process } \\
\text { impacted firms. }\end{array}$ \\
\hline $\begin{array}{l}\text { Philadelphia } \\
\text { distinctions }\end{array}$ & $\begin{array}{l}\text { Staff Attraction: } \\
\text { Attracted staff in } \\
\text { a tight job } \\
\text { market for } \\
\text { employers. }\end{array}$ & $\begin{array}{l}\text { Some appreciated } \\
\text { being part of a } \\
\text { community. Some } \\
\text { felt no community } \\
\text { impact. }\end{array}$ & $\begin{array}{l}\text { Shapers: The tool } \\
\text { shaped how some } \\
\text { companies } \\
\text { evolved. }\end{array}$ & $\begin{array}{l}\text { Apprentices: } \\
\text { Appreciated } \\
\text { guidance \& } \\
\text { external network. }\end{array}$ \\
\hline $\begin{array}{l}\text { Portland } \\
\text { distinctions }\end{array}$ & $\begin{array}{l}\text { Affirmation: } \\
\text { Some reported } \\
\text { little change, but } \\
\text { reaffirmation of } \\
\text { what already do. } \\
\text { Gave staff pride. }\end{array}$ & $\begin{array}{l}\text { One firm felt } \\
\text { minimal impact } \\
\text { through } \\
\text { community. Others } \\
\text { felt no impact. }\end{array}$ & $\begin{array}{l}\text { Data trackers: } \\
\text { Appreciated a tool } \\
\text { to track metrics. }\end{array}$ & $\begin{array}{l}\text { Impact Evaluators: } \\
\text { Appreciated } \\
\text { opportunity for } \\
\text { improvement } \\
\text { processes. }\end{array}$ \\
\hline
\end{tabular}

Table \#6.2. External Impact

\begin{tabular}{|l|l|l|l|l|}
\hline Study Site & Clients/Customers & $\begin{array}{l}\text { Impact on } \\
\text { Community or } \\
\text { Markets }\end{array}$ & $\begin{array}{l}\text { Perceived } \\
\text { Scalability of } \\
\text { Model }\end{array}$ & $\begin{array}{l}\text { Concerns about } \\
\text { Scalability }\end{array}$ \\
\hline $\begin{array}{l}\text { Study } \\
\text { population } \\
\text { trends }\end{array}$ & $\begin{array}{l}\text { Little financial } \\
\text { impact. Secondary } \\
\text { impacts possibly. }\end{array}$ & $\begin{array}{l}\text { Only community } \\
\text { impact was on B } \\
\text { Corps or other } \\
\text { networks. }\end{array}$ & $\begin{array}{l}\text { Potential to scale } \\
\text { up. }\end{array}$ & $\begin{array}{l}\text { Niche market now. } \\
\text { Many wish large } \\
\text { corporations would } \\
\text { join but some fear } \\
\text { consequences. }\end{array}$ \\
\hline $\begin{array}{l}\text { Philadelphia } \\
\text { distinctions }\end{array}$ & $\begin{array}{l}\text { Minimal marketing } \\
\text { impact: Some firms } \\
\text { wished for greater } \\
\text { impact. }\end{array}$ & $\begin{array}{l}\text { Minimal market or } \\
\text { community impact: } \\
\text { Secondary data } \\
\text { reveals minimal } \\
\text { impact. }\end{array}$ & $\begin{array}{l}\text { Niche now: More } \\
\text { think it's niche, but } \\
\text { potentially } \\
\text { scalable. Some } \\
\text { fear it's not but } \\
\text { hope it is. }\end{array}$ & $\begin{array}{l}\text { Authenticity } \\
\text { concern: } \\
\text { Greenwashing } \\
\text { could occur. } \\
\text { Meaning \& quality } \\
\text { could reduce. }\end{array}$ \\
\hline $\begin{array}{l}\text { Portland } \\
\text { distinctions }\end{array}$ & $\begin{array}{l}\text { Small investor } \text { or } \\
\text { marketing impact: } \\
\text { May attract other } \\
\text { associations. }\end{array}$ & $\begin{array}{l}\text { Market growth \& } \\
\text { community impact: } \\
\text { Secondary data } \\
\text { reveals growth \& } \\
\text { some impact } \\
\text { including on B } \\
\text { Corps. }\end{array}$ & $\begin{array}{l}\text { Scalable: Most } \\
\text { think the model } \\
\text { can or will scale } \\
\text { up to a larger } \\
\text { market level. }\end{array}$ & $\begin{array}{l}\text { Accessibility } \\
\text { concern: Could } \\
\text { become less } \\
\text { accessible. }\end{array}$ \\
\hline
\end{tabular}




\section{Impact Summary}

\section{Impact: Internal}

While the motivations section addressed desired impacts, the study also identified both actual and perceived potential impacts. Firms described ways becoming a B Corps impacted them internally at the firm level, or externally beyond the firm level.

Additionally, they shared their perceptions about the potential of impact at a macro level.

The most notable impact occurred as a workplace shift. Firms observed a change of workplace culture including some changed operations and the creation of an internal assessment process. Philadelphia firms found through participation as a B Corp they connected to a larger community and attracted more and quality staff. Some Portland firms reported little change, but found becoming a B Corp helped them reaffirm what they already do. Other Portland firms found the B Corp label gave staff pride.

Another impact for a few (but not many) firms, primarily in Philadelphia, came from community connections. Some Philadelphia firms appreciated being part of a community. However a few felt no impact from the community.

More significant for firms in both cities was the use of the tool to affirm or evaluate how well they achieve their values in their practices. In Philadelphia, The tool shaped how some companies evolved. Portland firms appreciated having a tool to track metrics. Generally, the process of becoming a B Corp itself created a substantial impact. The assessment process created an opportunity for external guidance, introduced new tracking tools, and led to changes within the firms. Philadelphia firms especially 
appreciated the guidance and external network. Portland firms appreciated the opportunity for improvement processes.

\section{Impact: External}

Externally, firms had less to report in terms of impact and more about their perceived potential. They reported minimal market-based impact, but still believe in the potential to scale up, although with some concerns about scalability.

In terms of clients and customers, firms observed little financial gain, although possibly some secondary impacts. Philadelphia firms wished for greater financial or marketing impact. However Portland firms observed the possible attraction of other financial partners, such as investors, even if they did not directly draw in more patrons to their business.

In terms of impacts on the external community or on markets at large, the only observed community impact affected other B Corps or the other ethically-oriented networks. Examination of secondary data implies very little impact in Philadelphia, given the extremely limited growth in the number of B Corps, while more substantial impact in Portland, where the number of B Corps nearly quadrupled.

Regardless, both interviews and secondary data sources imply potential scaling up of the B Corp model. Interviewees largely believe in the scalability potential. Many Philadelphia firms think it's a niche market now, but potentially scalable in the future. Some fear it's not but maintain hope. Most Portland firms had stronger conviction about the scalability potential. Many firms in both cities want large corporations to join but 
some fear consequences. Philadelphia firms warned greenwashing could occur, or that if it grows too big, the certification's meaning and quality could reduce, as happened with other certification campaigns. A couple Portland firms worry that growth could result in less accessibility.

\section{$\underline{\text { Conclusion }}$}

Generally, participants did not observe direct market impacts, but saw internal impacts, and many had hopes they were part of a growing scalable model, that at minimum, might contribute to a future market trend of more ethically-oriented business practices.

There is a potential contradiction as occurs in other certification processes. As certifications grow, they can become susceptible to greenwashing. In order for standards to reach more audiences, they also become more forgiving to accommodate larger scale players. Additionally, the B Corp certification process is reportedly demanding, and smaller firms may have fewer resources (time, money, capacity) to handle the process. However a large firm has resources. Thus while the standard appears to appeal most to small firms, the lack of a demonstrated marketing advantage may remain a deterrent to large, publicly traded corporations. Patagonia and Ben and Jerry's have niche markets themselves, thus these examples don't necessarily support substantial scaling up potential. Yet, there remains reason to support the notion for other corporations of their size, to follow suit. Perhaps the opportunity to best advance the potential scaling up of B 
corps, is for current B corps to grow substantially enough, then to demonstrate their model through example. 
Chapter 7: Conclusion 


\section{$\underline{\text { Research Agenda }}$}

\section{Why the Research Matters}

To date, much of the literature on ethical markets has focused on consumers, the research on social entrepreneurship has focused on firm behavior, and the research on community-advocating local policy often emphasizes nonprofit or public sectors. However, as local culture gives rise to ethically-oriented business practices with local firms, clients or consumers, a new place-based ethical market evolves for academics, advocates, and policy-makers to examine. Ethical markets are not primarily about either firm or customer, but both along with institutions and culture that connect them, and no longer reflect primarily a Global North/South dichotomy. Rather at the local level there is the prospect of social change with the possibility of extending impact outwards and upwards. Thus, as globalization studies often address the impact at the local level of global forces, this research launches an effort to consider how local urban communities can initiate local change that extends outward, to help foster alternative markets.

\section{$\underline{\text { Research Goals }}$}

The purpose of the study was to investigate the implementation process and effectiveness of ethical markets within a place-based context, with a focus on B Corps as a tool to foster positive social outcomes. The study aims to identify impediments, opportunities and emergent practices through an examination of the process and outcomes of B Corps certification. Specifically, the study looks at motivations, location- 
based factors, and impacts to better understand the potential and limits of certified benefit corporations as a tool for ethical market practices.

This research investigated B Corps to assess how they identify and evaluate their social benefits or outcomes. The research explores outcomes of these specific ethical market practices primarily at the company level as well as a within and across city level. The study uses interviews with B Corps and Key Informants (KIs) as well as secondary data from B Lab assessments to review business and place-based processes and outcomes. The goal was to reveal the emergent ethical market practices and the identifiable supporting or contributing conditions, and also to consider how B Corp certification enables businesses to pursue ethical market outcomes. The primary research question was: What are the factors influencing the adoption of certified benefit corporations as an ethical market practice, and what contextual factors facilitate or impede SBC adoption and outcomes?

The research also evolved to address the following secondary research questions:

- What are the motivations for companies to become B Corps and how do B Corps evaluate the value of participation?

- What place-specific factors enable or hinder B Corps including the local cultural, relational or institutional supports and challenges?

- What are the potential and perceived impacts of becoming a B Corp? What may encourage or limit these impacts and what is the potential scalability?

\section{Expected Findings}

In relation to the three secondary research questions, when the study began, the following findings were expected: 
Finding 1: The pursuit of positive social outcomes will be a primary, but not exclusive motivation for B Corps participation.

Finding 2: Place will play a role in the success and limits of B Corps. There are identifiable place-based conditions which may inform or impede the successful establishment of local ethical markets.

Finding 3: The process of becoming a B Corps will enable businesses to produce positive social impacts by providing a tool for their participation within a local ethical market.

Overall the research addresses how B Corps perceive markets as an arena for political change or tool for social outcomes, whether participation is another form of social entrepreneurship, as well as factors which contribute to or impede success and subsequent implications about ethical markets. Specifically, the research questions and methods investigate the motivations behind participation, the contextual location-based factors, and potential impacts. The theoretical discourses address political/ethical consumerism and markets, social entrepreneurship, economic development and localization of innovation, as well as social change and alternativeness (to mass production and economic globalization). The research considered the study's main theoretical discourses within the context of B Corp participation and the findings have applicable theoretical implications.

\section{Findings \& Theoretical Implications}

The findings have interesting implications for all of the addressed theoretical discussions, and contributions to scholarship. The findings in each chapter have 
implications for one primary theoretical discussion in the context of responses to a research question and expected findings.

\section{Motivations: Political Tool \& Social Entrepreneurship}

The study aimed to identify motivations for participation and to assess whether the pursuit of positive social outcomes was a primary, but not exclusive motivation for B Corps participation. Specifically the findings address how B Corps display markets as a tool for political change, and whether participation is a form of social entrepreneurship. The Motivations chapter reviewed data and presented findings to address the secondary research question: What are the motivations for becoming a B Corp and how do B Corps evaluate the value of participation? The research addressed the following theoretical implications for B corp participation:

1. How do participant motivations demonstrate markets as a tool for political change and/or social/community outcomes?

2. Is participation a form of social entrepreneurship?

\section{$\underline{\text { Tool for Political Change }}$}

How do the findings present markets as a potential tool for political change

and/or social/community outcomes? The achievement of positive outcomes appears to be a clear goal of participation in the B Corp membership. However, motivations vary from an interest in the small-scale impact of a single firm to an industry-specific larger impact, or to a desire for full shift of global market practices. Overall, motivation to create social change is an identified goal, thus suggest a degree of an underlying political motivation, 
but the specific goals may vary by firm. Many participants want to have a tool that leads to impact and evaluation of impact. Measurement of significant impact is outside the scope of this research-achievement of B corp certification indicates a minimal level of outcome, but the larger societal impact is too small to measure at this stage or with this research. Regardless, the frequent drive for market change suggests a goal of large-scale societal change, particularly in the context of outcomes equal to, or greater than, profit impacts. Additionally, the drive for a local or community impact, also suggests a desire to enact societal change, even if at a small scale. A very small number of firms primarily desired a workplace impact, not necessarily as distinctly change-oriented, however one could argue this model of workplace advocacy is political, too, as the act of B corp participation does not aim for economic value. Thus, while all the firms did not necessarily self-identify as political activists (and some did), their frequently conveyed desire for impacts reveals an underlying political motivation for change.

As a reminder, Micheletti (2003) describes the concept of political consumerism as a tool adopted by individuals, groups, organizations or regions to provide alternatives to market processes that are under the control of global forces. In the context of this research and that definition, the firms appear to be the adopters of a compatible tool, as the initiators of the market. Firms want to impact their community, the world, or to provide an alternative to mass corporate-based markets. More Philadelphia firms wanted general impact, while more Portland firms wanted a local impact. Otherwise, the pursuit of an alternative way to run a business or participate in markets appears to drive much of the motivation across cities. There is a general drive to change global businesses. Yet, 
there was less attention directed towards global markets at large. This is perhaps not surprising, as it is not necessarily realistic for small firms to change these global systems. However, interviewees expressed hope for this and compatible movements to grow, to be part of a global shift, a goal that several interviewees report as essential. This is covered in greater detail in the Impact section.

How firms came to participate is also relevant to the political intentions of participants. Most Philadelphia firms were Networkers, recruited to B Corps by a network they were already in. Some Portland firms were Early Adopters and started their firms with B Corps in mind. When unpacking their motivations, Philadelphia firms were often more Communitarian, and were motivated to participate in the network as well as to support workers. Many Portland firms were Change-makers, more general in support, they wanted to change markets. Essentially, Portland firms may be more politicallydriven than Philadelphia, though both were driven on some level to create change.

As briefly mentioned, the 'tool' itself is important. Participants in both cities appreciated the opportunity to use the B Corp assessment tool to track (impact) metrics, to measure and monitor improvements. Though through slightly different means, firms in both cities professed genuine desire for change and assurance of their positive impacts, by using the tool for validation or evaluation of their practices, most often in Philadelphia and Portland, respectively.

In response to the question - How do the findings present markets as a potential tool for political change and/or social/community outcomes? - participation seemed largely driven by a desire for impact and to have a tool to achieve that impact. While 
participation in both cities seemed largely geared towards creating that positive social impact, the means and goals to achieve that impact vary somewhat between the two cities. Philadelphia firms seemed more inclined to participate as part of a local community network following exposure to the concept of B Corps. More Portland firms pursued participation in active pursuit of a larger-scale change. Perhaps Philadelphia firms are arguably more ethically rather than politically driven, towards impact versus change. However, such a debate is potentially semantic at best, as overlaps between ethical impact and political change are not significantly distinct enough to be highly meaningful. More significant is how participation enabled firms to have the tools to achieve impacts.

\section{$\underline{\text { Social Entrepreneurship }}$}

Is participation another form of social entrepreneurship? A triple bottom line (TBL) approach appears to motivate some firms, while a few profess to want a marketing advantage from participation, but most firms more greatly emphasize being impactdriven or change-makers. In consideration of social entrepreneurship, it's worth first asking, whether general entrepreneurship is a motivator. Many of the interviewees desired the traditional benefits of business-profit and economic success or a marketing advantage-however these goals did not seem to inspire B Corp participation. Yet everyone explained participation required some effort on their part and did not pay off as a significant marketing or competitive advantage. Some achieved other advantages such as high employee morale, or benefits of participation in a network. For example, some 
firms desired to attract and retain good staff and saw the benefit of participation on morale, often during their internal assessment of how effective they were at achieving their values. Other firms wanted to communicate their values, but even when the audience was their customer base, the firms seemed genuine in their dedication to those values.

However, several firms were disappointed to not achieve more profit from participation. At the end of the day, they are firms, and to survive need a positive account balance. Moreover, they saw the success of their firms and the B corp network as advocacy for their values. Additionally, while participation or membership in the community-at-large of B corps was rarely a primary motivator, some firms desired a greater value from participation in the network. Thus, for some firms the entrepreneurial benefits overall could perhaps be further identified, valued or promoted, but overall their motives seemed primarily integrity, and in this way illustrated a degree of a social entrepreneurial motivation-a triple bottom line approach to create positive social impact yet also achieve economic success.

Yet, the desire for a marketing advantage or financial gain, could bring up questions of integrity for other participants, wary of greenwashing. Firms across cities largely hoped to convey ethical practices to a wider audience. Philadelphia's Authenticators and Portland's Communicators both hoped to broadcast their ethics to a larger audience, with small distinctions between the cities. More Philadelphia firms wanted to demonstrate their authenticity - not by greenwashing - through certification. More Portland firms wanted to make their customer base aware of their values. 
When it comes to how a business evaluates value, firms in both cities leaned towards traditional assessments of financial solvency. They measure financial value, though some Portland firms also measure impact. When they define success, most firms also hope to achieve financial success, however firms in both cities (especially Philadelphia) emphasized community impact over financial value.

Thus, in response to the question - is participation another form of social entrepreneurship? - there appears to be a small aspect of social entrepreneurship included as part of participation, but little indication of general entrepreneurship as a primary motivator. Some firms express a desire for financial or marketing advantage, but neither firms nor KIs identify entrepreneurship as a primary motivation equal to or over the over the underlying desires to achieve impact. However, there does seem to be a desire among a few participants, to achieve some financial or marketing advantage by broadcasting how a firm demonstrates its commitment to impact.

Motivations \& Evaluations: $\underline{\text { Implications for Political Consumerism \& Social Entrepreneurship }}$

Overall, in response to the secondary research question - What are the motivations for becoming a B Corp and how do B Corps evaluate the value of participation? - the pursuit of positive impact or changing business practices is a primary motivation, but a social entrepreneurial benefit inspires some participants. How participants evaluate the value of participation includes emphasis on impact, however they also hope to maintain, and in some cases improve, traditional business success such as of financial solvency. It's also important to note that the desire for financial achievement or a marketing advantage 
is not necessarily dichotomous with a motivation to pursue positive impact. The implications for political consumerism demonstrate how local markets can be an arena for political action; and a tool for social and community outcomes. The implication for social entrepreneurship is a demonstration of how business practices in pursuit of positive social impact though participation in an ethical market, may be social entrepreneurial, but may be mostly inspired to create a greater level of change.

If the question was presented as to whether motivation is primarily social entrepreneurial or if motivated by political or ethical markets, participation appears to be more of the latter based on the findings. More participants appeared to want to be part of an overall change of markets and practices, rather than primarily having a business that does good. Even if the business purpose is about doing good-for example, the product or service has a social benefit-the greater motivation to become a B Corp, was to model businesses that do good, as part of a change-making movement.

The differences between ethically-driven businesses and social entrepreneurs may seem small, but are important. While participants are not clearly one or the other, there is a distinction between businesses which aim to include a social impact, and businesses which want to use their firm to be part of a larger movement for changing business practices. Businesses can be both. In cases where the firm's good or service is geared towards social change, they may be more of a social entrepreneur, an example of the hybrid model. In cases where the firm wants to evaluate and change every aspect of their business practice, they may behave more like change-makers. One possible distinction, is those businesses which are also entrepreneurial in a general way and hoped to achieve 
some traditional benefit from participation. The question comes up whether the motivations are altruistic or self-interested, however that discussion itself is a rabbit hole given how one could argue that impact-driven actions of a political or entrepreneurial nature, are potentially either altruistic or for self-interest. To stay consistent with the study's main goals and reiterate, the findings suggest an influence of both political consumerism and social entrepreneurship, as these two tendencies can be compatible, however the change-making motivation was stronger overall.

\section{Location: Localization \& Agglomeration}

The study also aims to investigate location factors that influence firms to become or sustain as B Corps. Responses considered the study's main theoretical implications for B Corp development, with emphasis on economic development and localization and agglomeration, in the context of ethical markets. Specifically the findings begin to identify location factors which influence B Corp development, as an example of a localized innovative cluster for ethical markets. The Location chapter reviewed data and presented findings to address the secondary research question: What place-specific factors enable or hinder B Corps including the local cultural, relational or institutional supports and challenges? The research addressed the following theoretical implications for B corp participation:

1. What is the role of place within ethical markets? What location factors offer supports or challenges?

2. To what extent does location support ethical market practices to generate local agglomerative effects? 


\section{Location Supports \& Challenges}

Local support-from relationships, local policy and institutions of civil society, and local culture-seems to be a significant contributing factor to B Corps presence. During the interviews, B Corps were asked questions about local supports or challenges, and about their relationships with other B Corps. Key informants (KIs) were asked to explain their role in providing support to B Corps, as well as how they became involved with B Corps.

Networks-formal and informal-enable the relationships to flourish. Relationships promote and strengthen. They are collaborative with other B Corps unless virtual. Among interviewees, Philadelphia B Corps more frequently collaborate within a Formal Network and appreciate a network advantage. Portland B Corps more frequently collaborate with several Informal Networks and experience some marketing advantage.

Nonprofit institutions and advocates encourage policy and promotion of B Corps. Policy enables and legitimizes participation. Institutions and their policy support make B Corps and SBCs possible. They include public, nonprofit and for-profit supports. Philadelphia supports appear more Centralized and two primary institutions help, while city tax processes create an impediment for some firms. Portland supports appear more Decentralized, with support dispersed, and no particular challenges noted by firms.

\section{Policy and Change-making}

The identified location-based supports do not necessarily indicate a larger political movement but suggest a push for social change. They are certainly pushing for 
policy change or impact on social and environmental arenas, as well as on markets at large. Some participants appear to perceive themselves as participants in a movement. This appears applicable to some of the firms, in both cities, as well as the perceptions they shared about their clients, customers, etc. The firms' frequent reference to local culture, especially in Portland, suggests a cultural anomaly. Whether or not this cultural trend indicates a local distinctiveness, competitive advantage, or cultural shift potentially resembling political action, is debatable, but relevant.

However it seems worth noting that firms perceive their participation differently than their supportive KIs. Moreover, relationships with other B Corps seem important to the firms, and to provide essential support. While not exclusively locally-focused, they mostly are, and provide at minimum comradery, but also a potential marketing advantage. In Philadelphia, these relationships appear to provide a craved sense of community and connection centered around positive social impact. In Portland, these relationships seem to help validate or enhance commitment to ethically-oriented business practices. Regardless of the firms' reported importance, at minimum, passage of the legislation is an essential step towards establishing a local B Corp presence.

Interestingly, the influence of public sector and civil society appears to be more apparent to the KIs. The firms themselves emphasize more the relevance of local culture. To a degree firms even identify some civic aspects as challenges, such as local taxes in Philadelphia, or limitations of local industries and markets.

Cultural attitudes, activism trends, and the business climate are generally supportive. The economies pose limits. Firms describe Philadelphia's culture as Socially- 
minded, and socially aware. The city is a good size, affordable and supports small business, but is experiencing a brain drain. According to firms (and as reputed) Portland's culture emphasizes Localism. The city is locally, community and sustainably-minded, and is a good size for small businesses but potentially too small a market for significant growth.

\section{Place-Based Supports}

In response to the question - What is the role of place and what location factors offer supports or challenges? - all the location factors seem relevant, but with varying degrees of influence between the two cities. In Philadelphia, formal-network-driven relationships and centralized institutions are most essential supports, whereas civic demands pose some challenges to small businesses. Civil society seems essential, given proximity to two key institutional influences. Culture is supportive due to being sociallyminded, but is not necessarily as essential. In Portland, informal networks and decentralized relationships are supportive, but culture is reportedly the driving force, particularly Portland's change-making culture. Portland firms and KIs describe a large cultural climate to support ethically-oriented business. Challenges were minimal but for some firms, the size of Portland and its markets are too small to allow substantial growth. Overall while public support helps, the establishment of more substantial support may be dependent on numerous location factors. A city may either have a couple key civil society actors (as in Philadelphia) to launch or maintain a local ethical market, or a 
cultural climate that supports relationships and provides promotional opportunities to enable growth (as in Portland).

\section{$\underline{\text { Economic Development and the Localization of Ethical Market Practices }}$}

The findings suggest the possible economic development of a localized cluster, given the growing and sustained infrastructure developed and maintained in both cities to support B Corps. There does appear to be some perceived marketing benefit or shared promotion of participation in B Corps' ethically-oriented business practices.

Additionally, there is potential for clusters to arise, as well as spillover effects between supporting networks or through local civil society, and possible competitive advantage. However, a cluster is far more established in Portland than in Philadelphia.

The potential to foster a local cluster may in part be industry-specific, perhaps consistent with industry types at large. In other words, a local cluster may be most likely to develop if the location supports that particular industry needs. On one hand, most B Corps identify some degree of local relationships, infrastructure and supports. However, for industries dependent on a large market sector such as for distribution or production, the scale does not seem to reach the level of need, thus those firms seek and maintain relationships outside of the local vicinity. For firms that operate remotely or virtually, location is not necessarily relevant, but they appreciate participation in the local network, as well as to have business relationships outside of the local area.

Yet notably, an ethically-oriented market cluster (EMC) does appear to have evolved in Portland. Both the Portland interviews and data on the growth rates suggest 
this, along with the evolution of recent local collaborations and the partnerships among artisan beverage industries (wine, tea and coffee). Most notably, Portland has appeared to reach a critical mass/cluster of ethical market businesses that has allowed it to keep building momentum, while Philadelphia has experienced minimal growth, at a rate lower than the national average, despite the proximity to B lab. Currently there appears to be an evolving EMC in Portland with the knowledge spillover focused on ethical market practices. However, there also appears to be an industry-based EMC cluster, as well, which not only helps to establish that industry and participating firms, but may enable participating firms to draw greater attention to ethical practices by broadcasting their shared ethics via B Corp certification. Thus the potential exists for further expansion both locally and beyond, the ultimate goal of B Corps and EMCs that aim to change business practices at large.

In response to the question - To what extent does location support ethical market practices to generate local agglomerative effects? - the capacity for innovation within a location for B Corps seems partly determined by the scale and type of operations within a firm. As mentioned, if a firm wants to operate at a larger scale, they may experience limitations for growth and potentially impact. However a firm in an industry already well supported locally due to the local culture (for example sustainability firms in Portland), may achieve greater success. 


\section{$\underline{\text { Place-Specific Factors }}$}

In response to the secondary research question - What place-specific factors enable or hinder B Corps including the local cultural, relational or institutional supports and challenges? -culture appears to play a dominant role but institutions and relationships are important, while cultural support can even lead to an industry cluster depending on the scale and type of firm, including an ethical market cluster (EMC). Institutions, including those which support legislation, foster networks and relationships which in turn may be most influential in an environment that has several dispersed networks and a highly supportive local culture. These intersecting factors may be the enabling characteristics which generate an EMC: policy, decentralized and informal networks, and strong locally-focused culture. The cluster may not necessary help individual industries thrive-for example if they rely heavily on non-local, large, or virtual markets. Yet all participating firms may experience some type of local advantage, simply by participating in a highly supportive cultural climate, which may in turn increase the potential for wider-scale impact. The findings demonstrate the potential for an EMC to evolve within an urban area, to establish how location factors can support ethical market practices to generate local agglomerative or clustering effects.

\section{Impacts: Local Ethical Markets \& Social Change}

The study also pursued insight into participant perceptions about impact of the B Corp movement, as well as about potential for a future market expansion. Specifically the findings address B Corps' perceived impacts, the types of impacts, what factors 
contribute to or impede success, and potential scalability. The Impacts chapter reviewed data and presented findings to address the secondary research question: What are the potential and perceived impacts of becoming a B Corp? What may encourage or limit these impacts and what is the potential scalability? The research addressed the following theoretical implications for B corp participation:

1. How do ethical markets potentially provide an arena for alternativeness or social change and what location-based factors contribute to or impede success?

As already mentioned, a primary motivation for participation was to have a tool for evaluating or validating ethical business practices and impacts. Motivations alone are not necessarily impactful, thus the research also investigated the perceived or potential impact of participation.

\section{$\underline{\text { Internal Impact }}$}

Most notably, the findings revealed several impacts internal to the firm. Specifically these impacts were experienced as changes within the firm such as on workplace culture, or on general business practices. For example in workplaces, the achievement of B Corp certification either helped to attract (in Philadelphia) or inspire (in Portland) employees. An example of a changed business practice was how firms were able to evaluate their impact. Generally, primary impacts revealed in the research were on how firms run their businesses and on internal workplace shifts.

As already re-mentioned, a primary motivation for participation was to have a tool, and also relevant is the use of the tool. One finding of the research indicated how 
becoming a B Corp provides a tool which is used internally for a firm to self-evaluate or affirm their practices, a key impact for many firms in both cities. The tool provides evaluative metrics to examine multiple aspects of the firm, not just in terms of what the firm does, but also how they run their business. There was a little variation across cities, as some Philadelphia firms-the Shapers-used the tool to shape how their businesses evolved, while some Portland firms-the Data Trackers-used the tool primarily to have metrics to examine their businesses, thus could presumably improve their business practices. In this capacity, participation provided the means to actually change the firms, given that certification evaluated components of a business' purpose, as well as how the firm conducts business. Additionally, the tool helps a firm contribute to political or social change, as a step towards an alternative type of market that is ethically-driven.

Many firms also indicated they changed throughout the process, as a result of participation. More Philadelphia firms (Apprentices) change how they reviewed their practices under the guidance of the external network. More Portland firms (Impact Evaluators) used the process of certification as an opportunity to improve their own processes. Additionally, certification had an impact on workplace culture, which for some participants was significant. Certification helped Philadelphia firms attract staff, or provided an affirmation to Portland employees. In both scenarios the internal workplace impact appeared to be a shared improved morale. Moreover, given how both Portland and Philadelphia have tight labor markets, the ability to attract staff may be an important internal impact, particularly given how younger people reportedly look for work with meaning. 


\section{External Impact}

While primary impacts were internal to the firm, there were some impacts potentially understood as external, but with minimal reach. Specifically these impacts could also be indicative of growth, experienced as either the firm's ability to (potentially) recruit external capital to the firm, or to have an external impact on community or markets. Within this study, neither impact was substantial or frequently reported, when compared with internal impacts.

While external impacts were small, there were some distinctions between cities. Some Portland firms attracted small investors or described a marketing impact, while Philadelphia firms reported little growth, except a couple obtained a minimal marketing impact. This difference could in part reflect a variation in local markets, with a greater effort to stand out in Portland's more saturated sustainably or locally-minded market. A few Philadelphia firms hoped for a greater advantage because of the competitive nature of business-at-large.

Possibly, firms experienced an additional, though unreported marketing advantage. Upon reflection, one may suspect the internal workplace shifts could provide an element of CSR-a type of marketing advantage-as employees developed or grew positive perceptions about their firms, and then theoretically could present as ambassadors or social marketers on behalf of the firms. Thus, though speculative, in either a competitive or tight job market, certification may help with employee retention and boost the company's reputation. 


\section{Ethical Markets: Arena for Alternativeness \& Social Change}

While measurement of external impact was beyond the scope of this study, the findings certainly suggest potential for impact. B Corps are too small and recent a phenomenon to demonstrate significant impact on communities or markets-at-large, yet the data suggests some preliminary impacts in both cities. Philadelphia firms perceived only a minimal impact at best, but secondary data revealed a small impact on growth. Portland firms reported some indication of market growth and community impacts, backed up by secondary data as well, revealing a higher-than-average growth rate for B Corps, while some reported impact on B Corps-at-large, as well. While impact may be difficult or too small to demonstrate, the actions and practices, and networks to enable both especially at a local level, suggest a movement of globalizing from below.

\section{$\underline{\text { Potential for Successful Impact }}$}

In response to the research questions - What are the potential and perceived impacts of becoming a B Corp? What contributes to or impedes success? - the process of becoming a B Corp sets up potential for businesses to produce positive social impacts by accessing a tool for ethical market promotion and participation. There are implications for alternativeness and social change, as B Corps provide an example of how ethical market clusters may arise, with sufficient supportive contextual factors. Internal impacts seem more significant as a tool to shift workplace culture or provide a tool for evaluating impact. External impacts show potential to attract capital and expand to a wider scale, with the right set of supportive contextual factors, as better demonstrated in Portland. 
However, given how as one interviewee reported, younger people are looking for work with meaning, being a firm with ethical practices could actually become a strategy for firms to attract and maintain staff. Perhaps the most significant and identifiable impact, was the growth in Portland's B Corp market and seeming evolution of both an ethical market cluster, as well as a specific industry cluster (wine). This evolution suggests potential for a cluster that prioritizes impact at equal or possibly even a greater level than other industries locally or beyond.

However, such impact only matters and truly provides an alternative, if substantial enough to present widely-enough spread market choices. One primary issue to consider, in an effort to deeply understand potential impact, is about perceptions and observations regarding scalability (specifically for a scaling up). There was strong support from firms and KIs about the possibility for more firms including large corporations to become B Corps, but with some variation between the two cities, and also with some concerns expressed about consequences of this growth. For the most part, Philadelphia firms thinks B corps are niche, but potentially or hopefully scalable. Portland firms mostly think the model can or will scale up to a larger market level. Several Philadelphia firms, in keeping with the emphasis on authenticity, also express concerns that scaling up brings in the risk of greenwashing, which could lead to a reduction in meaning and quality. A few Portland firms worry scaling up could reduce the accessibility of participation. Thus, while perceptions about potential for scalability differ between the two cities, firms in both have concerns about whether scaling up could also have negative consequences. Regardless of whether scalability is decidedly more 
encouraging or concerning, the findings have implications about social change by demonstrating how locally based ethical markets may potentially offer alternatives to the mass production and corrupt corporate practices within economic globalization models.

\section{$\underline{\text { Conclusion }}$}

In summary, in response to the study's primary research question - What are the factors influencing the adoption of certified benefit corporations as an ethical market practice, and what contextual factors facilitate or impede B Corp adoption and outcomes? - there are identifiable motivations, location factors and potential impacts that largely favor the urban evolution of effective ethical markets. The pursuit of positive impacts or political change appears to be a primary, but not exclusive motivation for B corps participation. Location plays a role in the success and limits, with identifiable conditions around culture, institutions and relationships. The right combination of conditions (emphasizing a strong local change-making culture) support or help grow ethical markets, including enabling an ethical market cluster (EMC). Participation enables business to produce positive internal and external impacts with potential to grow ethical markets as an alternative option to the major economic globalization models. There are also potential limitations as well as risks, even if markets scale up. Yet, given the growing interest in ethically-driven businesses, cities can surely play a role in the 
development of supportive and limiting policies, and thus have the opportunity to foster locally-based ethical markets.

\section{$\underline{\text { Critiques }}$}

If ethical markets expand and gain traction, given rising support from key global and local actors, and EMCs evolve substantially, questions arise about how they might shift and whether reception to them will shift. If culture supports local and ethical markets, what if the standards are not met or firms make mistakes? The rise of 'cancel' culture and rapid communications and impact via social media, threaten to derail not only a company, but also the movement.

The case of New Season's Market (NSM) presents a potential conundrum. Portland's seemingly most recognized B Corp, has received press around its B Corp status, and is often questioned if deserving or if ethical enough ${ }^{34}$, resulting in protests all the way up in Seattle. ${ }^{35}$ On one hand, the interviewees and B Lab's website, emphasize a major goal to recruit larger corporations for participation. Yet when they do-for example NSM's recent buyer is a large international corporation-public distrust in the company appears to grow. ${ }^{36}$ This event potentially threatens to reduce support for a company that scales up, if faced with obstacles to a positive public perception. Moreover, what happens if a company or certification becomes more mainstreamed? Can it become diluted like

\footnotetext{
${ }^{34}$ McIntosh, Don. "NW Labor Press Press New Seasons Market paid a union-buster a third of a million dollars." May 5, 2019. https://nwlaborpress.org/2019/05/new-seasons-market-paid-a-union-buster-a-thirdof-a-million-dollars (accessed December 10, 2019).

${ }^{35}$ The Stand. "Rally on May 9 in Seattle to reject New Seasons Market."https://www.thestand.org/2018/05/rally-may9-to-reject-new-seasons-market/(accessed December 10, 2019).

${ }^{36}$ Davidson, Kate. OPB. “New Seasons Market Selling To Good Food Holdings.” December 10, 2019. https://www.opb.org/news/article/new-seasons-market-portland-oregon-to-be-sold/ (accessed December 30, 2019).
} 
organic and fair trade or eco-products, or adopt false localism marketing? Is B Corp certification rigorous enough to maintain integrity, so participants continue to have ethical practices? Scaling up also implies location outside the city, so in that case, the local only matters as much as it supports or impedes firms and the B Corp movement or EMCs. Yet scaling up also achieves one possible objective: larger market change. Given international trade and distribution models, scaling up is an ideal impact to create market change. Yet with the scaling up, comes risks to the certification's integrity (if diluted by the large corporation influence), and also to perceptions about integrity. Thus, B Corps or EMCs may become victims of their own success.

Perhaps over time, B Corps or EMCs will seem most effective for a certain type of industry and market. As with Portland DIY, integrity is important, and there's distrust in growth, or in 'selling out.' B Corps may be most successful either by forming a local industry cluster that thrives on the supportive local culture, or if in an industry of doing good not just in, but through, business. Interestingly, a couple firms which struggled most were in health-related fields, where the greatest advocates are in nonprofit and the forprofit sector reputedly is less concerned about impact than profit. These firm types may have a higher uphill battle, because they're held to nonprofit standards of behavior, yet need investments from for-profit partners with little impact interest. That's where impact investment could play an essential role and become increasingly relevant to the support and development of EMCs or individual B Corps.

Regardless of how successful EMCs become, if viewed through a critical theory lens, B Corps as for-profit entities remain dependent on capital flow which may 
ultimately limits potential for impact. If one accepts the Marxian perspective that wealth accumulation relies on exploitation of labor and resources, the movement as an important solution to societal problems seems flawed. Moreover, as B Corps grow or are franchised, their impact could lessen; and the question still persists, if a firm's survival is dependent on profit, how many firms or shareholders will approve of less money, in favor of greater impact? What happens during tight economic conditions, and can every firm enable equitable access to their goods and services, regardless of whether they otherwise demonstrate ethically-driven business practices? Worth noting, however, is the simultaneous potential for the local branch of a franchise, to influence behavior up the ladder-especially if they can make a case for ethical practices as a marketing advantage. Regardless, again a Marxian critique would not likely view growth in ethical markets or business practices as an appropriate solution to social programs, and warn of commodity fetishism or otherwise obscuring the necessary conditions for exploitation.

Other critics may warn that growth of impact-driven business could risk further devolution of the beneficent state, as social and environmental responsibility could be deflected into the private sphere. Moreover, some may worry that enabling business to exert additional influence over social and community benefits could transfer power further from state or civil society spheres, thus providing excess power.

Additionally, there's an irony if a firm's potential for positive societal impact is dependent on its growth. If growth also brings negative externalities, is that cost worth the gain of their positive impact? Moreover, if communities rely on impact-driven firms, will communities rely on growth? There is something problematic about this concept, 
even if mainly conjecture at this point, thus an issue to consider with additional future attention and thought. The issue is introduced in the nonprofit sector as well, where entire industries are supported by negative societal patterns. For example, Metro Regional Government is dependent on garbage fees to fund programs. Earnings from waste disposal fees fund waste aversion education and programs. If truly effective, theoretically the programs should lose funding by significantly reducing the volume of garbage, and thus their funding source. Similarly, Community Development Corporations and social service programs have entire organizations created to address social programs. If the organizations achieve all goals (which occurs rarely), they should defund as they lose purpose. Theoretically, regardless of the unlikelihood, if businesses are driven towards positive social impact yet meet all desired impacts and community needs, should they close down? Or become instead a traditional business? To reiterate, in theory, any impact-driven organization, if truly successful, will cease to be needed.

These critical arguments may all have merit. However, there is little reason to anticipate major threats currently or in the near future. The B Corp phenomenon has not shown any signs of growth (perhaps yet) at a rate sufficient enough to dismantle public or nonprofit sectors, which would have their champions if threatened. Plenty of corporations still prioritize profit, thus there is no forecast for profit-driven business to transition primarily to impact-driven. Moreover, the reverse scenario remains significantly true and one could debate which is more potentially threatening: the for-profit influence through lobbying over the public sector and dependency cycles in the nonprofit sector, or gradual cooptation of social organizations by impact-driven businesses? Perhaps growth of 
impact-driven business and EMCs can gradually help to lessen those lobbying influences and dependency cycles. Otherwise, the concepts of impact are still vague and broad enough, that it's hard to envision reaching a fully achieved level of impact. Finally, as the focus of this research is on the urban arena, local policy can presumably adjust to meet perceived changing needs of local communities and beyond.

\section{$\underline{\text { Policy Implications }}$}

What is the potential role for local policy? The movement to use business for community benefits suggests a blurring of the civil society/ for profit sector boundaries. The desire to achieve positive community impacts is often more commonly associated with a civil society goal, whereas businesses are traditionally viewed as primarily profitdriven. While some critics contest the idea that businesses are bound to exclusively pursue only profit as their sole goal and argue business has often had other goals than profit, this research adopts general understanding of civil society and the market-based private sector as distinct, even with overlapping boundaries. Moreover, the proposition that the public sector might increasingly disinvest in public services and shift responsibility to private sector actors (or markets), suggests a blurring boundary between the state and market, too. Divestment of communities by the beneficent state, along with transference of social responsibility to the private sector, may raise concerns about the devolution of the state for some scholars. Regardless of one's position, the trend warrants more investigation to assess the implications and impacts, particularly to choose a course of advocacy. 
One question to consider is whether a city or community might want to make policy that would support the expansion of ethical markets. One would expect community-oriented groups to appreciate the 'benefit' of a firm that strives to have impact at all levels, including locally. However, there is also a case to be made for a city recognizing the shared benefit of a more ethically-driven city, region, nation or world. Alternatively, a city or community may pursue an EMC for a local gain, as an economic development policy that enhances its local competitive advantage, or helps attract investment capital locally. Particularly, cities may aspire to carve out local economies more equitably than through standard economic strategies of development and real estate; or more sustainably than through large-scale manufacturing and industries. Moreover, not every region can attract and develop a research and development sector sufficient to enhance attraction. Yet an EMC is far more flexible because the commonality is simple and not confined to any industry: a (certified) commitment to ethical business practices. A city could carve out its own niche-even launch an ethically-driven tourist strategy. Of course all such efforts risk becoming susceptible to greenwashing trends or accusations, overly emphasizing the entrepreneurial aspect of the TBL, and may appear more exclusively social entrepreneurial than driven to implement change. However, perhaps a greater integrity could be maintained with the inclusion of local government oversight, supportive policy, and civil society.

Given these many unknowns, amid the expectations for initial implementation to be largely beneficial, the proposition of this research is to consider policy implications regarding how to best support the local expansion of ethical markets and impact-driven 
firms. On one hand targeted policies may advocate for legislation at minimum, to enable the practices, along with promotion and resources directed towards expansion of B Corps. Cities may want to consider tax breaks and other incentives to acknowledge positive impacts, and also to help develop an EMC. On the other hand, some indirect supports may also enable a more organic evolution of an EMC. For example, support for local, innovative, culture may expand informal networks. Portland may want to continue with the low-entry, flexible access policies for small businesses to start up (such as temporary use of space in pop-up shops or in public spaces); support for arts and culture, and technology; and promote informal networks. Portland may also want to leverage culture to obtain other types of support or funding, by finding compatible goals. For example, nonprofit or public agencies may want to partner with B Corps, to receive investment or grant funding, by sharing impact goals. Ideally, collaboration would strengthen impact goals, rather than divert resources away from civil society or government. Another key way for policy makers to support B Corps or EMCs is of course by supporting advanced research, particularly to use available or expanded data to track external impacts.

Is it fathomable that there could be a 'trickle up?' The challenge with the hardest consumer critics is reluctance to acknowledge corporations are composed of people, with potential for ethical considerations, including some locally-based actors. Corporate leaders are not necessarily solely driven by a capitalist greed or one indicative of extreme narcissism or worse, psychopathy. Alternatively, there are ways for cities to retain more power by providing credits for locally-powered companies connected with a franchise, willing to compromise at the local level. Scholars and policy-makers could look at 
incentives, policies, and credits to still draw large business with their promises of economic stimulus, job creation, and consumer goods/ choices, yet provide substantially more incentive for local locus of power with an emphasis on all-around ethical practices.

Importantly, policy will also want to consider and correct for any inequities perpetuated by ethical markets, as well-intending community and market-based efforts often replicate these during efforts at social contributions. For example, if greater sociodemographic homogeneity partly enables successful rise of an EMC, policymakers and advocates should assertively seek ways to correct for historical marginalization to circumvent recreating the same inequitable historical patterns, and challenge practices that reinforce cultural or socio-demographic domination. Of particular concern is the likelihood for ethical market patronage to be dependent on privilege for customers or consumers to participate. In other words, if too costly or otherwise prohibitive, these markets are boutique, inaccessible, and miss opportunities for diversification.

Otherwise, policymakers will want to take steps to acknowledge the concern that support for ethical businesses could extract resources from community-based organizations, and consider the critique that economic solutions are incomplete without integration with community development efforts. Even if the concern is exaggerated CBOs and CDCs are stretched thin, communities have ongoing significant needs, and thus are vulnerable to any potential cuts. Ideally, policies will want to support and creatively strengthen both nonprofit and for-profit social impact goals. Considering the sustainability and equity linking efforts described by Joan Fitzgerald in Emerald Cities (2010) may provide a good blueprint. However, as the book and policies occurred in a 
climate of domestic support for sustainability investment, some lessons may apply differently now. Moreover, given the current limitations of domestic support for local (especially urban) communities, policy will have to consider both appropriate capacity and limits to reliance on local markets to support communities following potential further federal disinvestment. Creative efforts may want to stimulate partnerships to larger national or even international civil society groups, in recognition that one driving force for these practices and this research, is finding greater space for globalizing from below.

\section{Limitations \& Future Research}

\section{$\underline{\text { Limitations }}$}

Generally, the study has some limitations, including some anticipated. One main limitation of the research was population size. This research was qualitative and includes two cities, with representation of a limited number of local firms. The research involved interviews and a case study approach, and naturally would be strengthened by follow-up research of multiple cities, potentially with a quantitative analysis with a large enough population size. The research explores outcomes at the company level and at most a city level, thus recognizes limits to scalability or generalizability of results. Additionally, as business representatives are the main target study population, there is a risk that concerns about marketing strategies influenced the responses among some participants, despite the subject matter. However, this researcher's impression was that nearly all participants 
shared freely and without expectation of a benefit to them, in part perhaps because they had assurances of confidentiality. Thus, there was a small threat to validity. More likely, they also appreciated being part of something new, and genuinely seemed to enjoy the opportunity to reflect on their firm and the B Corp movement. Overall, a major limitation of the research was a study focused more on perceived, reported and intended impacts, without any measurement of actual external impacts, particularly given both lack of available data and design challenges for that research goal. Given the relative newness of the B Corp phenomenon, assessment of external impact poses a research challenge but a worthwhile pursuit in future, creative capacities. Finally, given the newness and rarity of B Corps phenomena, evaluation has its limits; and comparison with non-B Corps was beyond the study's scope.

\section{$\underline{\text { Influential Trends }}$}

A number of variables occurred between research implementation and conclusion that influence the potential implications of these findings. Primarily, a change of US presidential leadership altered the political climate domestically and in localities including in direct association with business practices. The leadership shift from President Obama to President Trump also changed US relations internationally. Domestic tensions always have local impacts on policies, funding, and resources, but during the time period following data collection, substantial federal and state budget adjustments may influence local climates and practices. For example, reductions in funding for health and housing programs may exacerbate social problems, and add or alter local community 
needs or deficits. Additionally, a number of other countries recently experienced similar dramatic shifts including for example, Brexit, and the election of various businessfavoring politicians, particularly in the western Hemisphere. Coinciding, the world witnessed a dramatic growth in attention to global environmental action, and resistance. Meanwhile, the concept of ethical markets gained more traction in mainstream circles as both the United Nations and prominent US-based business alliances announced commitments to the pursuit of positive impacts, especially in regards to sustainability; perhaps in response to government resistance to action and reduced attention or funding of global problems. For example, the US, under federal guidance, retreated from various commitments globally and domestically. A changing political landscape is always a constant, but the shift appeared more substantial than during the prior two decades. Regardless, the changes do not negate the findings, but pose new questions about future directions and implications, perhaps increasing their relevancy.

During this time (and partly likely in response), some major cultural shifts occurred as well. Social media supported growth in silos, but also in a number of social justice movements. Expanded intergenerational conflicts across cultural, ideological and technological areas became more pronounced as racial, generational, immigration and other sociodemographic tensions appeared to rise in the U.S. and in other nations. The movements seemed to ignite the evolution of 'woke' or 'cancel' culture, which transmits messaging so rapidly through social media, that firms are faced with increased public pressure for accountability and the threat to business viability, although criticisms are not necessarily vetted. 
Changes at the local level also had impact. For example, Portland witnessed substantial growth in interest and attention to homeless issues and a looming housing crisis, amid budget shortfalls. In Philadelphia, some of the racial tensions received more prominent attention with the rise in the Black Lives Matter movement. Both cities saw significant neighborhood change, and growing gentrification, though to a far greater extent in Portland. As several firms identified counter-gentrification as a key component of the community impact they pursued, yet what about the firms which did not mention this? While the assessment does address social equities and local community investments, such concerns may need prioritization for an ethical market, firm or EMC to maintain its integrity. Moreover, a question persists, as in much of the sustainability and food systems work, about whether equality and social equity are as attractive issues for ethically-driven communities, firms, and customers/clients to address. More importantly, are greater homogeneity and relocated social issues a condition of success with ethical markets ad they may be with sustainability efforts? In other words, if gentrification and displacement enable economic development, sustainable industry growth, and an ethical market cluster, then the ethics and effectiveness are really called into question. Local communities will likely continue to struggle with these questions and solutions.

While social and political change, sociodemographic tension, and competition for resources are constant phenomena, the significant shifts are likely to have some impact on attitude, both positively and negatively. 


\section{$\underline{\text { Future Research }}$}

Future research may go in numerous directions, but for starters should consider an expansion based on this study's limitations and influential trends. For example, given changes in domestic and global climates, yet in the juxtaposition of renewed environmental and social justice movements, will interest and potential of B Corps wax or wane? Initial observations are unclear to what extent they will increase in numbers, and to what extent that progress will be place-based, given Portland's growth yet Philadelphia's stagnation. Additionally, expanding on the research with larger population sizes will provide deeper insights, including analysis of customers and clients, too. Moreover, evaluating and tracking the actual external impacts-while a lofty research goal-is likely to influence policy-makers and advocates who want to make the case for investment in local ethical markets.

Scholars interested in blurred institutional boundaries may also want to build on this research given how impact-driven businesses reflect the overlapping political, economic and civil society spheres. Blurred boundaries are already established, but the conversation may expand, as businesses act increasingly more like civil society. The boundaries become murkier, so what's an appropriate focus for advocates or activists? Is it appropriate given civil society's dependence on influential for-profit funders, to divert efforts towards impact-driven businesses? Or should they divert resources away from the public sector which has constant competition and at times increasingly strained resources or influence? Is it risky to transfer greater social responsibility to the private sector, which is often considered responsible for destruction and exploitation? Could excessive 
support of impact-driven business expand power and influence, and further devolve the beneficent state? These are questions scholars may want to further address.

Otherwise, research on the development of other EMCs and related clusters, will appeal to both academics and planners. Civic entities may even want to foster these clusters through support of local culture, informal networks, and of course enabling legislation. They may even find participation helps create an industry or local competitive advantage. Ultimately, more significant research will further enlighten the potential for locally-based markets to create impact at both the local and non-local level, and further evaluate limits, opportunities, and also risks. 
References 


\section{References}

Allen, Jennifer H. and Potiowsky, Thomas. 2008. "Portland's Green Building Cluster: Economic Trends and Impacts.” Economic Development Quarterly 22 (4): 303315.

Balarin, Maria. 2011. "Global Citizenship and Marginalisation: Contributions Towards a Political Economy of Global Citizenship." Globalisation, Societies and Education 9 (3-4): 355-366.

Balsiger, Philip. 2010. "Making Political Consumers: The Tactical Action Repertoire of a Campaign for Clean Clothes.” Social Movement Studies 9 (3): 311-329.

Batliwala, Srilatha. 2002. "Grassroots Movements as Transnational Actors: Implications for Global Civil Society.” Voluntas 13 (4): 393-409.

Battilana, Julie, and Matthew Lee. 2014. "Advancing Research on Hybrid OrganizingInsights from the Study of Social Enterprises." Academy of Management Annals 8: 397-441.

Blahnik, Heather. 2014. "Aisec Life. Industry Focus: B Corporation with Stephanie Ryan.” https://www.aieseclife.org/page/StephanieRyan June 24, 2014, Accessed February 22, 2020.

Blount, Justin, et al. 2013. "The Benefit Corporation: A Questionable Solution to a NonExistent Problem.” St. Mary's Law Journal 44 (3): 617-670.

Burris, Beverly H. 2004. "Globalization and its Discontents: Qualitative Research on the Second Industrial Divide.” Qualitative Sociology 27 (1): 117-121.

Chu, J. (2012). Filling A Nonexistent Gap: Benefit Corporation \& the Myth of Shareholder Wealth Maximization. Southern California Interdisciplinary Law Journal 22 (1): 155-191.

Curtis, Renee B. 2013. "Unpacking Producer/ Consumer Relationships in Ethical Markets: a Look at Portland's DIY Sector." Presented at Portland State University Student Research Symposium.

http://pdxscholar.library.pdx.edu/studentsymposium/2013/Presentation/1/

Curtis, Renée Bogin. 2016. "Ethical Markets in the Artisan Economy: Portland DIY." International Journal of Consumer Studies 40 (2): 235-41.

Davidson, Kate. 2019. OPB. "New Seasons Market Selling To Good Food Holdings." December 10, 2019. https://www.opb.org/news/article/new-seasons-marketportland-oregon-to-be-sold/ (accessed December 30, 2019). 
Dees, Gregory J \& Jaan Elias. (1998). "The Challenges of Combining Social and Commercial Enterprise.” Business Ethics Quarterly 8 (1): 165-178.

DeFelippis, James. 2004. Community Control in the Face of Global Capital. New York: Routledge.

DuPuis, E. Melanie and David Goodman. 2005. "Should We Go "Home" to Eat?:

Toward a Reflexive Politics of Localism.” Journal of Rural Studies 21 (3): 359371.

Dyer-Witheford, Nick. 1999. Chapters 6 \& 8. In Cyber-Marx: Cycles and Circuits of Struggle in High Technology Capitalism. Urbana: University of Illinois Press, 130-164, 192-218.

Evans, Peter. 2007. Counterhegemonic Globalization. In J. Timmons Roberts and Amy Bellone Hite (eds.), The Globalization and Development Reader. Malden: Blackwell Publishing, 420-442.

Fainstein, Susan. 1990. The Changing World Economy and Urban Restructuring. In Susan Fainstein and Scott Campbell (eds.) Readings in Urban Theory. Oxford: Blackwell Publishers Ltd, 110-123.

Feloni, Richard. 2019. "The Entrepreneur Behind the Coveted B Corp Label Shares Why He's Partnering with the UN to Solve our Most Pressing Workforce Problems." Business Insider. 04/19/19https://www.businessinsider.com/the-nonprofit-behindb-corp-is-making-tools-for-companies-like-danone-2019-4?r=US\&IR=T Accessed February 19, 2020.

Fitzgerald, Maggie. 2019. “The CEOs of Nearly 200 Companies Just Said Shareholder Value is no Longer their Main Objective." CNBC Markets, 08/19/19. https://www.cnbc.com/2019/08/19/the-ceos-of-nearly-two-hundred-companiessay-shareholder-value-is-no-longer-their-main-objective.html Accessed February 23, 2020.

Fitgerald, Joan. 2010. Emerald Cities: Urban Sustainability and Economic Development. Oxford: University Press.

Friedmann, John. 1998. Chapter 3: New Political Economy of Planning: The Rise of Civil Society. In Mike Douglass and John Friedmann (eds.), Cities for Citizens. Chichester: John Wiley \& Sons, 19-38.

Fridell, Gavin. 2007. "Fair Trade Coffee and Commodity Fetishism.” Historical Materialism 15: 79-104. 
Gawell, Malin. (2013). "Social Entrepreneurship: Action Grounded in Needs, Opportunities and/or Perceived Necessities?" Voluntas: International Journal of Voluntary \& Nonprofit Organizations 24 (4): 1071-1090.

Hacker, Michael A. (2016). “ "Profit, People, Planet” Perverted: Holding Benefit Corporations Accountable to Intended Beneficiaries." Boston College Law Review 57 (5): 1747-1780.

Haigh, Nardia \& Andrew Hoffman. 2012. "Hybrid Organizations: The Next Chapter of Sustainable Business." Organizational Dynamics 41:126-134.

Halpern, Robert. 1995. Chapters 2-4, 6, Conclusion in Rebuilding the Inner City: A History of Neighborhood Initiatives to Address Poverty. New York: Columbia University Press.

Harrison, Bennett, \& Amy K. Glasmeler. 1997. “Response: Why Business Alone Won't Redevelop the Inner City: A Friendly Critique of Michael Porter's Approach to Urban Revitalization." Economic Development Quarterly 11 (1): 28-38.

Harvey, David. 2006. In Spaces of Global Capitalism: Towards a Theory of Uneven Geographical Development. New York: Verso.

Herron, Elise. 2019. “Employees at Portland New Seasons' Central Kitchen Say They Were Given Abrupt Notice That It Is Closed Indefinitely." Willamette Week. December 30, 2019. https://www.wweek.com/news/business/2019/12/30/employees-at-portlandnew-seasons-central-kitchen-say-they-were-given-abrupt-notice-that-it-is-closedindefinitely/ Accessed February 19, 2020.

Herron, Elise. 2020. "New Seasons Market's Central Kitchen Will Remain Closed Indefinitely But Workers Will Not Lose Pay or Benefits.” Willamette Week. January 8, 2020. https://www.wweek.com/news/business/2020/01/08/new-seasons-marketscentral-kitchen-will-remain-closed-indefinitely-but-workers-will-not-lose-pay-orbenefits/ accessed February 19, 2020.

Heying, Charles. 2010. Brew to Bikes: Portland's Artisan Economy. Portland: Ooligan Press.

Hickman, Leila, John Byrd, and Kent Hickman. 2014. "Explaining the Location of Mission-Driven Businesses: An Examination of B-Corps." The Journal of Corporate Citizenship 55: 13-25.

Jacobs, Jane. 1969. The Economy of Cities. New York: Random House. 
Jargowsky, Paul A. 2005. Chaos or Community? Directions for Public Policy. In Nancy Kleniewski (ed.). Cities \& Society. Malden: Blackwell Publishing, 233-51.

Johnston, Joséé, Andrew Biro and Norah MacKendrick. 2009. "Lost in the Supermarket: The Corporate- Organic Foodscape and the Struggle for Food Democracy." Antipode 41 (3): 509-532.

Jungar, Katarina and Elaine Salo. 2008. “Shop and Do Good?” Journal of Pan African Studies 2 (6): 92-102.

Katz, Robert and Antony Page. 2013. "Sustainable Business." Emory Law Journal 62 (4): 851-884.

Köhler, Bettina and Markus Wissen. 2003. "Glocalizing Protest: Urban Conflicts and Social Movements." International Journal of Urban \& Regional Research 27 (4) 942-951.

Mair, Johanna, Julie Battilana \& Julian Cardenas. 2012. "Organizing for Society: A Typology of Social Entrepreneuring Models Journal of Business Ethics." Social Entrepreneurship in Theory and Practice 11 (3): 353-373.

Malmberg, Anders \& Peter Maskell 2002. "The Elusive Concept of Localization Economies: Towards a Knowledge-Based Theory of Spatial Clustering." Environment and Planning 34: 429-449.

Malpass, Alice, et al. 2007. "Fairtrade Urbanism? The Politics of Place Beyond Place in the Bristol Fairtrade City Campaign." International Journal of Urban \& Regional Research 31 (3): 633-645.

Mayer, Margit. 2003. "The Onward Sweep of Social Capital: Causes and Consequences for Understanding Cities, Communities and Urban Movements." International Journal of Urban \&Regional Research 27 (1): 110-32.

Micheletti, Michele. 2003. "Political Virtue and shopping: Individuals, Consumerism, and Collective Action.” Palgrave Macmillan: New York.

Micheletti, Michele \& Dietlind Stolle. 2008. "Fashioning Social Justice Through Political Consumerism, Capitalism, and the Internet." Cultural Studies 22 (5): 749-769.

Muldoon, Annie. 2006. "Where the Green Is: Examining the Paradox of Environmentally Conscious Consumption.” Electronic Green Journal Issue 23 (3).

O'Neill, Kate. 2004. "Transnational Protest: States, Circuses, and Conflict at the Frontline of Global Politics.” International Studies Review 6 (2): 233-251. 
Plerhoples, Alicia E. 2017. "Nonprofit Displacement and the Pursuit of Charity Through Public Benefit Corporations.” Lewis \& Clark Law Review 21 (3):, 525-571.

Porter, Michael. 1995. "The Competitive Advantage of the Inner City." Harvard Business Review 73 (3): 55-71.

Porter, Michael. 2000. "Location, Competition and Economic Development: Local Clusters in a Global Economy." Economic Development Quarterly 14 (1): 15-34.

Portnay, Kent E. and Berry, Jeffrey. 2014. "Civil Society and Sustainable Cities." Comparative Political Studies 47 (3): 395-419.

Pullman, Madeleine \& M. Sauter. 2012. Sustainability Delivered: Designing Socially and Environmentally Responsible Supply Chains. New York: Business Expert Press, LLC.

Purcell, Mark. 2006. "Urban Democracy and the Local Trap.” Urban Studies 43 (11): 1921-41.

Roelofs, Joan. 2003. Foundations and Public Policy: The Mask of Pluralism. Albany: State University of New York.

Schrock, Greg, Bassett, Ellen M. \& Green, Jamaal. 2015. "Pursuing Equity and Justice in a Changing Climate: Assessing Equity in Local Climate and Sustainability Plans in U.S. Cities.” Journal of Planning and Educational Research 35 (3): 282-295.

Scott, Allen J. \& Michael Storper. 2007. Regions, Globalization, Development, Regional Studies, 41: S191-S205.

Starr, Armory. 2010. “Local Food: A Social Movement?” Cultural Studies 10 (6): 479490.

Stolle, Dietland, Marc Hhoghe \& Michele Micheletti. 2005. Politics in the Supermarket: Political Consumerism as a Form of Political Participation. International Political Science Review 26 (3): 245-269.

Stubbs, Wendy. 2017. "Characterising B Corps as a Sustainable Business Model: An Exploratory Study of B Corps in Australia." Journal of Cleaner Production 144: 299-312.

Tarrow, Sidney. 2005. The New Transnational Activism. Cambridge: Cambridge University Press, 161-179. 
Toepler, Stefan. 2018. "Do Benefit Corporations Represent a Policy Threat to Nonprofits? "Nonprofit Policy Forum 9 (4): 1-9.

Weidenhoft, Wendy. 2008. "An Analytical Framework for Studying the Politics of Consumption: The Case of the National Consumer's League." Social Movement Studies 7 (3): 281-303.

Wolf-Powers, Laura, Marc Doussard, Greg Schrock, Charles Heying, Max Eisenburger \& Stephen Marotta. 2017. "The Maker Movement and Urban Economic Development." Journal of the American Planning Association 83:4, 365-376. 
Appendices 
Appendix A. Interview Instruments

Semi-Structured Interview Protocol

BCI\#___ Date____ Company______ Name

Semi-Structured Interview Protocol for B Corps Businesses

1. Why did you or your company decide to become a B Corps? What's your role?

2. What primary values (if not addressed) drove your company's motivations to become a B Corps?

3. Please tell me about the process. How did you become a B Corps? What outside supports assisted you? (Prompt: Individuals, organizations, firms?)

4. How did becoming a B Corps change the company? Clients/ customers? The community?

5. How do you evaluate the value to your business? Of Bcorps, of impacts? How do you define success?

6. Describe your relationship with other B Corps? Social enterprises? Competitive or collaborative? Other CSR biz?

7. How important is the location? What are the supports? Challenges? Role of local culture?

8. How important is it to positively impact your community? The world? Provide an alternative to mass corporate-based markets? Why?

9. What are the most important of the 4 assessment categories to your company? Where and how have you improved? What aspects of those categories were most important?

10. Please tell me about your assessment process. What did you track in order to complete the process? How did the certification process impact your ability for impact?

11 . Why not NI/ charity arm?

12. Niche market? Scalable?

13. Finally, do you see your primary role as a business or a community advocate (or other)?

14. Do you see any way you have contributed to B Corps/ B Lab; \&/or to CSR?

Notes: 
KI\#___ Date___ Company_____ Name

Semi-Structured Interview Protocol for Key Informants: B Corps Representatives and Advocates

1. Tell me about your organizational background and how you became involved?

2. How do you support companies that become B Corps?

3. What has your role been in advocacy?

4. What have you observed about companies that choose to be B Corps?

5. How would you compare B Corps to other ways that businesses might attempt to pursue social goals? (Prompt: vs. philanthropy, charity, nonprofits)

6. What have you observed through the process?

7. What, in your opinion, determines success? Good candidacy? What hasn't worked?

8. Do you promote adoption as B Corps or do most participants self-initiate?

9. Describe the individuals who contact you or seek support. (Prompt: Is there consistency, diversity?)

Notes: 
Appendix B. B Corp Blank Assessment: Categories \& Question Filters

\begin{tabular}{|c|c|}
\hline Level of Impact Focus & 乩口 \\
\hline Mission Statement Characteristics & 故口 \\
\hline Mission Statement & 光口 \\
\hline Stakeholder Engagement & 勾口 \\
\hline Social/Environmental Key Performance Indicators & 战口 \\
\hline Governance Structures & 放口 \\
\hline Code of Ethics & 战口 \\
\hline Reviewed / Audited Financials & 放口 \\
\hline Company Transparency & 放口 \\
\hline Last Fiscal Year & 放口 \\
\hline Reporting Currency & 式口 \\
\hline Revenue Last Year & 故口 \\
\hline Revenue Year Before Last & 光口 \\
\hline Net Income Last Year & 礼回 \\
\hline Net Income Year Before Last & 勾口 \\
\hline Mission Lock & 放口 \\
\hline
\end{tabular}




\begin{tabular}{|c|c|}
\hline Community Oriented Impact Business Model & 客口 \\
\hline Diverse Ownership and Leadership & 必口 \\
\hline Supplier Diversity Policies or Programs & 必口 \\
\hline Supplier Ownership Diversity & 必田 \\
\hline Geographic Structure and Scope & $\hat{\sim}$ \\
\hline New Jobs Added Last Year & 约 \\
\hline Non-accredited Investor Ownership & 必回 \\
\hline Spending on Local Suppliers & 必田 \\
\hline Impactful Banking Services & 必口 \\
\hline Corporate Citizenship Program & 必回 \\
\hline Advancing Social and Environmental Performance & 必田 \\
\hline Significant Supplier Descriptions & $\hat{\sim}$ \\
\hline Social or Environmental Screening of Suppliers & 为问 \\
\hline Outsourced Staffing Services & 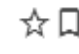 \\
\hline Outsourced Staffing Screening Topics & 必口 \\
\hline$\%$ of Outsourced Services Accountable to Code of Conduct? & 必田 \\
\hline Screening / Monitoring for Services & 必回 \\
\hline$\%$ of Outsourced Staffing Services Screened / Monitored & 象口 \\
\hline
\end{tabular}


Environment

\begin{tabular}{|c|c|}
\hline Type of Facilities & 田口 \\
\hline Environmental Business Model & 必口 \\
\hline Green Building Standards & 分口 \\
\hline Facility Improvement with Landlord & 分口 \\
\hline Virtual Office Stewardship & 公口 \\
\hline Environmental Management Systems & 必口 \\
\hline Monitoring Energy Usage & 为口 \\
\hline Total Energy Use & 为口 \\
\hline Total Renewable Energy Use & 公口 \\
\hline Renewable Energy Usage & 必口 \\
\hline Low Impact Renewable Energy Use & 公口 \\
\hline Facility Energy Efficiency & 为口 \\
\hline Monitoring Greenhouse Gas Emissions & 计 \\
\hline Total Scope 1 GHGs & 分口 \\
\hline Total Scope 2 GHGs & 公口 \\
\hline Total Scope 3 GHGs & 分口 \\
\hline Carbon Intensity & 证口 \\
\hline Monitoring and Managing Water Use & 分口 \\
\hline Total Water Use & 必口 \\
\hline Water Conservation Practices & 我口 \\
\hline Monitoring and Reporting Non-hazardous Waste & 必口 \\
\hline Total Waste Recycled & 我口 \\
\hline Total Waste Disposed & 分口 \\
\hline Non-hazardous Waste Generated & 必口 \\
\hline Recycling Programs & 约口 \\
\hline Reducing Waste & 今口 \\
\hline Hazardous Waste Disposal & 必口 \\
\hline Chemical Reduction Methods & 今口 \\
\hline
\end{tabular}




\section{Customers}

\begin{tabular}{|l|}
\hline Customer Impact Business Model Introduction \\
\hline Managing Customer Stewardship \\
\hline Managing Product Impacts
\end{tabular}

Awards Offered

Primary Award Offered

More than one year subbaccalaureate certificate

Professional certification

Less than one year subbaccalaureate certificate

Post-baccalaureate certificate

Associates Degree

Bachelors Degree

Masters Degree

Doctoral Degree

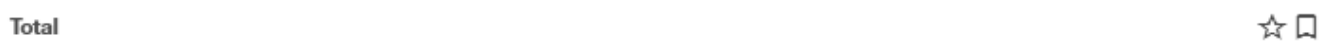

Other 光口

Professional Degrees

Percent Of Revenue from Federal Funds

Diversify Revenue Sources

Direct Services to Students

Administration

Marketing/Recruitment

Public Service and Research

Other

Community Engagement

Partnerships with Higher Education

Policies Accuracy of Marketing

Policies Contacting Prospective Students

Expectations of Enrolled Students

Provide Information on Homepage

战口 


\begin{tabular}{|c|c|}
\hline Require Acknowledgement of Program Level Info & 当口 \\
\hline Implementation of Practices & 店口 \\
\hline Policies to Improve Instruction & 社口 \\
\hline Policies on Faculty Qualifications & 部口 \\
\hline Admissions Counseling & 社口 \\
\hline Academic Advising & 古口 \\
\hline Personal counseling & 放口 \\
\hline Career counseling & 今口 \\
\hline Orientation and Counseling & 社口 \\
\hline Academic Advising & 店口 \\
\hline Mentoring & 社口 \\
\hline Flexible payment options & 古口 \\
\hline Financial Literacy Courses & 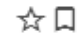 \\
\hline Personalized Loan Counseling & 的口 \\
\hline Student Civic Engagement Opportunities & 社口 \\
\hline Employment Outcomes & 光口 \\
\hline Student Satisfaction & 礼可 \\
\hline Mission to Serve Special Interest Populations & 索口 \\
\hline Pell Grant Recipients & 证口 \\
\hline Underrepresented minorities & 战口 \\
\hline GED recipients & 社口 \\
\hline First-generation college students & 古口 \\
\hline Students with Some College & 社回 \\
\hline Military veterans & 战口 \\
\hline Special Interest Populations & 部口 \\
\hline Traditional Students & 店口 \\
\hline Measure Student Learning & 社口 \\
\hline Assess Student Goals & 学口 \\
\hline Remedial Education Courses and Support & 社口 \\
\hline Pell Grant Recipients & $\Leftrightarrow \square$ \\
\hline
\end{tabular}




\begin{tabular}{|c|c|}
\hline Non-Pell Grant Recipients & 社口 \\
\hline White & 社口 \\
\hline Asian & 社口 \\
\hline Black & 索口 \\
\hline Hispanic & 战口 \\
\hline Native American or Alaska Native & 为口 \\
\hline Other & 社日 \\
\hline White & 社口 \\
\hline Asian & 为回 \\
\hline Hispanic & 视回 \\
\hline Black & 社口 \\
\hline Native American or Alaska Native & 究口 \\
\hline Other & 公口 \\
\hline Institutional Decisions on Programs & 初口 \\
\hline Pell Grant Recipients & 证口 \\
\hline Non-Pell Grant Recipients & 社口 \\
\hline Employment Records and Graduate Data & 视回 \\
\hline Program 1 & 今口 \\
\hline Program 2 & 吉口 \\
\hline Program 3 & 的口 \\
\hline Program 4 & 的口 \\
\hline Program 5 & 吉口 \\
\hline Compare Graduates Earnings & 公口 \\
\hline Average Net Price for Academic Year & 今口 \\
\hline All graduates & 社口 \\
\hline Student Withdrawal of Records & 部问 \\
\hline Assitance to Drop Outs with Debt & 故口 \\
\hline Probation or Loss of Accreditation & 战口 \\
\hline Federal or State Investigation & 战口 \\
\hline
\end{tabular}


Appendix C: IRB Approval

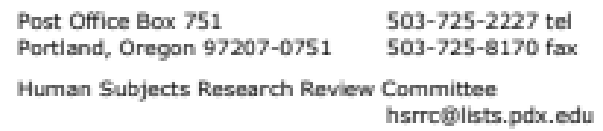

Date: October 14, 2014

To: Gregory Schrock / Renee Curtis

From: Karen Cellarius, HSRRC Chair

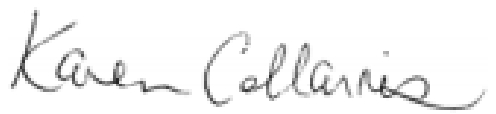

Re: HSRRC approval for your project titled, "Process and Outcomes of Ethical Markets: A Focus on Social Benefit Companies"

HSRRC Proposal \# 143175

Approval-Expiration: Oetober 14, 2014-Oetober 13, 2015

Review Type: Expedited, Categories 5, 6,7

In accordance with your request, the PSU Human Subjects Research Review Committee has reviewed your request for approval of the project referenced above for compliance with PSU and DHHS policies and regulations covering the protection of human subjects. The Committee is satisfied that your provisions for protecting the rights and welfare of all subjects participating in the research are adequate, and your project is approved. Please note the following requirements:

Approval: You are approved to conduct this research study only during the period of approval cited above; and the research must be condacted aceording to the plans and protocol submitted (approved copy enclosed).

Consent: Signed consent is waived from all participants in this study. A written consent statement is required.

Changes to Protocol: Any changes in the proposed study, whether to procedures, survey instruments, consent forms or cover letters, must be outlined and submitted to the Committee immediately. The proposed changes cannot be implemented before they have been reviewed and approved by the Committee.

Continuing Review: This approwal will expire on 10/3/2015. It is the investigator's responsibility to ensure that a Continuing Review Report on the status of the project is submitted to the HSRRC two months before the expiration date, and that approval of the study is kept current. The Continuing Review Report is available at www.rsp.pdx.edu/compliance human.php and in the Office of Research and Strategic Partnerships (RSP).

Adverse Reactions and/or Unanticipated Problems: If any adverse reactions or unanticipated problems oceur as a result of this study, you are required to notify the Committee immediately. If the issue is serious, approval may be withdrawn pending an investigation by the Committee.

Completion of Study: Please notify the Committee as soon as your research has been completed. Study records, including protocols and signed consent forms for each participant, must be kept by the investigator in a secure location for three years following completion of the study (or per any requirements specified by the project's funding agency).

If you have questions or concerns, please contact the Office of Research Integrity in the PSU RSP at 503-725-2227. 


\section{IRB Final Approval}

\section{\& Portland State}

Cffice of Research Interrity 1600 5W 4 th Avenus, Suite 620 Partland, Co 9720 t

[503] 725.5484 psuirtoppdx.sdu

\section{Human Research Protection Program Notice of Continuing IRB Approval}

October 07, 2019

Dear inwestigator,

The PSU institutional Review Board (1SB) reviowed the following continuing review submission:

\begin{tabular}{|l|l|}
\hline Investigatee(s) & Greg Schrock / Renee Curtis \\
\hline HRPP * & 143175 \\
\hline Title & Process and Outcomes of Ethical Markets: A Focus on Social Benefit Companies \\
\hline Funding Agency / KuaE: & N/A \\
\hline Expiration Date & $10 / 13 / 2020$ \\
\hline Review Category(ies) & Expedited: a 8 (a) ii \\
\hline
\end{tabular}

The IRB determined the cominuation request satisfies the required provisions for peotecting the rights and welfare of all sabjects partiopating in research. This study approval has been renewed and must be conducted in accordance with the protocol submitted (HRPP Forms endosed). Please note the following ongoing Human Besearch Protection Program (Ha) requirements.

Consent: IRB-approved consent materials must be used with subjects.

Changes to Study Activities Any changes to the study must be submitted to ORI for review and determination prior to implementation.

Unanticipated Problems of Adverse Events: Notify OAI within 5 days of any unanticipated problems of adwerse ewents that occur as a result of the stody.

Continuing Review: Studies that are over 5 years old, and 1) still collecting data from subjects, or 2) performing identifiable-data analysis must be re-reviewed under the new federal regulations and do not qualify for continuing review. Submit a new protocol under the Revised Common Rule requirements, wing the forms on our website. If this study qualfies for Continuing feview, a Continuation request must be submitted prior to enpiration.

Study Closure: This study may be closed when there is no longer contact with subjects and al analysis with idemtifiable data is complete. Identifable data may be maintained as long as anclysis is complete. If you wish to utilize the identifiable data in the future a new study submission is required.

Compliance: The PSU IRB (FWAC0000091; 19800000903) and the CAI comply with 45 CFR Fart 46, 21 CFR Parts 50 and 56, and other foderal and Oregon laws and reguations, as applicable. Hasp-eflated materials must be hept for at least three years following study completion.

If there are any questions, please contact the ORI at psuirbepdxedu or call 503-725-5484.

Sincerely.

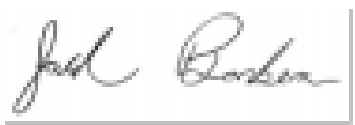

Jack Bartera, is: Chair 
IRB Application Appendices for Renee B. Curtis' Dissertation Application, September 23,2014

a. Informed consent permission forms

Individuals contacted for this study will be informed at the outset that they are being asked to participate in a research project being conducted by a student at Portland State University. The research presents no known risks to subjects and involves no vulnerable procedures. Information relating to the purpose and scope of the research design will be available to be shared either during in-person interviews or through Internet links shared electronically. All research subjects will be able to provide answers to the interviews with confidentiality. All research subjects are expected to be adults. The consent policies apply to adult individuals who are legally able to give consent, mentally able to process the information, and emotionally and socially able to make decisions. When adult individuals are directly invited to participate they will be asked to provide either written or verbal consent. In (rare) instances where no identifying information is collected, verbal consent will suffice. In instances where identifying information is collected, participants will be asked to complete a written consent form before initiating their participation.

Informed Consent Description for form:

This study involves research to understand the processes and impacts of B Corp Firms. Your participation will contribute to understanding of B Corps. The interview will take 45-60 minutes for an interview and you may discontinue participation at any time. Your participation and identifying records will be confidential. Contact my advisor, Greg Schrockat gschrock@pdx.edu for questions, concerns or complaints about the research, questions about your rights, to obtain information or to offer input.

Informed Consent Form (for telephone interviews):

Process and Outcomes of Ethical Markets: A Focus on Social Benefit corporations You are being asked to participate in a research study that is being conducted by Renee Curtis who is a PhD candidate in the Urban Studies and Planning School at Portland State University in Portland, Oregon.

This research investigates the implementation process and effectiveness of ethical markets within a place-based context, with a focus on Social Benefit corporations (SBCs) as a tool to foster positive social outcomes. The study aims to identify impediments, opportunities and emergent practices through an examination of the process and outcomes of certified SBCs knows as Benefit Corporations (B Corps), to better understand the potential and limits of social benefit corporations as a tool for ethical market practices.

Your participation in this research is completely voluntary. Participation will take about 60 minutes for an interview. You may suspend or otherwise discontinue the interview at any point, with no penalty. There are no direct benefits to your participation, other than to promote learning from your experiences with social benefit corporations. 
The information that you provide through this interview will be confidential, meaning that no quotations or references to information provided through this interview will be made in a manner that would allow readers to identify you, directly or indirectly. In some cases, quotes or statements may be used based on non-identifying descriptors, such as "company representative."

With your permission, we would like to record our interview using a digital audio recorder. The purpose of the recordings is to ensure the accuracy of collection of the information, and to allow for a more interactive conversation. However, you may request for me to not record the interview, or certain parts of it.

If you have questions following the completion of this interview, you can reach or Renee Curtis at 503.725.8447, or by email at rbogin@pdx.edu. If you have concerns regarding the methods used, or questions about your rights as a research subject, you may contact Renee's advisor- Professor Greg Schrock from Urban Studies \& Planning at PSU- by phone at 503.725.8312, or by email at gschrock@ pdx.edu; or the PSU Human Subjects Research Review Committee at 503.725.4288 or 877.480.4400 or hsrrc@ lists.pdx.edu. You may keep this form for your records.

Informed Consent Form (for in-person interviews):

\section{The Portland State University}

\section{Consent to Participate in Research}

Process and Outcomes of Ethical Markets: A Focus on Social Benefit corporations

You are being asked to participate in a research study that is being conducted by Renee Curtis who is a PhD candidate in the Urban Studies and Planning School at Portland State University in Portland, Oregon.

This research investigates the implementation process and effectiveness of ethical markets within a place-based context, with a focus on Social Benefit corporations (SBCs) as a tool to foster positive social outcomes. The study aims to identify impediments, opportunities and emergent practices through an examination of the process and outcomes of certified SBCs knows as Benefit Corporations (B Corps), to better understand the potential and limits of social benefit corporations as a tool for ethical market practices.

Your participation in this research is completely voluntary. Participation will take about 60 minutes for an interview. You may suspend or otherwise discontinue the interview at any point, with no penalty. There are no direct benefits to your participation, other than to promote learning from your experiences with social benefit corporations. 
The information that you provide through this interview will be confidential, meaning that no quotations or references to information provided through this interview will be made in a manner that would allow readers to identify you, directly or indirectly. In some cases, quotes or statements may be used based on non-identifying descriptors, such as "company representative."

With your permission, we would like to record our interview using a digital audio recorder. The purpose of the recordings is to ensure the accuracy of collection of the information, and to allow for a more interactive conversation. However, you may request for me to not record the interview, or certain parts of it.

If you have questions following the completion of this interview, you can reach or Renee Curtis at 503.725.8447, or by email at rbogin@pdx.edu. If you have concerns regarding the methods used, or questions about your rights as a research subject, you may contact Renee's advisor- Professor Greg Schrock from Urban Studies \& Planning at PSU- by phone at 503.725.8312, or by email at gschrock@ pdx.edu; or the PSU Human Subjects Research Review Committee at 503.725.4288 or 877.480.4400 or hsrrc@lists.pdx.edu. You may keep this form for your records.

You are making a decision whether to participate in this study. Your signature below indicates that you have read the information provided (or the information was read to you). By signing this consent form, you are not waiving any of your legal rights as a research participant.

You have had an opportunity to ask questions and all questions have been answered to your satisfaction. By signing this consent form, you agree to participate in this study. A copy of this consent form will be provided

Name of Adult Subject (print) Signature of Adult Subject Date

This research study has been explained to the participant and all of his/her questions have been answered. The participant understands the information described in this consent form and freely consents to participate.

Name of Investigator/ Research Team Member (type or print)

(Signature of Investigator/ Research Team Member) Date

b. Training \& Experience 
Renee B. Curtis CITI TRNG RECORDS

\begin{tabular}{|c|c|c|c|c|c|}
\hline$\frac{\text { Module }}{\underline{\text { ID }}}$ & $\underline{\text { Module }}$ & $\begin{array}{c}\text { Module } \\
\text { Completed } \\
\end{array}$ & $\begin{array}{c}\text { Date Last } \\
\text { Completed } \\
\end{array}$ & Exam ID & $\frac{\text { Exam }}{\text { Date }}$ \\
\hline 1127 & $\begin{array}{l}\text { Belmont Report and CITI Course } \\
\text { Introduction }\end{array}$ & Yes & $\begin{array}{l}3 / 25 / 2010 \\
16: 38\end{array}$ & 34426502 & $3 / 25 / 2010$ \\
\hline 960 & Biomed Refresher 1 - Instructions & Yes & $\begin{array}{l}\text { 4/24/2013 } \\
19: 07\end{array}$ & $\begin{array}{l}\text { no module } \\
\text { exam }\end{array}$ & \\
\hline 491 & $\begin{array}{l}\text { Defining Research with Human } \\
\text { Subjects - SBR }\end{array}$ & Yes & $\begin{array}{l}3 / 25 / 2010 \\
20: 22\end{array}$ & 34432341 & $3 / 25 / 2010$ \\
\hline 490 & $\begin{array}{l}\text { History and Ethical Principles - } \\
\text { SBR }\end{array}$ & Yes & $\begin{array}{l}3 / 25 / 2010 \\
19: 39\end{array}$ & 34431559 & $3 / 25 / 2010$ \\
\hline 504 & Informed Consent - SBR & Yes & $\begin{array}{l}4 / 23 / 2010 \\
8: 16\end{array}$ & 35208111 & $4 / 23 / 2010$ \\
\hline 510 & Internet Research - SBR & Yes & $\begin{array}{l}4 / 30 / 2010 \\
18: 03\end{array}$ & 35424948 & $4 / 30 / 2010$ \\
\hline 675 & $\begin{array}{l}\text { IRC - Independent Review } \\
\text { Consulting }\end{array}$ & Yes & $\begin{array}{l}4 / 30 / 2010 \\
17: 30\end{array}$ & $\begin{array}{l}\text { no module } \\
\text { exam }\end{array}$ & \\
\hline 505 & Privacy and Confidentiality - SBR & Yes & $\begin{array}{l}4 / 23 / 2010 \\
8: 47\end{array}$ & 35208386 & $4 / 23 / 2010$ \\
\hline 507 & Research with Children - SBR & Yes & $\begin{array}{l}4 / 30 / 2010 \\
17: 42\end{array}$ & 35424409 & $4 / 30 / 2010$ \\
\hline 937 & $\begin{array}{l}\text { SBE Refresher } 1 \text { - Federal } \\
\text { Regulations for Protecting } \\
\text { Research Subjects }\end{array}$ & Yes & $\begin{array}{l}4 / 24 / 2013 \\
19: 12\end{array}$ & 81409740 & $4 / 24 / 2013$ \\
\hline 15034 & SBE Refresher 1 - Assessing Risk & Yes & $\begin{array}{l}4 / 24 / 2013 \\
18: 51\end{array}$ & 81409044 & $4 / 24 / 2013$ \\
\hline 15029 & $\begin{array}{l}\text { SBE Refresher 1 - Defining } \\
\text { Research with Human Subjects }\end{array}$ & Yes & $\begin{array}{l}4 / 24 / 2013 \\
18: 39\end{array}$ & 81408653 & $4 / 24 / 2013$ \\
\hline 936 & $\begin{array}{l}\text { SBE Refresher } 1 \text { - History and } \\
\text { Ethical Principles }\end{array}$ & Yes & $\begin{array}{l}4 / 24 / 2013 \\
19: 08\end{array}$ & 81409636 & $4 / 24 / 2013$ \\
\hline 938 & $\begin{array}{l}\text { SBE Refresher } 1 \text { - Informed } \\
\text { Consent }\end{array}$ & Yes & $\begin{array}{l}4 / 24 / 2013 \\
19: 14\end{array}$ & 81409795 & $4 / 24 / 2013$ \\
\hline 943 & SBE Refresher 1 - Instructions & Yes & $\begin{array}{l}4 / 24 / 2013 \\
19: 34\end{array}$ & $\begin{array}{l}\text { no module } \\
\text { exam }\end{array}$ & \\
\hline 15028 & $\begin{array}{l}\text { SBE Refresher 1 - International } \\
\text { Research }\end{array}$ & Yes & $\begin{array}{l}4 / 24 / 2013 \\
18: 58\end{array}$ & 81409338 & $4 / 24 / 2013$ \\
\hline 15035 & $\begin{array}{l}\text { SBE Refresher } 1 \text { - Privacy and } \\
\text { Confidentiality }\end{array}$ & Yes & $\begin{array}{l}4 / 24 / 2013 \\
18: 49\end{array}$ & 81409003 & $4 / 24 / 2013$ \\
\hline 940 & $\begin{array}{l}\text { SBE Refresher } 1 \text { - Research in } \\
\text { Educational Settings }\end{array}$ & Yes & $\begin{array}{l}4 / 24 / 2013 \\
19: 29\end{array}$ & 81410280 & $4 / 24 / 2013$ \\
\hline 15036 & $\begin{array}{l}\text { SBE Refresher } 1 \text { - Research with } \\
\text { Children }\end{array}$ & Yes & $\begin{array}{l}4 / 24 / 2013 \\
18: 53\end{array}$ & 81409151 & $4 / 24 / 2013$ \\
\hline 939 & $\begin{array}{l}\text { SBE Refresher } 1 \text { - Research with } \\
\text { Prisoners }\end{array}$ & Yes & $\begin{array}{l}4 / 24 / 2013 \\
19: 28\end{array}$ & 81410267 & $4 / 24 / 2013$ \\
\hline 1321 & Students in Research & Yes & $\begin{array}{l}3 / 25 / 2010 \\
16: 58\end{array}$ & 34426958 & $3 / 25 / 2010$ \\
\hline 502 & $\begin{array}{l}\text { The Regulations and The Social } \\
\text { and Behavioral Sciences - SBR }\end{array}$ & Yes & $\begin{array}{l}3 / 25 / 2010 \\
20: 36\end{array}$ & 34432658 & $3 / 25 / 2010$ \\
\hline 483 & $\begin{array}{l}\text { Vulnerable Subjects - Research } \\
\text { Involving Workers/Employees }\end{array}$ & Yes & $\begin{array}{l}4 / 30 / 2010 \\
18: 08\end{array}$ & 35425046 & $4 / 30 / 2010$ \\
\hline
\end{tabular}


Renee has research experience having served as PI or Co-PI, while working as PSU research faculty since 2007. She also has successfully completed IRB applications on individual and collaborative projects.

\section{c. Recruitment Materials}

\section{Sample Email - Representatives from B Corp Firms}

Hi. I am student from Portland State University. My PhD work in Urban Studies examines B Corps to understand the process and impacts of participation. I am contacting firms within my targeted cities to recruit participation and contribution to this study. Would you be willing to arrange for a time to be interviewed? Any involvement will be confidential. If you would like to learn more about the study or see the results, I can follow up with you after the study's completion. Thank you!

\section{Sample Email - B Corps Advocates}

Hi. I am student from Portland State University. My PhD work in Urban Studies examines B Corps to understand the process and impacts of participation. I am contacting advocates of B Corps to recruit participation and contribution to this study. Would you be willing to arrange for a time to be interviewed? Any involvement will be confidential. If you would like to learn more about the study or see the results, I can follow up with you after the study's completion. Thank you!

\section{Sample Phone Call - Representatives from B Corp Firms} Hi. I am student from Portland State University. My PhD work in Urban Studies examines B Corps to understand the process and impacts of participation. I am contacting firms within my targeted cities to recruit participation and contribution to this study. Would you be willing to arrange for a time to be interviewed? Any involvement will be confidential. If you would like to learn more about the study or see the results, I can follow up with you after the study's completion. Thank you!

Sample Phone Call - B Corps Advocates

Hi. I am student from Portland State University. My PhD work in Urban Studies examines B Corps to understand the process and impacts of participation. I am contacting advocates of B Corps to recruit participation and contribution to this study. Would you be willing to arrange for a time to be interviewed? Any involvement will be confidential. If you would like to learn more about the study or see the results, I can follow up with you after the study's completion. Thank you!

\section{d. Data collection Instruments}

Semi-Structured Interview Protocol for Key Informants: B Corps Representatives and Advocates

10. Tell me about your organizational background and how you became involved?

11. How do you support companies that become B Corps?

12. What has your role been in advocacy?

13. What have you observed about companies that choose to be B Corps? 
14. How would you compare B Corps to other ways that businesses might attempt to pursue social goals? (Prompt: vs. philanthropy, charity, nonprofits)

15. What have you observed through the process?

16. What, in your opinion, determines success? Good candidacy?

17. Do you promote adoption as B Corps or do most participants self-initiate?

18. Describe the individuals who contact you or seek support. (Prompt: Is there consistency, diversity?)

\section{Semi-Structured Interview Protocol for B Corps Businesses}

15 . Why did you or your company decide to become a B Corps?

16. What primary values (if not addressed) drove your company's motivations?

17. Please tell me about the process. How did you become a B Corps?

18. What outside supports assisted you? (Prompt: Individuals, organizations, firms?)

19. How did becoming a B Corps change the company? Clients/ customers? The community?

20. Describe your relationship with other B Corps? Social enterprises? Competitive or collaborative?

21. How do you evaluate the value to your business?

22. How important is the location? What are the supports? Challenges? Role of local culture?

23. What are the most important of the 4 assessment categories to your company? Where and how have you improved? What aspects of those categories were most important?

24. Please tell me about your assessment process. What did you track in order to complete the process? How did the certification process impact your ability for impact?

25. How important is it to positively impact your community? The world? Provide an alternative to mass corporate-based markets? Why?

26. Finally, do you see your primary role as a business or a community advocate (or other)?

Continue onto next page for Addendum 2: Waiver of Documentation

Addendum 2: Waiver of Documentation (Signature of Participant) of Informed Consent, Permission or Assent Process

\begin{tabular}{|l|l|}
\hline Principal Investigator: Greg Schrock & Date: September 23, 2014 \\
\hline $\begin{array}{l}\text { Study Title: Process and Outcomes of Ethical Markets: A Focus on Social Benefit } \\
\text { corporations }\end{array}$ &
\end{tabular}

If you are requesting IRB approval for waiver of the requirement for documentation (Signature of Participant) of informed consent from participant (i.e. telephone survey or mailed survey, internet research, or certain international research), check the box next to 
the condition that best fits your study in Section 2, explain in the space provided in Section 2 how your study meets that condition, and answer the question that follows.

Note: The IRB cannot waive the requirement for documentation or alter the consent form for FDA-regulated research unless it meets Condition \#2 below. FDA does not accept Condition \#1.

\section{SECTION 1:}

1. This addendum request is for

$\mathrm{X} \square$ Consent form

$\square$ Permission form

$\square$ Assent Form

(If you have multiple consent, permission or assent forms that you are requesting a waiver of documentation of consent form, submit the addendum 2 for each request separately and include it with your IRB application. For example if you have one consent form and one assent form in which you are requesting a waiver for documentation of consent you must complete a separate addendum 2 for each. Likewise if you have two consent forms both of which you want to request a waiver of documentation you must submit a separate addendum 2 for each)

\section{SECTION 2:}

1. $\square$ The only record linking the subject and the research would be the consent document, and the principal risk would be potential harm resulting from a breach of confidentiality (i.e., study that involves subjects who use illegal drugs).

Under this condition, each subject must be asked whether $(s)$ he wants to sign a consent form; if the subject agrees to sign a consent form, only an IRB approved version should be used.

A. Justify why your research meets this condition:

B. Does this research involve procedures that are minimal risk except for the linking of the consent document to private information?

$\square$ Yes $\square$ No

IRB ADDENDUM $1 \quad$ Page 1 of $1 \quad$ ORI VERSION

$4 / 21 / 2014$

If "yes", describe what potential harm a subject may experience as a result of a breach in confidentiality 


\section{OR}

2. $\mathrm{X} \square$ The research presents no more than minimal risk to the subject and involves no procedures for which written consent is normally required (i.e. a cover letter on a survey, or a phone script).

A. Justify why your study meets this condition: Research includes telephone interviews with participants at no more than minimal risk.

B. Does this study involve procedures that, outside of the research context, would require written consent?

$\square$ Yes $\mathrm{X} \square$ No

If "yes", waiver of documentation is not appropriate. 